\title{
IUCN
}

\section{Nature-based Solutions to address global societal challenges}

Editors: E Cohen-Shacham, G Walters, C Janzen, $S$ Maginnis
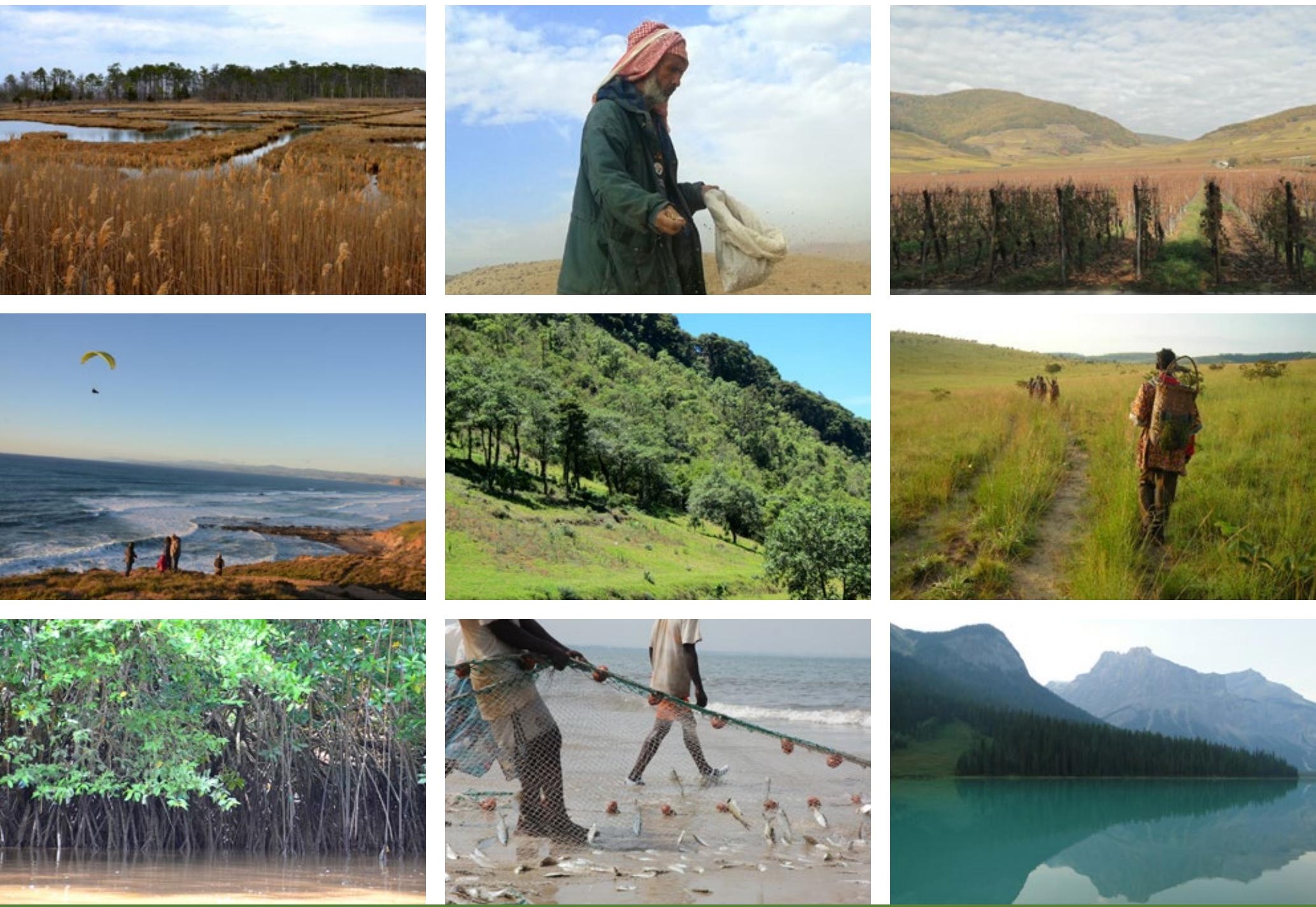

\section{CEM





\section{Nature-based Solutions to address global societal challenges}

Editors: E Cohen-Shacham, G Walters, C Janzen, $S$ Maginnis 
The designation of geographical entities in this book, and the presentation of the material, do not imply the expression of any opinion whatsoever on the part of the International Union for Conservation of Nature (IUCN), the government of the United Kingdom or other participating organisations concerning the legal status of any country, territory, or area, or of its authorities, or concerning the delimitation of its frontiers or boundaries.

The views expressed in this publication do not necessarily reflect those of IUCN or other participating organisations.

This report has been produced by IUCN, funded by United States Voluntary Contribution (United States Department of State), Norad, BMUB-IKI, and UNDP-GEF.

Published by: $\quad$ IUCN, Gland, Switzerland

Copyright: $\quad$ C 2016 International Union for Conservation of Nature and Natural Resources

Reproduction of this publication for educational or other non-commercial uses is authorised without prior written permission from the copyright holders provided the source is fully acknowledged

Reproduction of this publication for resale or other commercial purposes is prohibited without prior written permission of the copyright holders.

Citation: $\quad$ Cohen-Shacham, E., Walters, G., Janzen, C. and Maginnis, S. (eds.) (2016). Nature-based Solutions to address global societal challenges. Gland, Switzerland: IUCN. xiii + 97pp.

ISBN:

978-2-8317-1812-5

DOI:

http://dx.doi.org/10.2305/IUCN.CH.2016.13.en

Cover photos: $\quad$ (From top to bottom, left to right): Viticultural landscape, France; Seed sower, Jordan; Wetland, East USA; Coastal area, West coast, USA; Conserved watershed forest, Guatemala; Women farmers, Savannah, Gabon; Mangroves, Costa Rica; Fishermen, Gabon; Watershed, Canada

Jordan photo credit: IUCN ROWA. All other photos are from Gretchen Walters and Emmanuelle Cohen-Shacham

Back cover photos: Rocky Mountains, USA. Photo credit: Emmanuelle Cohen-Shacham

Photo in Part A: $\quad$ Humid forest, Gabon. Photo credit: Olivier Hymas

Photo in Part B: $\quad$ Transporting mangrove seedlings for planting, Costa Rica. Photo credit: Marco Quesada

Layout by: $\quad$ Chadi Abi (www.chadiabi.com)

Editing by: $\quad$ Jennifer Rietbergen-McCracken

Graphics by: $\quad$ Studio Eshkat

Available from: $\quad$ IUCN (International Union for Conservation of Nature)

Global Forest and Climate Change Programme

Rue Mauverney 28

1196 Gland Switzerland

www.iucn.org/resources/publications 


\section{Table of Contents}

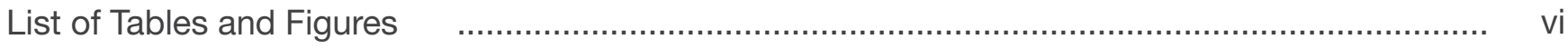

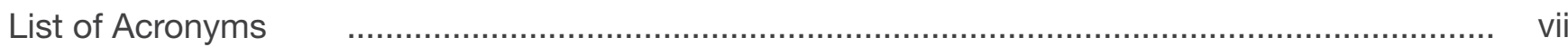

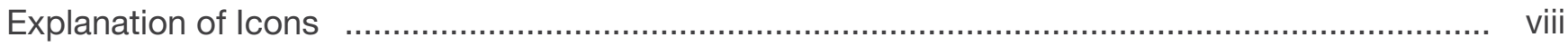

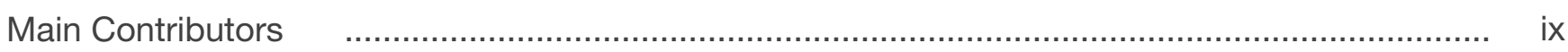

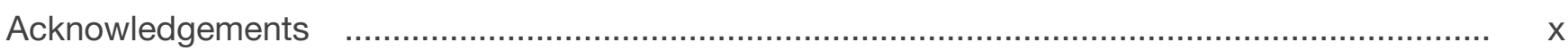

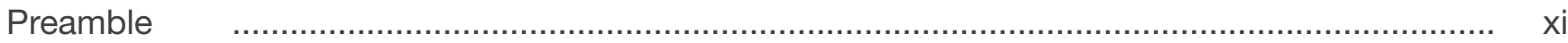

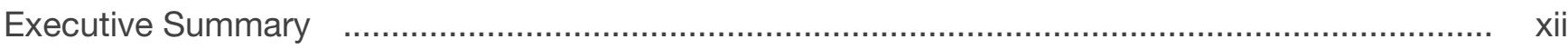

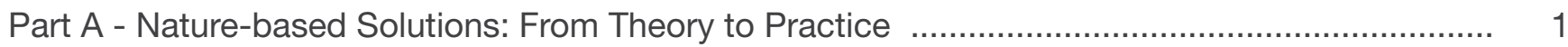

1. What are Nature-based Solutions? $\quad$ ……............................................................ 2

1.1 Development of the NbS concept $\quad$..................................................... 2

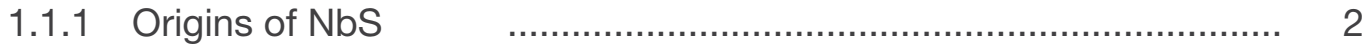

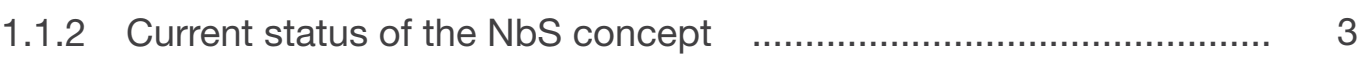

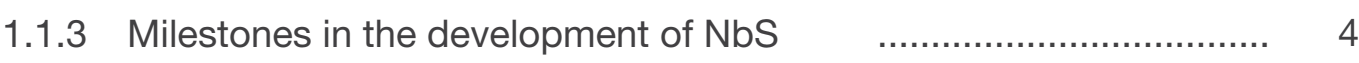

1.2 Defining NbS $\quad$....................................................................................... 5

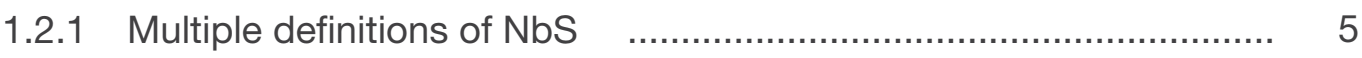

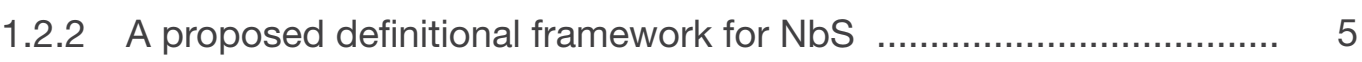

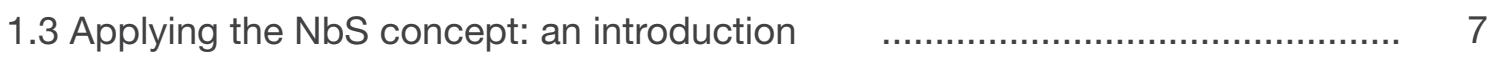

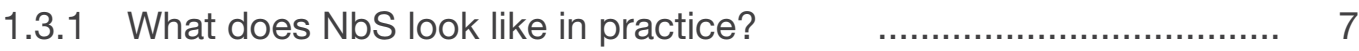

1.3.2 A typology of $\mathrm{NbS}$ applications $\quad$............................................ 9

1.3.3 NbS as an umbrella concept for ecosystem-related approaches $\quad . .10$

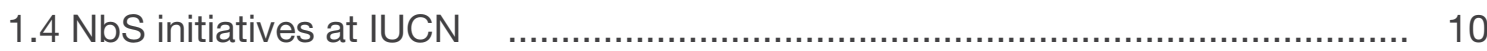

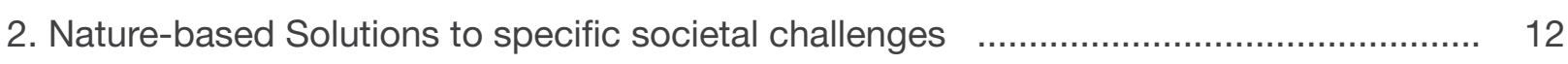

2.1 Nature-based Solutions for water security $\quad$............................................. 12

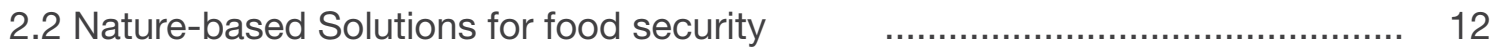

2.3 Nature-based Solutions for human health $\quad$............................................. 13

2.4 Nature-based Solutions for disaster risk reduction $\quad$.................................. 14

2.5 Nature-based Solutions for climate change $\quad$............................................... 15

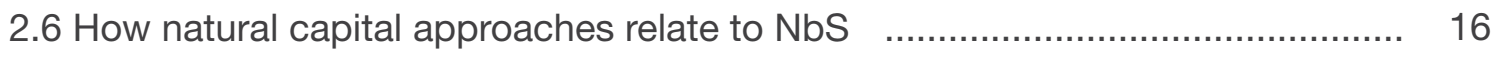




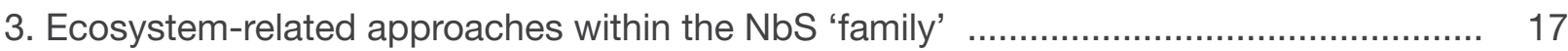

3.1 Ecosystem restoration approaches ........................................................... 17

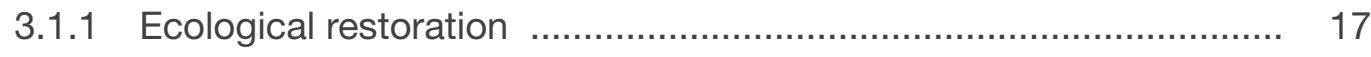

3.1.2 Ecological engineering ........................................................ 17

3.1.3 Forest landscape restoration …................................................ 18

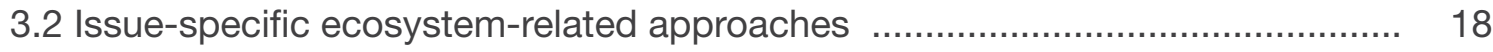

3.2.1 Ecosystem-based adaptation ................................................. 18

3.2.2 Ecosystem-based mitigation ...................................................... 19

3.2.3 Climate adaptation services …................................................. 19

3.2.4 Ecosystem-based disaster risk reduction ................................... 20

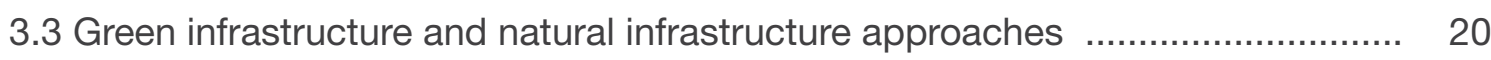

3.4 Ecosystem-based management approaches ............................................. 22

3.5 A brief comparison of these NbS approaches .............................................. 22

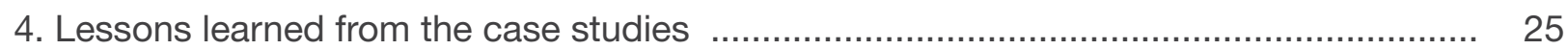

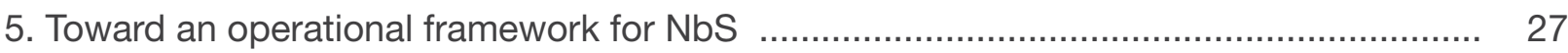

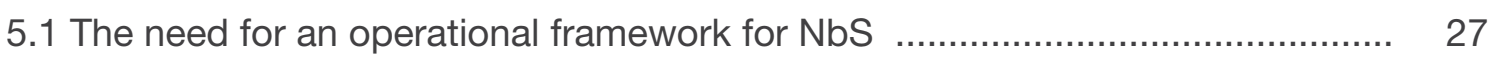

5.2 Ecosystem Approach as the basis for an NbS operational framework ............ 28

5.3 What should a single operational framework deliver? .................................. 29

5.4 Determining the key parameters of an NbS operational framework ................. 30

5.5 Proposed operational parameters for NbS ............................................... 30

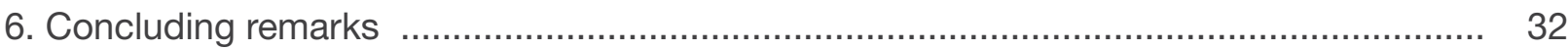

Part B Case Studies: Nature-based Solutions on the ground 33

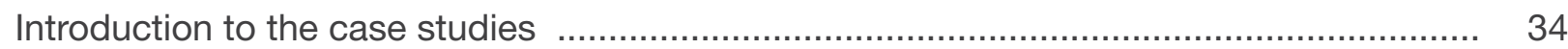

Case Study $1 \quad$ USA: Restoration of Cache la Poudre River to recover ecological function and reduce flood risk in Fort Collins, Colorado .................. 37

Case Study $2 \quad$ Japan: Wetlands and rice paddy fields contribute to biodiversity conservation, flood control and the local economy

Case Study $3 \quad$ UK: A collaborative approach to managed realignment of coastal defences in South-East England ................................................ 45

Case Study $4 \quad$ Rwanda: Forest Landscape Restoration as a national priority

Case Study $5 \quad$ Ecuador: One landowner's approach to forest restoration and sustainable management

Case Study $6 \quad$ Jordan: Securing rights and restoring lands for improved livelihoods 
Case Study 7

Case Study 8

Case Study 9

Case Study 10
Costa Rica: Securing livelihoods through mangrove conservation and restoration

USA: Restoration of wetlands and barrier islands for storm protection in the Northern Gulf of Mexico

Spain: Developing the Barcelona Green Infrastructure and Biodiversity Plan

Guatemala and Mexico: Implementing transboundary water governance through community ecosystem-based action in the Tacaná watersheds

References

Annex 1: NbS approaches: definitions and related terminologies 


\section{List of Figures and Tables}

\section{List of Figures}

Figure 1. Forests and their restoration as Nature-based Solutions that can complement other measures to address, in this case, food security

Figure 2. Timeline of the development of the $\mathrm{NbS}$ concept

Figure 3. Establishing a definitional framework for $\mathrm{NbS}$, to support the development of standards for NbS applications

Figure 4. Hypothetical scenario of Nature-based Solutions being used in conjunction with infrastructure development

Figure 5. A typology of $\mathrm{NbS}$ showing three main categories of solutions based on natural, restored and new ecosystems

Figure 6. $\quad \mathrm{NbS}$ as an umbrella term for ecosystem-related approaches

Figure 7. Natural infrastructure for water management

Figure 8. Trends in number of research papers mentioning NbS approaches (1980-2014)

Figure 9. Map of case study locations

\section{List of Tables}

Table 1. IUCN's and the European Commission's definitions of NbS

Table 2. Clarification of terms used in the NbS definitional framework

Table 3. Foundational ideas used in the development of NbS principles

Table 4. Categories and examples of NbS approaches

Table 5. Case studies presented in the report 


\section{List of Acronyms}

\begin{tabular}{ll} 
AFOLU & Agriculture, Forestry and Other Land Use \\
CAS & Climate Adaptation Services \\
CBD & Convention on Biological Diversity \\
CORNASAM & Inter-Institutional Coordination for Natural Resources and the Environment \\
CO2 & (Guatemala) \\
EbA & Carbon dioxide \\
EbM & Ecosystem-based Adaptation \\
EbMgt & Ecosystem-based Mitigation \\
Eco-DRR & Ecosystem-based Management \\
EDPRS & Ecosystem-based disaster risk reduction \\
EE & Economic Development and Poverty Reduction Strategy (Rwanda) \\
ER & Ecological Engineering \\
FLR & Ecosystem (or Ecological) Restoration \\
FONERWA & Forest Landscape Restoration \\
GI & National Climate and Environment Fund (Rwanda) \\
IUCN & Green Infrastructure \\
IWRM & International Union for Conservation of Nature \\
MINIRENA & Integrated Water Resource Management \\
MStAG & Ministry of Natural Resources (Rwanda) \\
NbS & Medmerry Stakeholder Advisory Group (UK) \\
NCAP & Nature-based Solution(s) \\
NI & Natural Capital Approach \\
Ramsar & Natural Infrastructure \\
REDD+ & Convention on Wetlands of International Importance \\
RNRA & Reducing Emissions from Deforestation and forest Degradation + \\
ROAM & Rwanda Natural Resources Authority \\
RSPB & Restoration Opportunity Assessment Methodology \\
UNDP & Royal Society for the Protection of Birds \\
UNFCCC & United Nations Development Programme \\
WANI & United Nations Framework Convention on Climate Change \\
WRI & Water and Nature Initiative \\
& World Resources Institute \\
\hline SW &
\end{tabular}




\section{List of Icons}

\section{Societal Challenges}
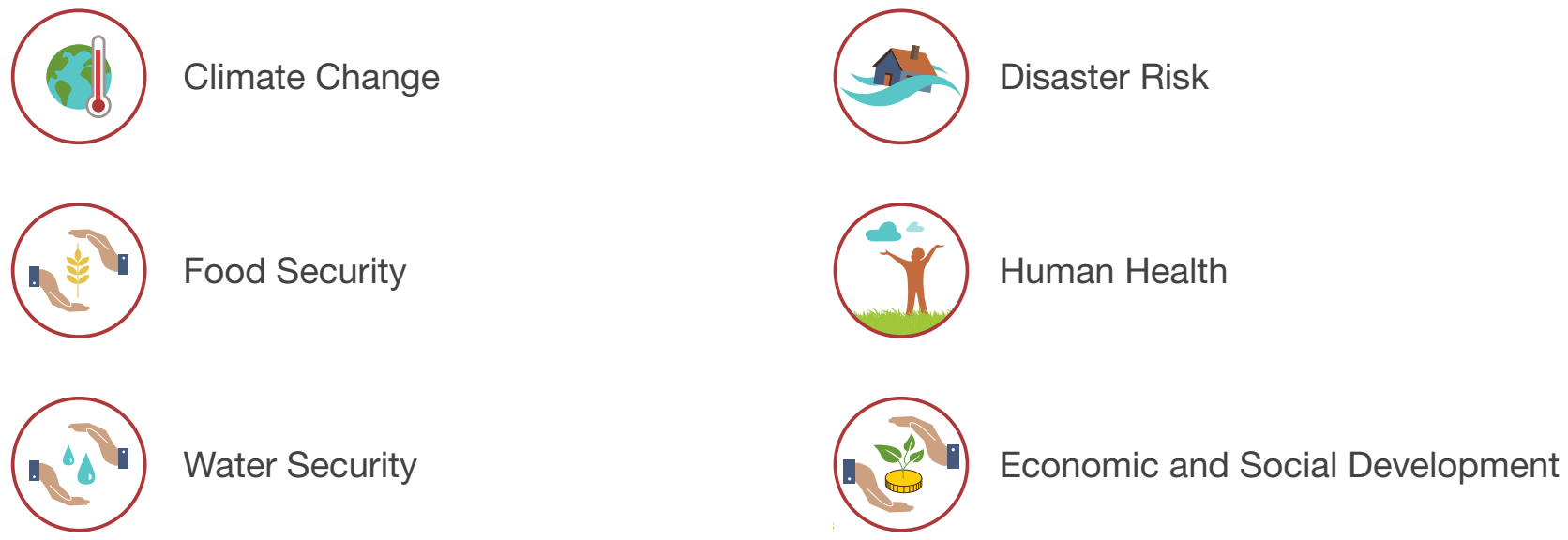

\section{NbS concepts}

ER Ecological Restoration

EE Ecological Engineering

FLR Forest Landscape Restoration

GI Green Infrastructure

NI

Natural Infrastructure

EbA Ecosystem-based Adaptation

EbM Ecosystem-based Mitigation

Ecosystem-based Disaster Risk Reduction

CAS Climate Adaptation Services

Abc Area-based Conservation

EbMgt Ecosystem-based Management 


\section{Main Contributors}

This report was prepared in a highly collaborative manner, drawing on the expertise of numerous people from within IUCN, its Commissions and Members, and other organisations including NGOs, research institutes, governmental bodies and private sector businesses.

The principal authors and editors of the report are Emmanuelle Cohen-Shacham (IUCN's Commission on Ecosystem Management Ecosystem Services Thematic Group), Gretchen Walters (IUCN's Global Forest and Climate Change Programme), Christine Janzen (Brock University and Commission on Ecosystem Management) and Stewart Maginnis (IUCN's Nature-based Solutions Group).

Contributors for specific sections of Part A of the report are as follows:

- Angela Andrade, Commission on Ecosystem Management

- Nigel Dudley, Equilibrium Research and IUCN's World Commission on Protected Areas

- Marie Fischborn, IUCN's Protected Area Solutions Group

- Mike Jones, Swedish Biodiversity Centre and IUCN's Commission on Ecosystem Management Resilience Thematic Group

- Chetan Kumar, IUCN's Global Forest and Climate Change Program

- Penelope Lamarque, IUCN's Nature-based Solutions Group

- Constanza Martinez, IUCN's Global Policy Unit
- Radhika Murti, IUCN's Ecosystem Management Programme

- Nathalie Olsen, IUCN's Economic Program

- Sandeep Sengupta, IUCN's Global Policy Unit

- Mark Smith, IUCN's Global Water Programme

- Chantal van Ham, IUCN's European Regional Office

- Rebecca Welling, IUCN's Global Water Programme

Contributors for the case studies in Part B are as follows:

- Biohabitats

- Rick Bachand, City of Fort Collins Natural Areas

- Naoya Furuta, IUCN's Japan Liaison Office

- Nick Gray, Joe Pearce, and Colin Maplesden, UK Environment Agency

- Charles Karangwa, IUCN's Eastern and Southern Africa Office

- Hugo Cerda and Brian McLaren, ESPOCH, Ecuador

- Fidaa F. Haddad, IUCN's Regional Office for West Asia

- Marco Quesada, Conservation International

- Mark Ford, United States National Park Service

- Marga Parés, Coloma Rull, and Montse Rivero, the City of Barcelona

- Rebecca Welling, IUCN's Global Water Programme 


\section{Acknowledgements}

We would like to thank everyone who contributed to the preparation of this report. Technical contributions were provided by Keith Bowers, Thomas Brooks, Chris Buss, Dorothee Herr, Rudolf de Groot, Mike Jones, Sandra Lavorel, Radhika Murti, Fabrice Renaud, Ali Raza Rizvi, Lilian Sauni, Peter Smith, Mason Smith, Pauline Teillac-Deschamps and Liette Vasseur. Administrative support was provided by Sue Both, Pat Hawes, Sue Mills and Virginie Trillard.

We thank those who provided comments on previous versions of the document: Angela Andrade, Edmund Barrow, Luc Bas, Camille Buyck, Justine Delangue, Marie Fischborn, Mike Jones, Penelope Lamarque, Trevor Sandwith, Mark Smith, Chantal van Ham, Rebecca Welling and Piet Wit.

We thank two reviewers, Nigel Dudley and Robert Fisher for giving critical feedback, which improved this work. Any remaining errors remain the responsibility of the authors/editors.
We thank Jennifer Rietbergen-McCracken for editing, Chadi Abi for the layout, Studio Eshkat for the graphics and Craig R. Beatty for the map. Camille Buyck, Sandra Caya, Marie Fischborn, Mark Gnadt, Deborah Murith, Cory Nash, Chantal van Ham and Rebecca Welling are thanked for their support on communications and graphics.

Many parts of IUCN contributed to understanding the depth and breadth of $\mathrm{NbS}$ implementation and thinking across the Union. This included those working in Oceania, the French National Committee, the IUCN Centre for Mediterranean Cooperation, Brussels and Gland offices.

The report was made possible through the contribution of the United States Voluntary Contribution (United States Department of State), Norad, BMUB-IKI, DfID, and UNDP-GEF. 


\section{Preamble}

This report has been prepared as part of an effort by IUCN to define its position on Naturebased Solutions (NbS) and plan for future work to advance this concept and support effective implementation of $\mathrm{NbS}$ to enhance ecosystem services provision and address societal challenges.

The report proposes a definitional framework for $\mathrm{NbS}$, including a set of general principles for any NbS intervention. The report also defines the scope of $\mathrm{NbS}$ as an umbrella concept embracing a number of different ecosystembased approaches. These NbS approaches include, for example, ecological restoration, ecological engineering, forest landscape restoration, ecosystem-based adaptation, ecosystem-based mitigation, ecosystem-based disaster risk reduction, green infrastructure, ecosystem-based management, and the various area-based conservation approaches such as protected area management.

The report considers several potential parameters that can be used to build an operational framework, on the basis of which the efficiency, effectiveness and sustainability of $\mathrm{NbS}$ interventions can be systematically assessed. IUCN is committed to supporting further development of an operational framework for $\mathrm{NbS}$. The report outlines how the Ecosystem Approach offers a solid foundation for the NbS concept.

Finally, the report presents ten case studies of $\mathrm{NbS}$ applications from around the world. These cases have been chosen to represent the range of ecosystem services and societal challenges that can be addressed by $\mathrm{NbS}$ interventions. The report looks at some of the lessons learned from these cases and discusses the importance of building an evidence base for $\mathrm{NbS}$ in order to support future replication and upscaling.

It is hoped that this report will provide conservation and development practitioners, policy makers and researchers, as well as civil society organisations, with a useful basis for understanding what Nature-based Solutions involve and what they offer in terms of benefits for human and nature, by contributing to resolving societal challenges. 


\section{Executive summary}

Nature-based Solutions (NbS) are defined by IUCN as actions to protect, sustainably manage and restore natural or modified ecosystems, which address societal challenges (e.g. climate change, food and water security or natural disasters) effectively and adaptively, while simultaneously providing human well-being and biodiversity benefits. The NbS concept, as used in environmental sciences and nature conservation contexts, has emerged within the last decade or so, as international organisations search for ways to work with ecosystems rather than relying on conventional engineering solutions (such as seawalls) - to adapt to and mitigate climate change effects, while improving sustainable livelihoods and protecting natural ecosystems and biodiversity.

$\mathrm{NbS}$ is a relatively 'young' concept, still in the process of being framed. There is a need now to deepen our understanding of $\mathrm{NbS}$ and confirm the principles upon which $\mathrm{NbS}$ is based, in order to move towards an operational framework that can guide applications of the NbS concept. The following set of $\mathrm{NbS}$ principles are proposed.

\section{Nature-based Solutions:}

1. embrace nature conservation norms (and principles);

2. can be implemented alone or in an integrated manner with other solutions to societal challenges (e.g. technological and engineering solutions);

3. are determined by site-specific natural and cultural contexts that include traditional, local and scientific knowledge;

4. produce societal benefits in a fair and equitable way, in a manner that promotes transparency and broad participation;

5. maintain biological and cultural diversity and the ability of ecosystems to evolve over time;

6. are applied at the scale at a landscape;

7. recognise and address the trade-offs between the production of a few immediate economic benefits for development, and future options for the production of the full range of ecosystems services;

8. are an integral part of the overall design of policies, and measures or actions, to address a specific challenge.

$\mathrm{NbS}$ is best considered an umbrella concept that covers a range of different approaches. These approaches have emerged from a variety of spheres (some from the scientific research domain, others from practice or policy contexts) but share a common focus on ecosystem services and aim to address societal challenges. These NbS approaches can be classified into:

(i) ecosystem restoration approaches (e.g. ecological restoration, ecological engineering and forest landscape restoration); (ii) issuespecific ecosystem-related approaches (e.g. ecosystem-based adaptation, ecosystem-based mitigation, and ecosystem-based disaster risk reduction); (iii) infrastructure-related approaches (e.g. natural infrastructure and green infrastructure approaches); (iv) ecosystembased management approaches (e.g. integrated coastal zone management and integrated water resources management); and (v) ecosystem protection approaches (e.g. area-based conservation approaches including protected area management).

A lack of operational clarity presents a major obstacle to the credibility and applicability of new concepts in the fields of conservation and development. Several parallel exercises are currently underway to develop operational parameters for specific NbS approaches (such as Ecosystem-based Adaptation and REDD+), each proposing its own set of criteria. Many of these criteria could be relevant for other approaches within the NbS 'family' and there is likely an overarching set of parameters, or 'standards', that can guide implementation of 
all types of $\mathrm{NbS}$ interventions. To help in this endeavour, five preliminary parameters are proposed: ecological complexity, long-term stability, scale of ecological organisation, direct societal benefits and adaptive governance.
By unifying $\mathrm{NbS}$ approaches under a single operational framework, it becomes possible to scale up their implementation and strengthen their impact in mitigating the world's most pressing challenges. 


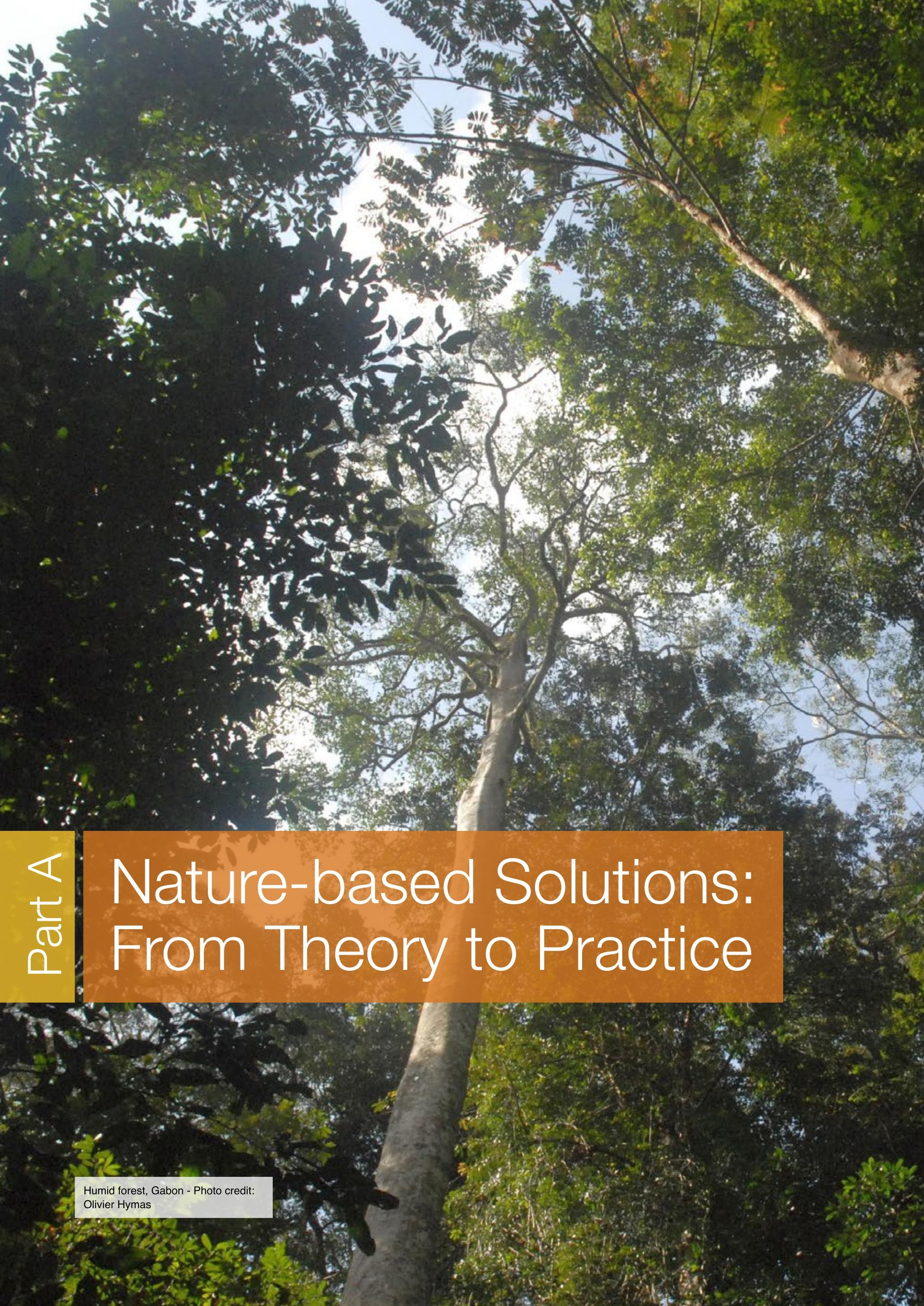




\section{What are Nature-based Solutions?}

\subsection{Development of the NbS concept}

G Walters, E Cohen-Shacham, S Maginnis, $P$ Lamarque (authorship unless otherwise stated)

\subsubsection{Origins of $\mathrm{NbS}$}

Nature-based Solutions (NbS) use ecosystems and the services they provide to address societal challenges such as climate change, food security or natural disasters. IUCN defines $\mathrm{NbS}$ as: "Actions to protect, sustainably manage and restore natural or modified ecosystems that address societal challenges effectively and adaptively, simultaneously providing human well-being and biodiversity benefits."

Nature-based Solutions can often be used in conjunction with others types of interventions. Food security challenges, for example, are best addressed using a combination of measures including $\mathrm{NbS}$ (e.g. introducing agroforestry systems, restoring wetlands) as well as more conventional solutions such as improving access to food and making trade policy more supportive of local food supply (see Figure 1).

Recognition of the fundamental role that ecosystems play in supporting human wellbeing is a cornerstone of many indigenous peoples' belief systems and has been reflected in traditional knowledge systems for centuries. However, it was only in the 1970s that the idea of environmental or ecosystem services began to establish itself in the modern scientific literature. By the 1990s it was generally realised that a more systematic approach was required to document and understand this relationship between people and nature. The 2005 Millennium Ecosystem Assessment, itself a product of this growing awareness, provided a strong evidence base for subsequent policies

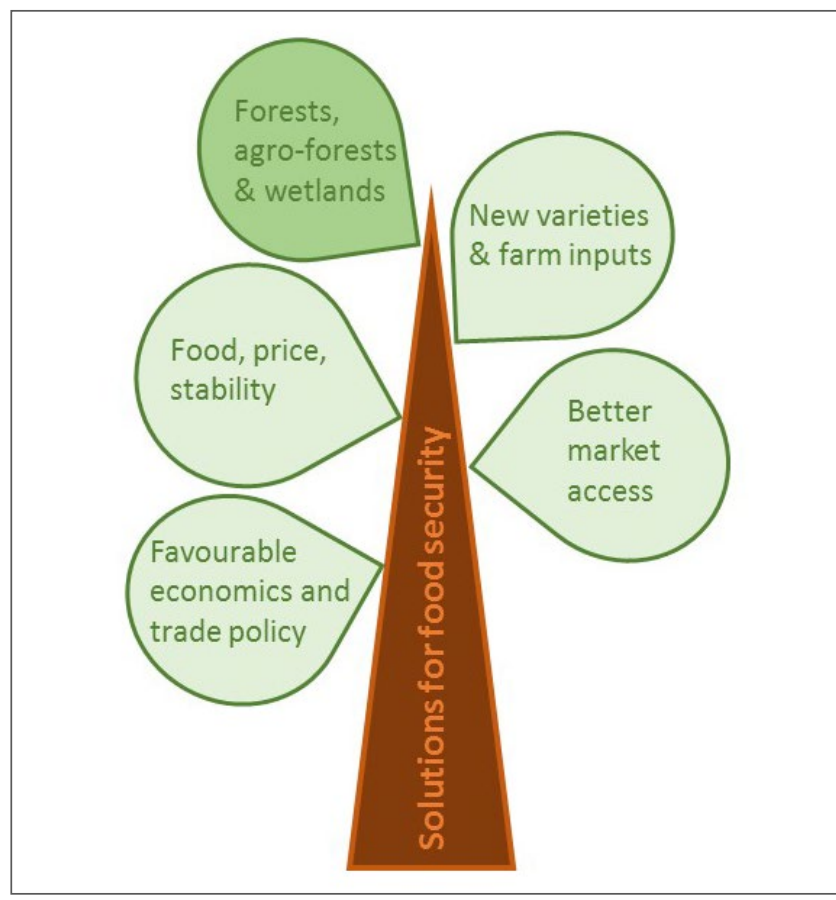

Figure 1. Forests and their restoration as Nature-based Solutions that can complement other measures to address, in this case, food security

1 This definition was developed and agreed within IUCN through a consultative process. More details on a proposed definitional framework for NbS are provided in Section 1.2.2. 
to promote the conservation, restoration and sustainable management of ecosystems while also taking into account the increasing demands placed on ecosystem services (Millennium Ecosystem Assessment, 2005). A few years later, during the late 2000s, the term 'NatureBased Solutions' emerged, marking a subtle yet important shift in perspective: not only were people the passive beneficiaries of nature's benefits, but they could also proactively protect, manage or restore natural ecosystems as a purposeful and significant contribution to addressing major societal challenges.

The emergence of the NbS concept in environmental sciences and nature conservation contexts came as international organisations, such as IUCN and the World Bank, searched for solutions to work with ecosystems rather than relying on conventional engineering interventions (such as seawalls), to adapt to and mitigate climate change effects, while improving sustainable livelihoods and protecting natural ecosystems and biodiversity (Mittermeier et al., 2008). Following the same approach, 'Natural solutions' has been used as a similar concept, in this case focusing on the particular role of protected areas in offering solutions to societal challenges such as climate change and desertification (Dudley et al., 2010).

More broadly, the development of the NbS concept has been firmly grounded in global practice as the nature conservation and development sectors, formerly viewed as having contradictory objectives, have moved toward a common recognition of the positive as well as negative linkages between people and nature. This has been evidenced by, for example, the emergence and evolution of the whole field of sustainable development. Similarly, perspectives on nature conservation have broadened considerably over the last half-decade, expanding beyond an exclusive focus on the protection of wilderness and wild, charismatic species to approaches that tackle the drivers of biodiversity decline such as pollution and the loss of species habitats. More recently, the conservation agenda has evolved further to embrace a more complex understanding of social-ecological systems, as evidenced by the establishment of the Ecosystem Approach, which was endorsed and adopted by the CBD in 1995 (Mace, 2014; CBD, 2004). . The international ambitions of both the sustainable development and biodiversity conservation communities now clearly take into account the need to provide sustainable benefits for people and the broader environment.

\subsubsection{Current status of the NbS concept}

To date, the term NbS has been used mainly in communications targeting policy makers and with the exception of two scientific briefs (MacKinnon et al., 2011; MacKinnon \& Hickey, 2009), it has only recently started to be used in the scientific literature (e.g. Eggermont et al., 2015; Kabisch et al., forthcoming.; Kabisch et al., 2016; Maes \& Jacobs, 2015).

The NbS concept is increasingly being developed and applied by IUCN and other organisations, such as the European Commission. IUCN actively promoted the NbS concept in its 2009 position paper on the United Nations Framework Convention on Climate Change (UNFCCC) COP 15, and in 2012 IUCN formally adopted $\mathrm{NbS}$ as one of the three areas of work within its 2013-2016 Programme. For its part, the European Commission has made NbS part of its Horizon 2020 Research and Innovation Programme and is investing in a series of projects to strengthen the evidence base on NbS (Maes \& Jacobs, 2015). Part $B$ of this report describes a small fraction of the many and varied practical applications of the NbS concept in developed and emerging economies around the world.

2 For discussion on how the Ecosystem Approach can provide a foundational basis for the development of an operational framework for NbS, see Section 5.2. 


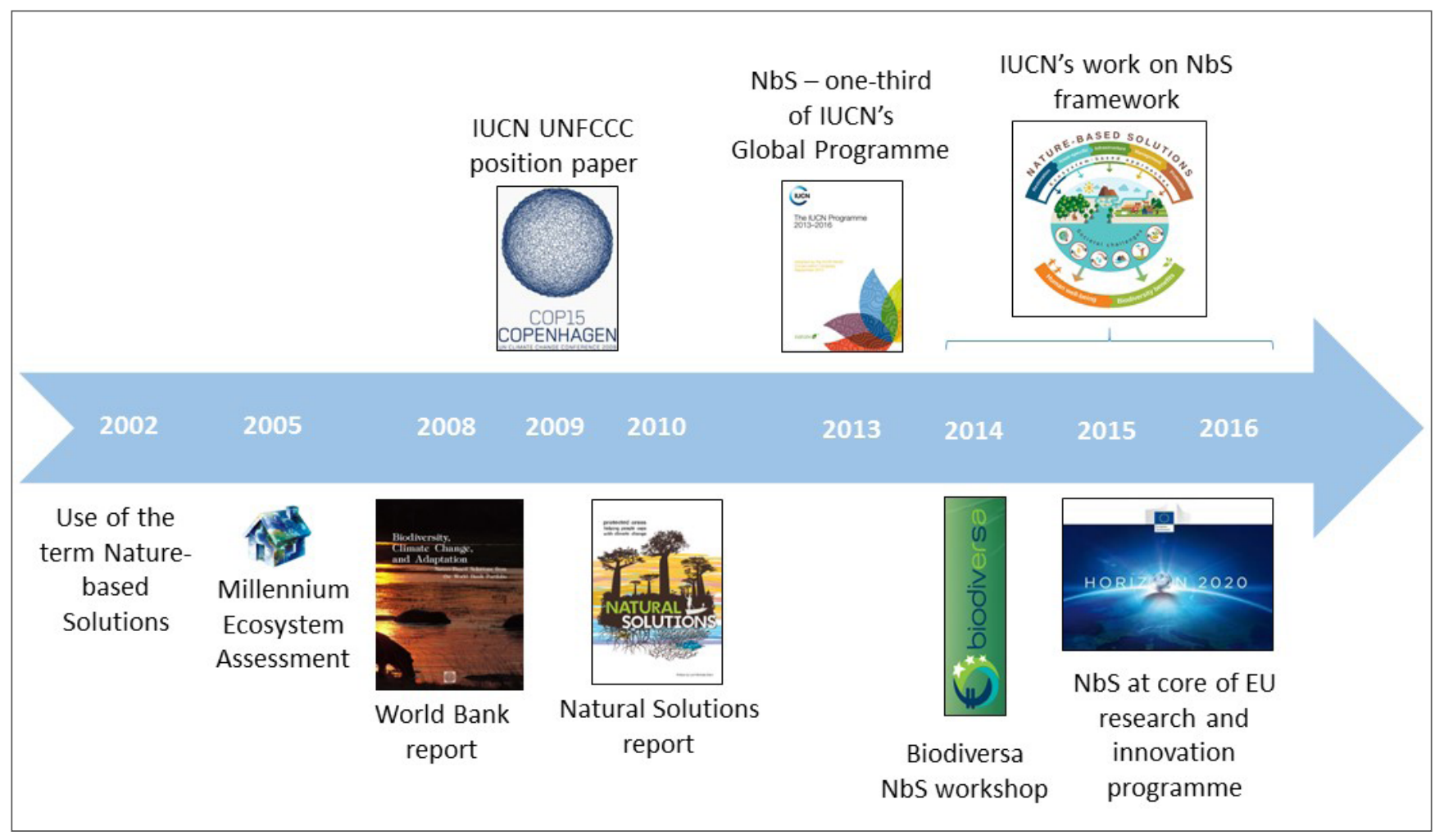

Figure 2. Timeline of the development of the NbS concept

\subsubsection{Milestones in the development of $\mathrm{NbS}$}

The timeline shown in Figure 2 highlights the major milestones in the evolution of the NbS concept, including the following publications and events:

- The World Bank report, Biodiversity, Climate Change and Adaptation: Nature-Based Solutions from the World Bank Portfolio (World Bank, 2008);

- IUCN's position paper on the UNFCCC COP 15 (IUCN, 2009);

- Natural Solutions: Protected areas helping people cope with climate change, a report commissioned by IUCN-World Commission on Protected Areas, The Nature Conservancy, UNDP, Wildlife Conservation Society, the World Bank and WWF (Dudley et al., 2010);

- A workshop on 'Nature-Based Solutions in a BiodivERsA context' (Balian et al., 2014);

- A series of publications focusing on Naturebased Solutions (e.g. Eggermont et al., 2015, Maes \& Jacobs, 2015, European
Commission \& Directorate-General for Research and Innovation, 2015, Potschin et al. 2015).

\section{Nature-based Solutions}

are defined as actions to

protect, sustainably manage, and restore natural or modified ecosystems, that address societal challenges effectively and adaptively, simultaneously providing human well-being and biodiversity benefits. 


\subsection{Defining NbS}

E Cohen-Shacham, S Maginnis, M Smith, A Andrade, M Jones, N Dudley, C Martinez, C Kumar.

\subsubsection{Multiple definitions of NbS}

The term NbS has been defined and used in a number of different ways. For example, IUCN and the European Commission have developed their own definitions of $\mathrm{NbS}$, which while broadly similar (they share the overall goal of addressing major societal challenges through the effective use of ecosystem and ecosystem services) have a few significant differences (see Table 1). IUCN's definition emphasises the need for a well-managed or restored ecosystem to be at the heart of any $\mathrm{NbS}$, while the European Commission definition is somewhat broader and places more emphasis on applying solutions that not only use nature but are also inspired and supported by nature.

\subsubsection{A proposed definitional framework for $\mathrm{NbS}$}

Good science requires the use of precise definitions rather than phrases working as metaphors (Aronson, 2011). Furthermore, as multiple definitions of $\mathrm{NbS}$ develop, they may lead to some confusion about the concept and potentially hinder its development and uptake. In order for $\mathrm{NbS}$ to become operational, a clear definition and a set of principles are needed.

In this context, IUCN recently undertook a brief consultation process with practitioners and scientists across its networks as the basis for establishing an IUCN definitional framework for $\mathrm{NbS}$. This framework includes three components: (i) the overarching goal of $\mathrm{NbS}$, (ii) a definition of $\mathrm{NbS}$; and (iii) a list of NbS principles. The articulation of these three elements will enable a coherent set of parameters, or standards, for $\mathrm{NbS}$ to be developed (see Section 5). This process is illustrated in Figure 3 and the proposed articulations are set out below.

\section{Overarching goal of $\mathrm{NbS}$}

$\mathrm{NbS}$ are intended to support the achievement of society's development goals and safeguard human well-being in ways that reflect cultural and societal values and enhance the resilience of ecosystems, their capacity for renewal and the provision of services. $\mathrm{NbS}$ are designed to address major societal challenges, such as food security, climate change, water security, human health, disaster risk, social and economic development.

\section{NbS definition}

Nature-based Solutions are defined as actions to protect, sustainably manage, and restore natural or modified ecosystems, that address societal challenges effectively and adaptively, simultaneously providing human well-being and biodiversity benefits.

\section{NbS principles}

Based on our consultations, a list of preliminary principles was developed for NbS. To define that list, several existing frameworks were

Table 1. IUCN's and the European Commission's definitions of NbS (main differences highlighted in bold text)

\begin{tabular}{|c|c|}
\hline IUCN definition & European Commission definition \\
\hline $\begin{array}{l}\text { Actions to protect, sustainably manage and } \\
\text { restore natural or modified ecosystems that } \\
\text { address societal challenges effectively and } \\
\text { adaptively, simultaneously providing human } \\
\text { well-being and biodiversity benefits. }\end{array}$ & $\begin{array}{l}\text { Living solutions inspired by, continuously } \\
\text { supported by and using Nature designed } \\
\text { to address various societal challenges in a } \\
\text { resource efficient and adaptable manner and } \\
\text { to provide simultaneously economic, social and } \\
\text { environmental benefits. (see Maes \& Jacobs, } \\
\text { 2015) }\end{array}$ \\
\hline
\end{tabular}



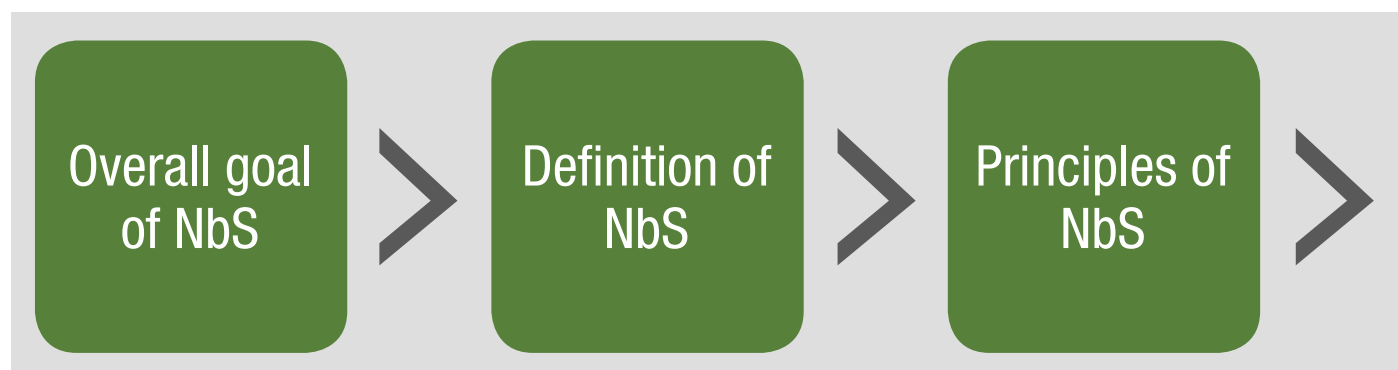

Operational parameters for $\mathrm{NbS}$

Note: The green represents steps already completed while the orange represents work that is planned.

Figure 3. Establishing a definitional framework for NbS, to support the development of standards for NbS applications

analysed (e.g. Ecosystem Approach and its principles, Ecosystem Services approach, the original list of principles for $\mathrm{NbS}$ in the 20132016 IUCN Programme (IUCN, 2013b) and others (Woodhouse et al., 2015).

A set of $\mathrm{NbS}$ principles, to be considered in conjunction with the NbS definition, will be essential in providing a full understanding of $\mathrm{NbS}$ for IUCN. The eight proposed NbS principles are as follows:

\section{Nature-based Solutions:}

1. embrace nature conservation norms (and principles);

2. can be implemented alone or in an integrated manner with other solutions to societal challenges (e.g. technological and engineering solutions);

3. are determined by site-specific natural and cultural contexts that include traditional, local and scientific knowledge;
4. produce societal benefits in a fair and equitable way, in a manner that promotes transparency and broad participation;

5. maintain biological and cultural diversity and the ability of ecosystems to evolve over time;

6. are applied at a landscape scale;

7. recognise and address the trade-offs between the production of a few immediate economic benefits for development, and future options for the production of the full range of ecosystems services; and

8. are an integral part of the overall design of policies, and measures or actions, to address a specific challenge.

Tables 2 and 3 provide further explanation of the thinking behind this definitional framework for $\mathrm{NbS}$.

Table 2. Clarification of terms used in the NbS definitional framework

\begin{tabular}{l|l} 
Term & $\begin{array}{l}\text { Clarification } \\
\text { Ecosystems }\end{array}$ \\
& $\begin{array}{l}\text { This term refers to and addresses all types of ecosystems, including natural and } \\
\text { modified ecosystems. }\end{array}$ \\
\hline Societal & $\begin{array}{l}\text { NbS explicitly address societal challenges. The solutions are not aimed at } \\
\text { addressing only environmental challenges or minimising only environmental } \\
\text { impacts, although these may be part of what the NbS is targeting. }\end{array}$ \\
\hline Actions & $\begin{array}{l}\text { This term was chosen to underline the need for active solutions to major societal } \\
\text { challenges. All NbS interventions are nature- or ecosystem-based solutions, and } \\
\text { do not include interventions that are merely inspired by nature, such as biomimicry. }\end{array}$ \\
&
\end{tabular}


Table 3. Foundational ideas used in the development of NbS principles

Nature-based Solutions are no substitute for nature conservation and Principle 1 they embrace nature conservation and its principles. At the same time, not all conservation efforts would necessarily be considered NbS.

$\mathrm{NbS}$ offer one group of solutions, among numerous others, to solve Principles 2, 8 global societal challenges; NbS can complement, and be implemented alongside, other types of interventions.

A clear objective of $\mathrm{NbS}$ should be to support cultural and social Principles 3, 4, 5 components and values.

$\mathrm{NbS}$ are context-specific, both in time and space. For example, Principle 3, 4 although climate change is a global issue, the issue can be addressed in different ways, at different scales, and in different parts of the world. The appropriate $\mathrm{NbS}$ will need to be tailored to the specific conditions present.

\subsection{Applying the NbS concept: an introduction}

\subsubsection{What does NbS look like in practice?}

$\mathrm{NbS}$ has been applied in a wide variety of sectors and to address a plethora of societal issues, as will be outlined in detail in Sections 2 and 3. NbS interventions can take many forms including, for example:

- Restoring and sustainably managing wetlands and rivers to maintain or boost fish stocks and fisheries-based livelihoods, reduce the risk of flooding, and provide recreational and tourism benefits (see for example Case study 7);

- conserving forests to support food and energy security, local incomes, climate change adaption and mitigation, and biodiversity (see for example Case Studies 4 and 5);

- restoring drylands to strengthen water security, local livelihoods and resilience to climate change impacts (see or example Case Study 6);

- developing green infrastructure in urban environments (e.g. green walls, roof gardens, street trees, vegetated drainage basins) to improve air quality, support wastewater treatment, and reduce stormwater runoff and water pollution as well as improve the quality of life for residents (see for example Case Study 9);

- using natural coastal infrastructure such as barrier islands, mangrove forests and oyster reefs to protect shorelines and communities from coastal flooding and reduce the impacts of sea-level rise (see for example Case Studies 3 and 8).

A hypothetical scenario of an NbS is shown in Figure 4. This case illustrates two important points about $\mathrm{NbS}$ interventions: (i) they can complement other measures (as mentioned above); and (ii) they can involve the use of natural areas or conservation measures that were originally established for a purpose other than that of the NbS.

This hypothetical case relates to a protected area in a coastal landscape. The protected area, originally created to provide an intact habitat for a particular rare species, is located near a watershed that is bordered by human settlements. In the past, flooding had not been 


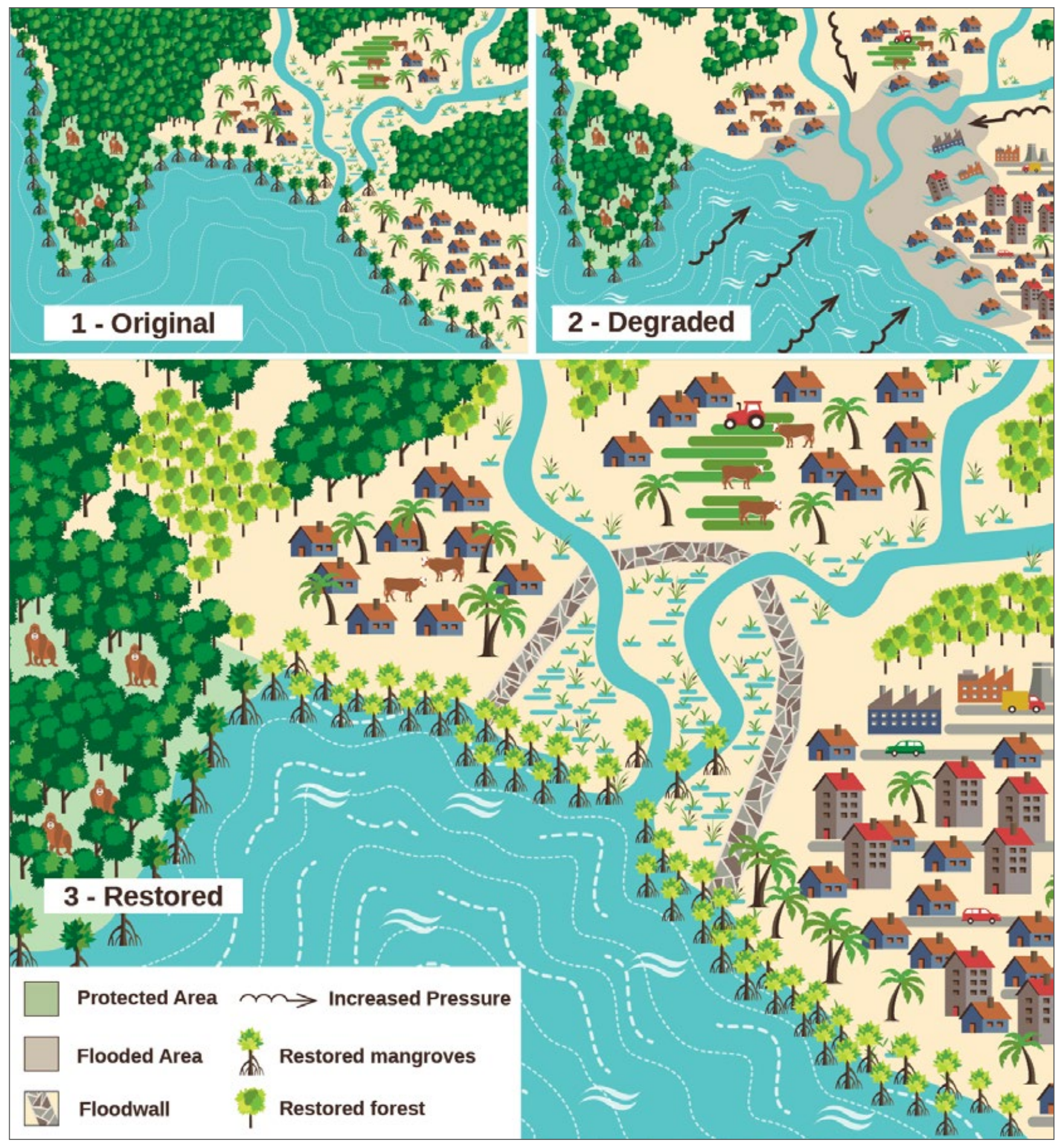

Figure 4. Hypothetical scenario of Nature-based Solutions being used in conjunction with infrastructure development and protected area conservation

a frequent problem as the forest and wetland had been able to absorb a large part of any storm surges. Over time however, deforestation and degradation of the forest and wetland ecosystems have left the expanding settlements more susceptible to flooding. The remaining forest in the protected area now plays a critical role in absorbing flood flows. In order to strengthen the ability of the protected area to perform this 'new' function and reduce flooding risk, it needs to be reconnected to the wider landscape to improve the entire watershed's functionality. The main NbS intervention namely, restoration of the watershed, including the protected area - is therefore undertaken in combination with other $\mathrm{NbS}$ interventions 
(such as mangrove replanting and wetland restoration) and conventional measures (such as construction of a concrete flood barrier). Together these solutions not only mitigate flooding, but also support biodiversity and local livelihoods.

\subsubsection{A typology of NbS applications} Analysis by BiodivERsA ERA-NET, a network of national and regional funding organisations that supports pan-European research on biodiversity and ecosystem services, has produced a typology of $\mathrm{NbS}$ interventions (see Figure 5). The proposed typology categorises NbS interventions along two gradients: (i) the required level of engineering of biodiversity and ecosystems involved in the $\mathrm{NbS}$; and (ii) the level of enhancement of ecosystem services achievable by the NbS (Eggermont et al., 2015). This typology identifies three main types of NbS:

- Type 1: solutions that involve making better use of existing natural or protected ecosystems (e.g. measures to increase fish stocks in an intact wetland to enhance food security);

- Type 2: solutions based on developing sustainable management protocols and procedures for managed or restored

\section{Nature-based Solutions can be implemented alone or in an integrated manner with other solutions to societal challenges (e.g. technological and engineering solutions).}

ecosystems (e.g. re-establishing traditional agro-forestry systems based on commercial tree species to support poverty alleviation); and

- Type 3: solutions that involve creating new ecosystems (e.g. establishing green buildings (green walls, green roofs)). Such a typology can help in categorising the wide variety of $\mathrm{NbS}$ approaches into different groupings, based on sets of shared characteristics, as a means of framing the $\mathrm{NbS}$ concept and considering the kinds of approaches that would classify as NbS. This classification is further explored in the next part of this report, Section 1.3.3.

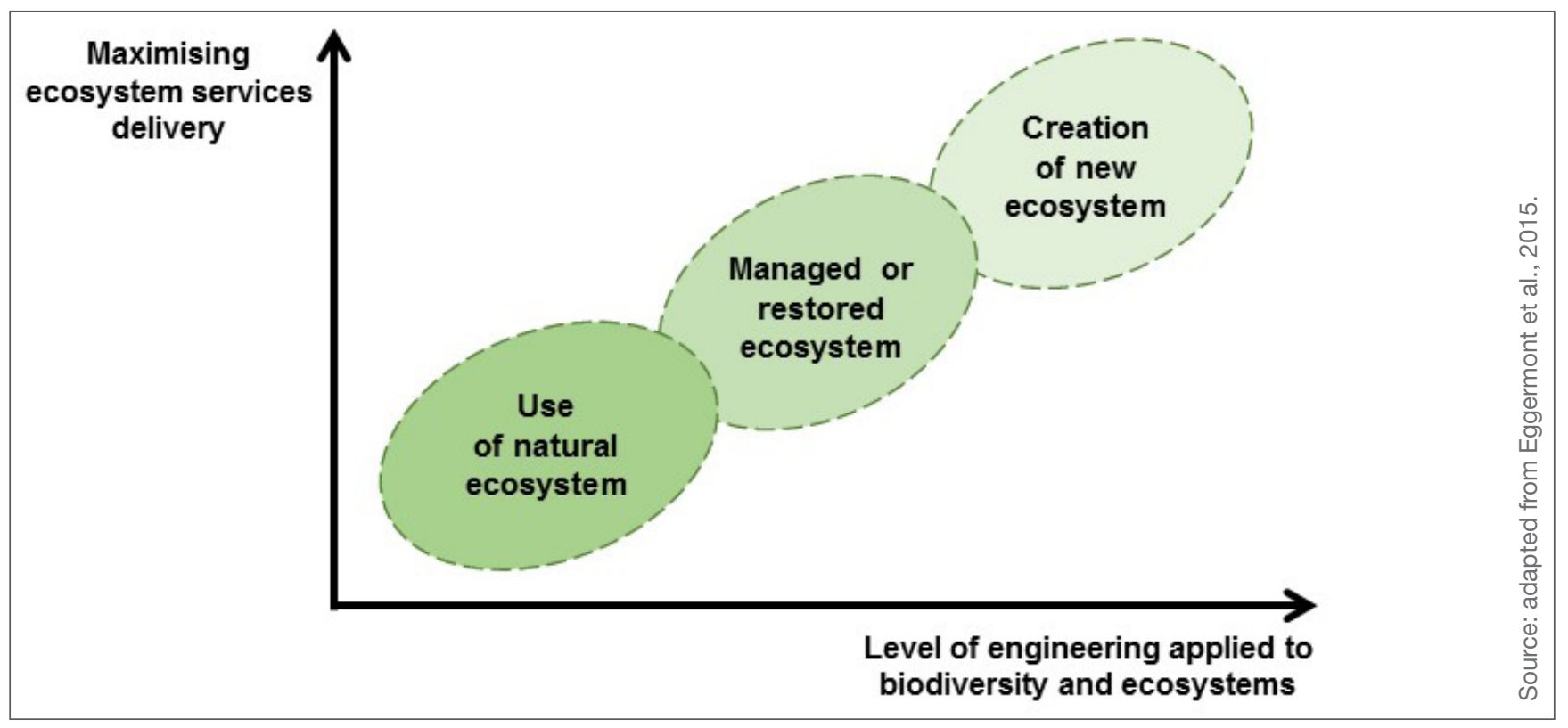

Figure 5. A typology of NbS showing three main categories of solutions based on natural, restored and new ecosystems 


\subsubsection{NbS as an umbrella concept for ecosystem-related approaches}

In framing $\mathrm{NbS}$ and considering its applications, it is useful to think of it as an umbrella concept that covers a whole range of ecosystem-related approaches all of which address societal challenges.

These approaches can be placed into five main categories, as shown in Table 4.

These approaches, most of which actually predate the emergence of $\mathrm{NbS}$, generally fulfil the NbS definition, set out in Section 1.2.2. They also share many similarities, for example in terms of the ecosystem services they address and the types of interventions they involve. These approaches can therefore not only be clustered together under NbS as the overarching concept (as shown in Figure 6), but also contribute to the development of an operational framework for $\mathrm{NbS}$ (as discussed later in Section 5). More details on most of these approaches, and how they relate to each other and to $\mathrm{NbS}$, are provided in Section 3 and Annexes 1 and 2 .

\subsection{NbS initiatives at IUCN}

A wide range of $\mathrm{NbS}$-related initiatives is being undertaken by IUCN and its Members. These can be divided into two broad categories: (i) building the knowledge base for NbS; and (ii) putting $\mathrm{NbS}$ into practice. This section touches on just a few examples of each of these areas of work. Further examples of practical applications of NbS by IUCN are found in Case Studies 4, 6 and 10 in Part B of this report.

In the Oceania region, for example, IUCN's work on $\mathrm{NbS}$ focuses on water resource management and coastal resilience and management. The Mangrove Ecosystems for Climate Change Adaptation and Livelihoods (MESCAL) and the Pacific Mangrove Initiative are two examples of such work. These initiatives aim to increase the resilience of Pacific Island countries to climate change, through adaptive co-management of mangroves and associated ecosystems in target countries.

In the Mediterranean, the IUCN Centre for Mediterranean Cooperation has launched an

Table 4. Categories and examples of NbS approaches

Category of NbS approaches

Ecosystem restoration approaches

Issue-specific ecosystem-related approaches

\section{Examples}

Ecological restoration

Ecological engineering

Forest landscape restoration

Ecosystem-based adaptation

Ecosystem-based mitigation

Climate adaptation services

Ecosystem-based disaster risk reduction

Natural infrastructure

Green infrastructure

Integrated coastal zone management Integrated water resources management

Area-based conservation approaches including protected area management 


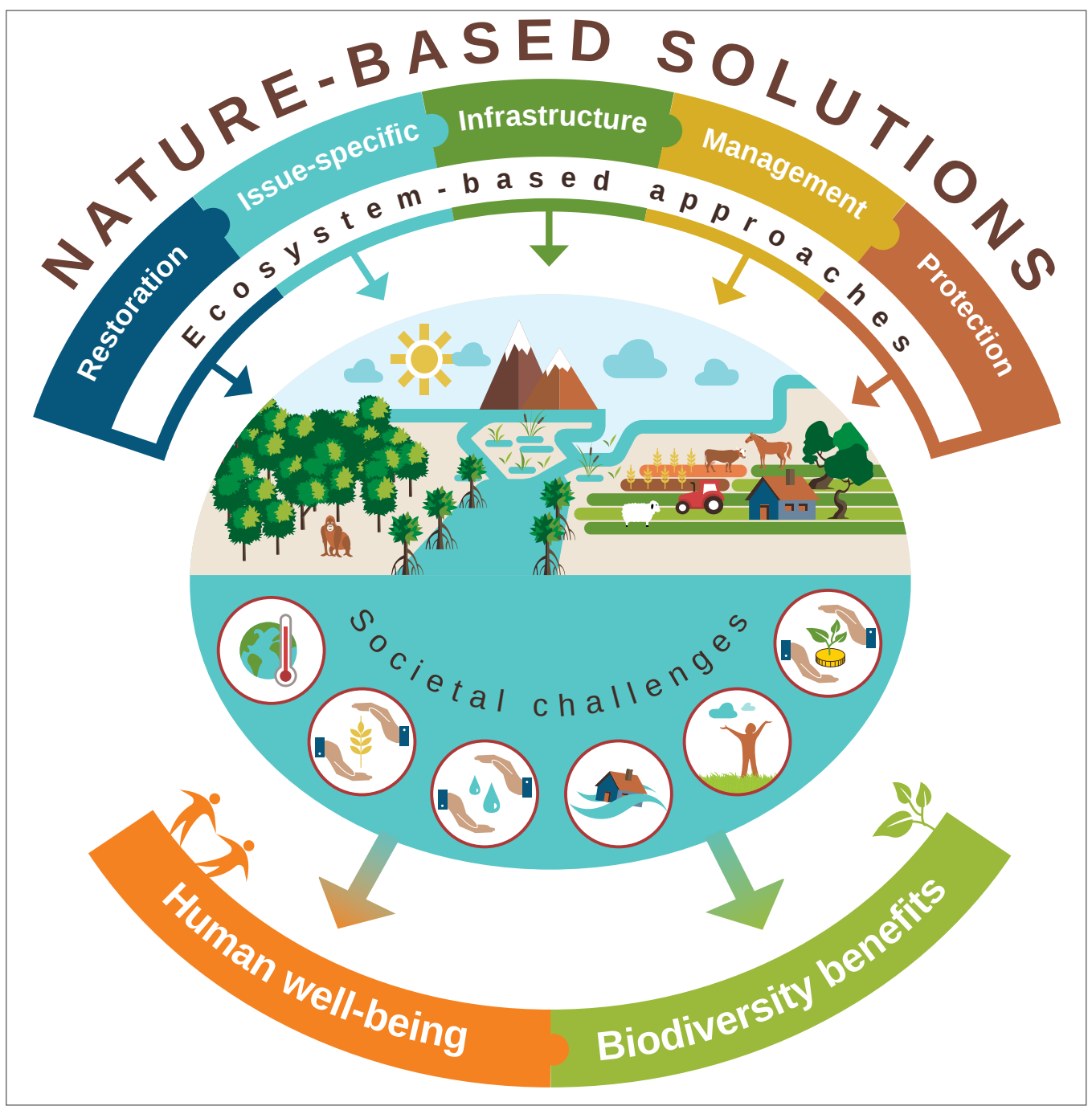

Figure 6. NbS as an umbrella term for ecosystem-related approaches

initiative to identify NbS work in the region, select those $\mathrm{NbS}$ projects demonstrating best practice, and develop and disseminate these case studies to help improve knowledge of $\mathrm{NbS}$ and support upscaling of $\mathrm{NbS}$ in the region.

The Nature Conservancy, an IUCN Member, is focusing its NbS-related work on producing support material for secondary school education (TNC, n.d.) and communication of NbS (Weigel \& Metz, 2015), as well as supporting the development of green infrastructure (UNEP, 2014). In France, the National IUCN Committee and its members have been working since 2014 on the role of $\mathrm{NbS}$ in climate change mitigation and adaptation strategies (UICN France, 2015).

Work by IUCN and its partners on the Blue Solutions project, provides a global platform to collate, share and generate knowledge and capacity for sustainable management and equitable governance of coastal and marine ecosystems, as 'Blue' Solutions (GIZ, 2015). ${ }^{3}$ This work has been expanded to look at Nature-based Solutions relating to protected areas, under the Panorama initiative, which aims to collect and share case studies of these solutions (IUCN, 2016).

3 The Blue Solutions project is being implemented by the Deutsche Gesellschaft für Internationale Zusammenarbeit, GRID-Arendal, IUCN and the United Nations Environment Programme, funded by the Federal Ministry for the Environment, Nature Conservation, Building and Nuclear Safety of Germany under the International Climate Initiative. 


\section{Nature based Solutions to specific societal challenges}

\subsection{Nature-based Solutions for water security}

M Smith, $R$ Welling

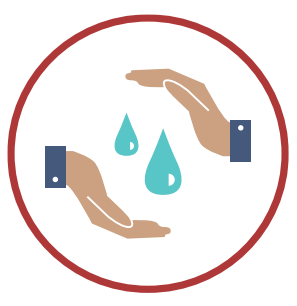

Built infrastructure alone is increasingly unlikely to provide future water security and resilience against predicted climate change impacts (Ozment et al., 2015; Dalton \& Murti, 2013). New demands on solutions for water security are emerging in a global context where about four billion people - 60 percent of the world's population - live in regions with a state of nearpermanent water stress, where net withdrawals of surface and groundwater meet or exceed the available supply, meaning that no additional water is available for ecosystem use or to meet future demand. Water stress is exacerbated by pollution; some $80-90 \%$ of all wastewater in developing countries is discharged directly into surface water bodies, creating severe risks for human health (Corcoran et al., 2010).

Applying NbS by harnessing the water-related services of 'natural infrastructure', such as forests, wetlands and floodplains, will help combat the risk of water crisis, particularly in the face of future climate stresses (Ozment et al., 2015). For example, in the case of flood risk management, whereas flood-control infrastructures such as levees and dams often degrade aquatic habitat by altering the natural river flow regime and cut off floodplains from rivers, preserving floodplains and/ or reconnecting them to rivers can instead provide flood management benefits while also conserving ecosystem values and functions (Ozment et al., 2015; Opperman et al., 2009).
As nature is both the source of our water and a water user itself, solutions to water security must consider 'water for nature and nature for water' (Smith, 2013).

However, nature alone cannot guarantee water security for people in every situation. Both built and natural infrastructure are needed for efficient and effective management of water resources (Smith, 2013). The value of waterrelated ecosystem services - to people's wellbeing, to food and energy security, to industry, the economy and to the engines of economic growth in cities - make nature a fundamental building block of water security. If we account for nature's services and invest wisely, nature is a source of solutions for water security.

Nature-based Solutions for water security are addressed in SDG 6 on ensuring sustainable water management, including through integrated water resource management approaches.

\subsection{Nature-based Solutions for food security}

\section{G Walters}

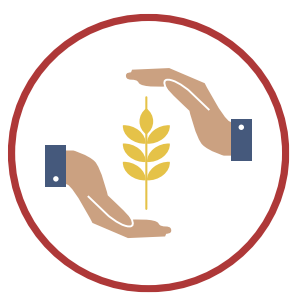

Food security - the availability of food that is accessible to all, safe and locally appropriate, and reliable through time and across space - is one of the major issues facing the world today (IUCN, 2013a). More than 795 million people are estimated to be undernourished, the vast majority of whom live in developing countries (FAO et al., 2015). 
In the past, food security has been considered an issue of agricultural production. However, recent thinking suggests that 'technical fixes' to food production will be insufficient on their own to improve food security. Solutions will need to be multi-faceted, including for example adapting food systems to environmental change, understanding the wider issues underpinning food security, and mainstreaming climate change perspectives in development initiatives (Ericksen et al., 2009). When food security is conceptualised with an ecosystem-aware approach, it moves beyond considerations of productivity, trade and macro-economic issues - to take on a holistic view of sustainable food systems (MohamedKaterere, \& Smith, 2013; see also Case Studies 4 and 6).

There are therefore many entry points for Nature-based Solutions to address food security issues. These include, for example, protecting wild genetic resources (animal and plant), managing wild species (especially fish), and providing irrigation water. Focusing on the restoration, conservation and management of ecosystems to deliver services can help stabilise food availability, access and use during periods of natural disaster, climate change, or political instability (IUCN, 2013b). Specific examples include protecting plant resources from pest and disease outbreaks (Macleod et al., 2016), addressing water and food security together (Hanjra \& Qureshi, 2010), using forest landscape restoration approaches (Kumar et al.,2015), and addressing land tenure issues.

Food security is addressed by the Sustainable Development Goal (SDG) 2 on zero hunger and under which there is provision, along with other solutions, to maintain ecosystems and develop sustainable food production systems; however, food can also be interconnected to all SDGs (Rockström \& Sukhdev 2016).

\subsection{Nature-based Solutions for human health}

\section{Van Ham}

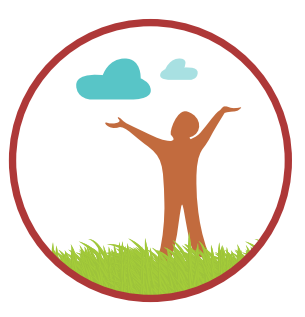

The natural environment, and more specifically ecosystems, the climate and biodiversity, are increasingly recognised as being influential determinants of human health, well-being and social cohesion (Naeem et al., 2015; Barton \& Grant, 2006). There is an established and diverse body of evidence detailing these complex linkages and their underlying mechanisms (Hartig et al., 2014; Keniger et al., 2013; Bowler et al., 2010).

Several studies have focused on how the benefits of green space encounters (whether active or passive) can influence health and well-being. These include improvements in environmental quality, such as heat regulation and noise abatement (Hartig et al., 2014), the promotion of physical activity and associated Body Mass Index improvements (Thompson Coon et al., 2011), enhanced social interaction, social inclusion and cohesion and perceived safety (Maas et al., 2009; De Vries et al., 2003), and opportunities for spiritual wellbeing experiences, typically in more remote 'wilderness' green spaces (Warber et al., 2013). Ecosystems such as forests and coral reefs have also been found to play a vital role in providing a source of medicines and pharmaceutical products (Stolton \& Dudley, 2009; Colfer et al., 2006), which greatly contribute to human health and well-being.

In order to capture the multiple benefits of nature for health and well-being, broader stakeholder collaboration is needed, as is the integration of nature across policy domains at all levels. 
$\mathrm{NbS}$ to human well-being are addressed by SDG 3, SDG 11 and SDG 13, which focus on human health and well-being.

\subsection{Nature-based Solutions for disaster risk reduction}

\section{R Murti}

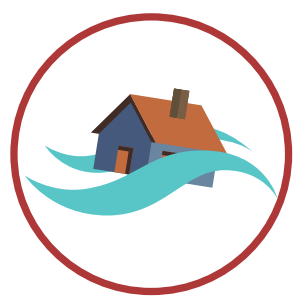

Major disasters in the past decade have clearly demonstrated the role nature plays in reducing risks to natural hazards.

Following Hurricane Katrina, the US Congress approved US\$ 500 million for the restoration of its coastal national parks and salt marshes, following evidence that the parks and marshes had helped reduce the damage. Similarly, the Government of Japan declared the expansion of its coastal forests, in the form of the Sanriku Fukko Reconstruction Park, as these forests had helped reduce the impacts of the tsunami caused by the Great East Japan Earthquake in 2011 (Renaud \& Murti, 2013).

These experiences demonstrate that the regulatory role of ecosystem services can be cost-effective in reducing risks posed to society by disasters. A study conducted by Swiss Reinsurance demonstrates that every dollar invested in protection of the Folkestone Marine National Park in Barbados can avoid US\$20 million-worth of annual damages from hurricanes (Mueller \& Bresch, 2014). Ecosystems such as wetlands, forests and coastal systems can reduce physical exposure to natural hazards by serving as protective barriers or buffers. Furthermore, such NbS can protect development infrastructure and property as well as support quicker recovery of livelihood sources. A study from Bhitarkanika Conservation Area in India, for example, shows that rice crops can take three times longer to recover from salt intrusion following coastal storms, without the presence of mangrove forests along the coastline (Duncan et al. 2014) . Such learning from past events has led to the development of the ecosystem-based disaster risk reduction (Eco-DRR) approach.

It is important to recognise that a natural hazard event has the potential to turn into a disaster if the community or society is not able to cope with the impacts, using its own resources (UNISDR 2007). Disaster risk reduction efforts can significantly reduce the likelihood of a natural hazard event turning into a disaster "through systematic efforts to analyse and manage the causal factors of disasters, including through reduced exposure to hazards, lessened vulnerability of people and property, wise management of land and the environment, and improved preparedness for adverse events"(Renaud et al. 2013). NbS such as the Eco-DRR approach can strongly support a community's risk reduction efforts. In the past two years there has been increasing recognition of this approach within global policy frameworks, namely the Convention on Biological Diversity (2014), The Sendai Framework for Disaster Risk Reduction (2015) and the Ramsar Convention on Wetlands (2015). ${ }^{4}$

While the lessons learnt from past devastations have led to greater recognition of nature as a critical solution for disaster risk management, scaling up these $\mathrm{NbS}$ requires active facilitation of dialogues and capacity development amongst scientists, policy makers and practitioners of conservation and disaster management.

$\mathrm{NbS}$ to disaster is addressed in part by SDGs 11 and 13 which focus respectively on making cities and human settlements safe and resilient

4 Years refer to the last conferences, where the Eco-DRR concept was adopted by those global policy frameworks. 
and on mitigating and adapting to climate change. Through its implementation it also contributes to various SDGs such as SDG 1 (no poverty), 2 (no hunger), 3 (good health and wellbeing), 6 (clean water and sanitation) and 15 (life on land).

\subsection{Nature-based Solutions for climate change}

\section{S Sengupta}

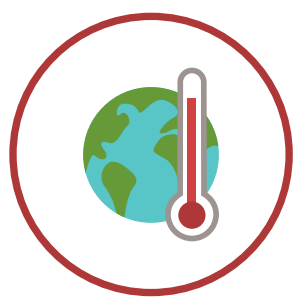

Climate change is one of the most pressing challenges confronting humanity today. Depending on how the world's ecosystems are managed, they can either contribute to the problem or provide effective Nature-based Solutions for climate change mitigation and adaptation.

First, $\mathrm{NbS}$ in the form of ecosystem-based mitigation (EbM) can make a powerful contribution in the fight against climate change by preventing the degradation and loss of natural ecosystems. Deforestation and forest degradation, for example, release an estimated 4.4 Gt of $\mathrm{CO} 2$ per year into the atmosphere (Matthews \& van Noordwijk, 2014), or around $12 \%$ of anthropogenic CO2 emissions (IPCC, 2014). When the land sector as a whole, including agriculture, forestry and other land uses (AFOLU), is considered, the contribution is about $24 \%$ of annual global anthropogenic emissions (ibid). Avoidance of these emissions, through better conservation and land management actions, is a powerful intervention that can make a significant contribution towards global mitigation efforts.

Second, natural and modified ecosystems can also make highly effective contributions in combating climate change through their function as a 'natural carbon sink' by absorbing and sequestering $\mathrm{CO} 2$ emissions. Approximately $60 \%$ of cumulative anthropogenic GHG emissions since the pre-industrial era have been stored either on land (in plants and soils) or in the ocean (IPCC, 2014). Conservation, restoration and sustainable management of forests, wetlands and oceans thus plays a critical role in the healthy functioning of the carbon cycle and the balanced regulation of the planet's climate. It has been estimated, for example, that restoring 350 million hectares of degraded or deforested landscapes by 2030 can sequester 1-3 billion tonnes of $\mathrm{CO} 2 \mathrm{e}$ per year while also generating about US\$170 billion per year in benefits from other ecosystem services, thereby making it a cost-effective $\mathrm{NbS}$ to climate change (New Climate Economy, 2014).

Finally, in addition to providing these direct mitigation benefits, ecosystems can also help vulnerable communities, especially those who depend on natural resources, to better adapt and become more resilient to the adverse effects of climate change, including extreme weather events and climate-related disasters, through ecosystem-based adaptation (EbA) and ecosystem-based disaster risk reduction (EcoDRR). Such ecosystem-based interventions, or natural infrastructure, can complement and enhance the effectiveness of physical infrastructure such as sea walls and dykes in a blended, cost-effective manner.

It must be noted that for global efforts on climate change to be successful in keeping the temperature rise to well below 2 degrees $\mathrm{C}$, action from all sectors, across all levels and involving all actors, is required. But $\mathrm{NbS}$ are a fundamentally important part of this mix, and no long-term solution to climate change can be successful without fully drawing on them.

$\mathrm{NbS}$ to climate change is also addressed in part by SDG 13 which focuses on climate change. 


\subsection{How natural capital approaches relate to $\mathrm{NbS}$}

\section{N. Olsen}

Natural capital is the finite stock of environmental assets, such as water, land, air, species and minerals that produces a flow of ecosystem goods and services which are important for human well-being and for the economy. Natural Capital Approaches (NCAP) aim to make the value of nature more visible in decision making and ultimately to drive better outcomes for biodiversity and ecosystems, particularly by governments, businesses and financial institutions. A key feature of NCAP is the focus on maintaining and restoring natural capital stocks in order to ensure that the flows from these stocks in the form of services is maintained or enhanced.

Natural capital is complementary to and provides the foundation for other types of capital, including manufactured, financial, human and social capital. This is particularly relevant to $\mathrm{NbS}$ and the typology based on the relationship between the level of ecosystem service delivery on the one hand and the level of ecosystem engineering on the other as depicted in Figure 5. From a natural capital perspective, the entire spectrum could be said to represent natural capital. The area of contention, however, is the degree to which natural capital is able to be substituted by other forms of capital, particularly manufactured capital. The world view implicit in the current economic model is that substitution between natural and manufactured capital and the benefits of technological progress are sufficient to overcome emerging resource scarcities and environmental problems. However, faced with the effects of degraded poorly functioning ecosystems which undermine human welfare, the term critical natural capital is increasingly used to emphasise that some natural capital is essential to human welfare and has no substitutes (Ekins, 2003). The same idea is echoed in planetary boundaries framework (Rockström et al., 2009), according to which the transgression of established biophysical thresholds will have a significant negative impact on human well-being. It can be argued that natural capital is a complement to manufactured capital, i.e. both manufactured and natural capital are needed for effective water resources management. In some cases, natural capital can substitute for manufactured capital, e.g. mangroves rather than seawalls for coastal defence. 


\section{Ecosystem-related approaches within the NbS 'family'}

\author{
E Cohen-Shacham, G Walters, P Lamarque \\ (authorship unless otherwise stated)
}

This section describes some of the ecosystemrelated approaches that make up the current scope of $\mathrm{NbS}$. These approaches, introduced in Section 1.3.3, are briefly outlined here in terms of their origins and their applications. The accepted definitions of these approaches, as well as other terms used to describe them, are presented in Annex 1. It is important to point out that this section does not provide an exhaustive list of all approaches that would qualify as NbS. It does not include, for example, the landscape approach (Fisher et al., 2008) or community-based adaptation (Girot et al., 2011).

The nine approaches described here fall within the first four categories of ecosystemrelated approaches shown in Table 4.

Approaches belonging to the fifth category, i.e. ecosystem protection approaches (area-based conservation approaches including protected area management), are not included here, as these approaches are much more commonly seen and better known. Case Studies 3 and 8 provide good examples of these $\mathrm{NbS}$ approaches.

\subsection{Ecosystem restoration approaches}

\subsubsection{Ecological restoration}

\section{ER} Ecological restoration emerged first as a practice, and only much later as a research discipline (Stanturf et al., 2014). Ecosystem restoration and ecological restoration tend to be similarly defined or used synonymously (Suding, 2011; Baird, 2005; Covington et al., 1998), although in many cases ecological restoration may only focus on environmental objectives.

The first evidence of ecological restoration dates back at least to the 6th century where Greek farmers were encouraged to plant olive trees to counteract deforestation (Davies, 1996). Many attribute the first thinking on ecosystem restoration to Aldo Leopold in the 1930s (Higgs, 1997); he was strongly influenced by his land management experiences (Covington et al., 1998; Leopold, 2013). The establishment of the Society for Ecological Restoration in 1987, and its scientific journal Restoration Ecology in 1993, consolidated the movement and its practices (Hobbs et al., 2011). The Society is also responsible for the well-accepted definition of ecological restoration as: "The process of assisting the recovery of an ecosystem that has been degraded, damaged, or destroyed." (Society for Ecological Restoration, 2004).

Implementing ecological restoration typically refers to the technical process of restoring ecosystems and conserving biodiversity, informed by an ecological study of habitats and species (Hobbs et al., 2011). Ecological restoration can be applied at a wide variety of scales (Palmer et al., 2014). A few examples of its application include: (i) the restoration of a polluted river basin; and (ii) the restoration of a forest area degraded by gold mining. Recent work by the CBD supports further implementation of ecological restoration using the Ecosystem Approach (CBD, 2016).

\subsubsection{Ecological engineering}

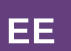
The ecological engineering concept has its roots in ecological science (Palmer et al., 2014) and it can be 
considered a branch of both ecology and engineering (Schulze, 1996). It is closely linked to ecological restoration and they are often described as sister fields (Mitsch, 2012). Odum is considered to be the father of ecological engineering; he began studying the subject in the 1960s (Gosselin, 2008; Mitsch, 2012). A decade or so later in China, Ma developed a concept referred to as ecological engineering, which mainly addressed environmental issues such as wastewater treatment, recycling and pollution problems (Mitsch \& Jørgensen, 2004; Barot et al., 2012). This approach was later adopted country-wide (Schulze, 1996).

The ecological engineering concept is applied both in practical and scientific research contexts. It can be implemented at all scales, from species (or smaller) to planetary level (Gosselin, 2008). Some examples include the self-design of tidal creeks, the introduction of particular plant species for salt marsh restoration (Teal \& Weinstein, 2002), and the use of species that trap sediment for coastal protection of a sandy shore (Borsje et al., 2011).

\subsubsection{Forest landscape restoration}

\section{FLR}

Forest landscape restoration (FLR) is a process of restoration that, despite its name, extends beyond forested ecosystems. The conceptualisation of restoration at the landscape level began in the early 1990s (Hobbs \& Norton, 1996; Harker et al., 1993), with some interventions dating back to the 1980s (Barrow, 2014). The FLR approach was first described by WWF and IUCN in 2000, with a focus on restoring ecological integrity and human well-being. Its importance was underscored by numerous countries' commitments to the 2011 Bonn Challenge (Laestadius et al., 2015) and the restoration components of several international conventions (such as CBD, UNCCD, UNFCCC). Forest landscape restoration can involve both the spheres of policy and practice. The initial description of the approach as a "planned process that aims to regain ecological integrity and enhance human well-being in deforested or degraded landscapes" (Mansourian et al., 2005) was further developed to underline its focus on restoring the functionality of ecosystems. This refined definition shifts the focus from the species composition of native ecosystems and their processes, to regulating service provision and multiple benefits (Maginnis et al., 2014). The approach does not focus on restoring a landscape back to a preexisting state. There can be various reasons for using the FLR approach; objectives may include, for example, enhancing connectivity between protected areas, protecting water and soil resources, and reinforcing cultural values (Mansourian \& Vallauri, 2014).

Two examples of FLR applications include the restoration of the forests of Shinyanga, Tanzania (Barrow, 2014) and the Loess Plateau, China (Lü et al., 2012). Implementation can involve different degrees of human intervention, ranging from planting trees to allowing natural processes of forest succession to occur.

\subsection{Issue-specific ecosystem- related approaches}

\subsubsection{Ecosystem-based adaptation}

EbA Following clear evidence of climate demonstrated in 2003 by two large-scale studies (Parmesan \& Yohe, 2003; Root et al., 2003), an understanding emerged that ecosystems need to be managed for adaptation to climate change (Hansen et al., 2003). Ecosystem-based adaptation (EbA) was developed as a framework for addressing the role of ecosystem services in moderating climate impacts on people (Staudinger et al., 2012; Locatelli et al., 2011).

The term EbA was first coined in 2008, and in the same year was introduced to the UNFCCC COP 14 , by IUCN in a position paper. In 2009, the CBD officially defined EbA as an operational tool for climate change adaptation (Rizvi et al., 2014). The CBD later refined its 
definition of ecosystem-based adaptation as the "sustainable management, conservation and restoration of ecosystems, as part of an overall adaptation strategy that takes into account the multiple social, economic and cultural co-benefits for local communities" (CBD, 2010).

While EbA can be applied at a variety of levels, it generally provides benefits on a local scale (Locatelli et al., 2011; Rizvi, 2014).

Examples of EbA applications include the renaturation of rivers or canals to attenuate flooding, or the replanting of forests with more future climate-tolerant species to adapt to climate change (Doswald \& Osti, 2011). EbA projects usually include a strong element of community engagement of the community to raise awareness about natural resource management and seek local support for the restoration and sustainable management activities.

\subsubsection{Ecosystem-based mitigation}

\section{EbM} Ecosystem-based mitigation (EbM), like EbA, contributes to the objectives of UNFCCC and for this reason is often treated together with $\mathrm{EbA}$ as approaches to ensure continued ecosystem functionality, human health and socio-economic security, through storage of carbon. In 2007, the UNFCCC adopted a comprehensive process in which adaptation was linked to mitigation through the programme now called Reducing Emissions from Deforestation and forest Degradation+ (UNFCCC, 2008).

EbM emerged from these processes as a framework to address the causes of climate change by reducing the sources or enhancing the sinks of greenhouse gases (Staudinger et al, 2012; Locatelli et al., 2011). EbM activities specifically underscore the importance of forest ecosystems (in terms of afforestation, reforestation and avoided deforestation and marine and coastal ecosystems (e.g. mangroves, peatlands, tidal salt marshes, kelp forests and seagrass beds) to contribute to climate change mitigation (CBD, 2010). EbM aims to provide global benefits and long-term effects on climate change (Locatelli et al., 2011).

Although the primary example of EbM is the use of forest, another example would be the restoration and sustainable use of coastal and marine ecosystems in order to allow blue carbon to be stocked and not released to the atmosphere (Pendleton et al., 2012; Ammar et al., 2014).

\subsubsection{Climate adaptation services \\ CAS The Climate Adaptation Services (CAS) approach emerged in the} scientific literature in 2012 (Jones et al. 2012). This concept aims to complement the ecosystem services concept and contribute to the development of options for adaptation to climate change (Lavorel et al., 2015). CAS focuses on understanding the key ecological mechanisms and characteristics that support the capacity of ecosystems to adapt to changes (Lavorel et al., 2015). Although CAS and $\mathrm{EbA}$ are sometimes used as synonyms, the CAS approach is considered to be broader than $\mathrm{EbA}$, as it focuses on ecological mechanisms and characteristics that support adaptation of ecosystems to change (Lavorel et al., 2015). While EbA highlights how ecosystems support new valuable services under climate change, the CAS approach supports the additional value of healthy ecosystems in enabling these ecosystems "to resist or cope with climate change (direct and indirect) impacts, or to transform autonomously to a state that supports social adaptation" (Lavorel et al., 2015). This approach highlights the prospect of substantial ecosystem change and stresses the importance of options and insurance values of services not currently considered important for human well-being, but which may prove critical in the future (Colloff et al., 2016). 


\subsubsection{Ecosystem-based disaster risk reduction}

ECO-DRR

In the early 2000s, terms such as

hazard mitigation and damage

reduction were used to emphasise the importance of ecosystems and their services in disaster risk reduction (Hook, 2000; Kreimer \& Arnold, 2000; Bronstert, 2003). The Millennium Ecosystem Assessment stated that "while well-managed ecosystems reduce risks and vulnerability, poorly managed systems can exacerbate them by increasing risks of flood, drought, crop failure, or disease" (Millennium Ecosystem Assessment, 2005).

The term 'ecosystem-based disaster risk reduction' (Eco-DRR) was first mentioned in a 2009 IUCN publication (Sudmeier-Rieux et al., 2011) and later defined by the Partnership for Environment and Disaster Risk Reduction (see definition in Annex 1). The Eco-DRR approach focuses mainly on minimising the impacts of hazard events by enhancing people's capacities to better manage and recover from the effects of hazards (Renaud et al., 2013). This emerging approach, applied in policy as well as practice, is closely linked to the ecosystem-based approaches to adaptation and mitigation, but is more specific, focusing on particular hazard events (e.g. tsunamis, earthquakes, flooding, cyclones), often within specified time periods and locations. Unlike EbA and EbM, the Eco-DRR approach also addresses hazard events that are not necessarily linked to climate change or climate variability (Renaud et al., 2013).

The Eco-DRR approach can be implemented at all scales. Examples include the restoration of large marshlands to protect from hurricane flooding (Temmerman et al., 2013), and the use of protected areas to reduce disaster risk in coastal areas (Murti \& Buyck, 2014).

\subsection{Green infrastructure and natural infrastructure approaches}

\author{
M Smith, $R$ Welling, C Van Ham
}

GI

NI

Ecosystems perform a number of the same

functions as conventional 'grey' infrastructure, such as water collection, purification, storage, and conveyance (Dalton \& Murti, 2013).

Water-related ecosystem services perform an 'infrastructure-like' function (Ozment et al. 2015; Smith 2013). For example, upland forests, aquifers, lakes and wetlands provide water storage, wetlands filter water, rivers provide conveyance and transportation, floodplains and wetlands lower flood peaks in downstream cities, while mangroves, coral reefs and barrier islands protect coasts against storms and inundation (Krchnak et al., 2011). Natural infrastructure underpins the way we manage our river basins and therefore the way we grow food, generate electricity, and supply water to cities (Coates \& Smith 2012). These types of functions are shown in Figure 7.

The term infrastructure is defined as the stock of facilities, services and installations needed for the functioning of a society. Therefore, built infrastructure has natural counterparts in watersheds which complement, augment or replace conventional built infrastructure such as reservoirs, dams, levees and canals (Krchnak et al., 2011). For example, although representing less than one percent of the earth's land surface, river floodplains are estimated to provide nearly $25 \%$ of the terrestrial (i.e. non-marine) ecosystem services, with primary benefits including attenuation of flood flows, fisheries productivity, groundwater recharge, and water filtration (Costanza et al., 2014). 


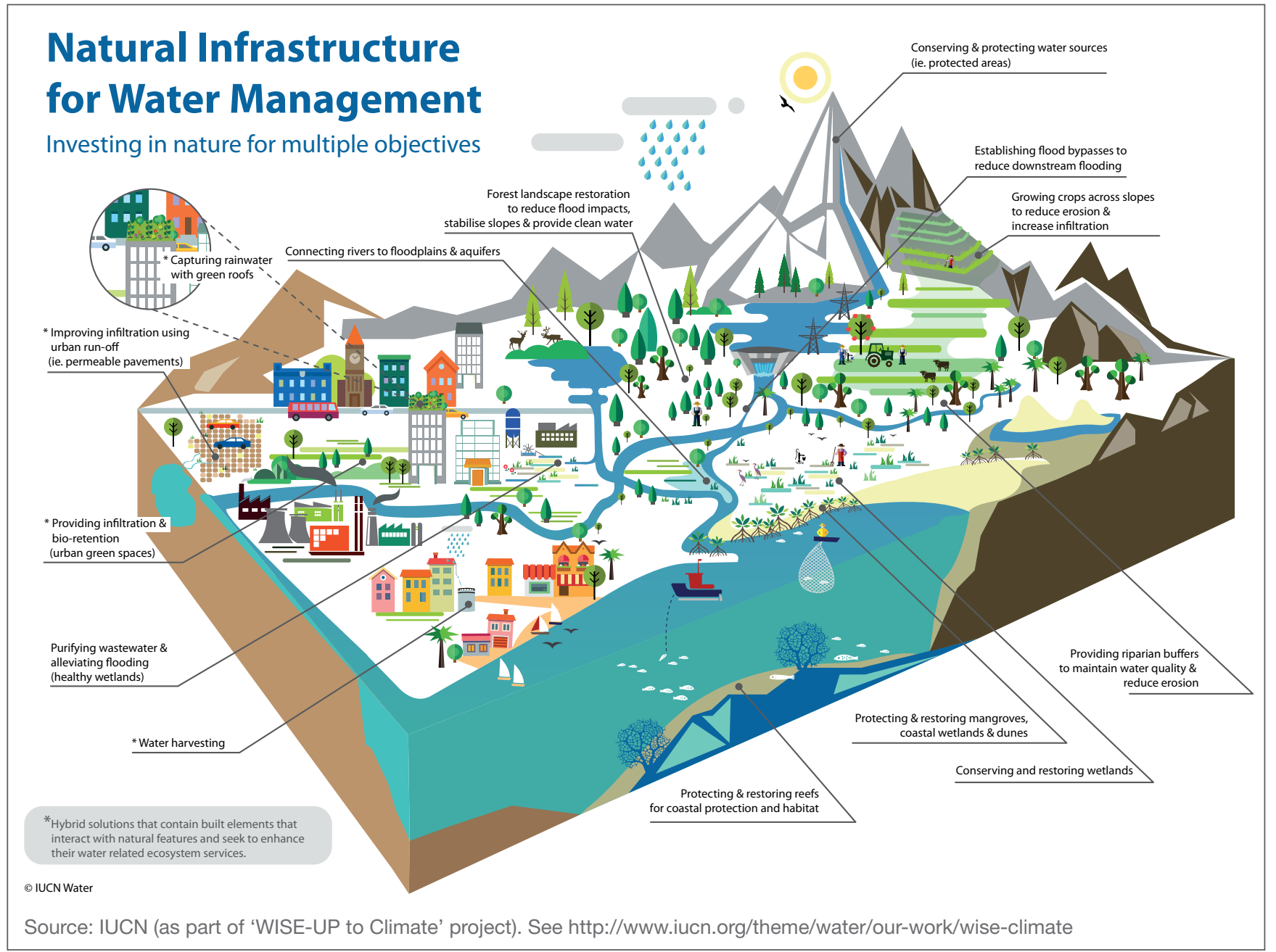

Figure 7. Natural infrastructure for water management

The Green Infrastructure approach emerged in the USA in the mid-1990s, but has its origins in the 1850s, with the first references to greenbelts in the UK and urban open-space networks in the USA.

The European Commission in the context of the EU Green Infrastructure Strategy defines GI as: "a strategically planned network of natural and semi-natural areas with other environmental features designed and managed to deliver a wide range of ecosystem services" (European Commission, 2013). Green infrastructure incorporates green spaces (or blue if aquatic ecosystems are concerned) and other physical features in terrestrial (including coastal) and marine areas. A green infrastructure approach considers conservation values and actions related to land development, growth management and built infrastructure planning, thus differing from conventional approaches to open space planning (Benedict \& McMahon, 2002). Due to its broad definition, the term green infrastructure is used both as a theoretical concept and as a practical tool.

The terms green infrastructure (Gl) and natural infrastructure (NI) are often used interchangeably (UNEP, 2014), though they tend to be used to refer to planning and conservation work in different contexts and at different scales. A natural infrastructure approach could be seen to be restoring structure, function and composition of ecosystems to deliver ecosystem services, whereas a green infrastructure approach would enhance these aspects of ecosystems, 
to deliver these services. Furthermore, while a green infrastructure approach is used at both an urban and a landscape scale, a natural infrastructure approach is used only at only a landscape scale. However, the two approaches share many of the same principles and objectives, including connectivity, multifunctionality and smart conservation (European Environment Agency, 2011). In both GI and NI approaches, hybrid solutions are commonly used, mixing hard infrastructure with ecosystem-based infrastructure.

Green infrastructure is used in the spheres of policy, practice and scientific research; its research applications tend to relate to urban settings (Tzoulas et al., 2007).

\subsection{Ecosystem-based management approaches}

\section{EbMgt}

Ecosystem-based management derives conceptually and practically from the Ecosystem Approach (Gregory et al., 2013; Slocombe, 1998), as a response to challenges and initiatives in protected areas as well as in regional and environmental planning (Slocombe, 1998; Uy \& Shaw, 2012). An ecosystem-based approach has an integrative, transdisciplinary focus that considers the entire ecosystem, including humans (Leslie \& McLeod, 2007), thus differing from traditional regional planning and ecosystem management, which are conducted at smaller spatial scales and focus on the domain of ecological science (Samson \& Knopf, 1996).

Ecosystem-based management is used in scientific research as well as in policy and practice, although scientists, practitioners and policy makers tend to view it in different ways. Ecosystem-based management is often used in ecological and environmental management contexts and a number of similar approaches, such as ecosystem-based fisheries management (Arkema et al., 2006), ecosystembased approach to marine and coastal management (Leslie \& McLeod, 2007) and integrated water resource management (Roy et al., 2011) have been specifically developed to focus on marine- and water-related issues.

A number of instruments support the implementation of an ecosystem-based management approach, such as management plans or specific legal instruments for multipleuse coastal marine protected areas (Cárcamo et al., 2013).

\subsection{A brief comparison of these $\mathrm{NbS}$ approaches}

This section provides a brief review of the different ecosystem-based approaches that can be considered part of the NbS 'family', highlighting some of the similarities and differences among them.

First it can be noted that, while these NbS approaches have developed over different periods of time, there has been a recent marked increase in their inclusion in the scientific literature, as shown in Figure $8 .{ }^{5}$ As would be expected, those approaches that have emerged from practice rather than from scientific research have had fewer citations in the literature, as have the most recently developed approaches (ecosystem-based mitigation, for example, does not appear in Figure 8 , due to its low number of citations).

A search for co-occurrences of these terms in the peer-reviewed scientific papers reveals that such co-occurrence happens quite frequently. A discussion of one $\mathrm{NbS}$ approach often refers to another $\mathrm{NbS}$ approach. Again, this is to be expected, given the interlinkages between these different approaches. At a definitional

5 The Web of Science, the source of data for Figure 8, is an online scientific citation indexing platform, covering peerreviewed literature. The platform is maintained by Thompson Reuters. 


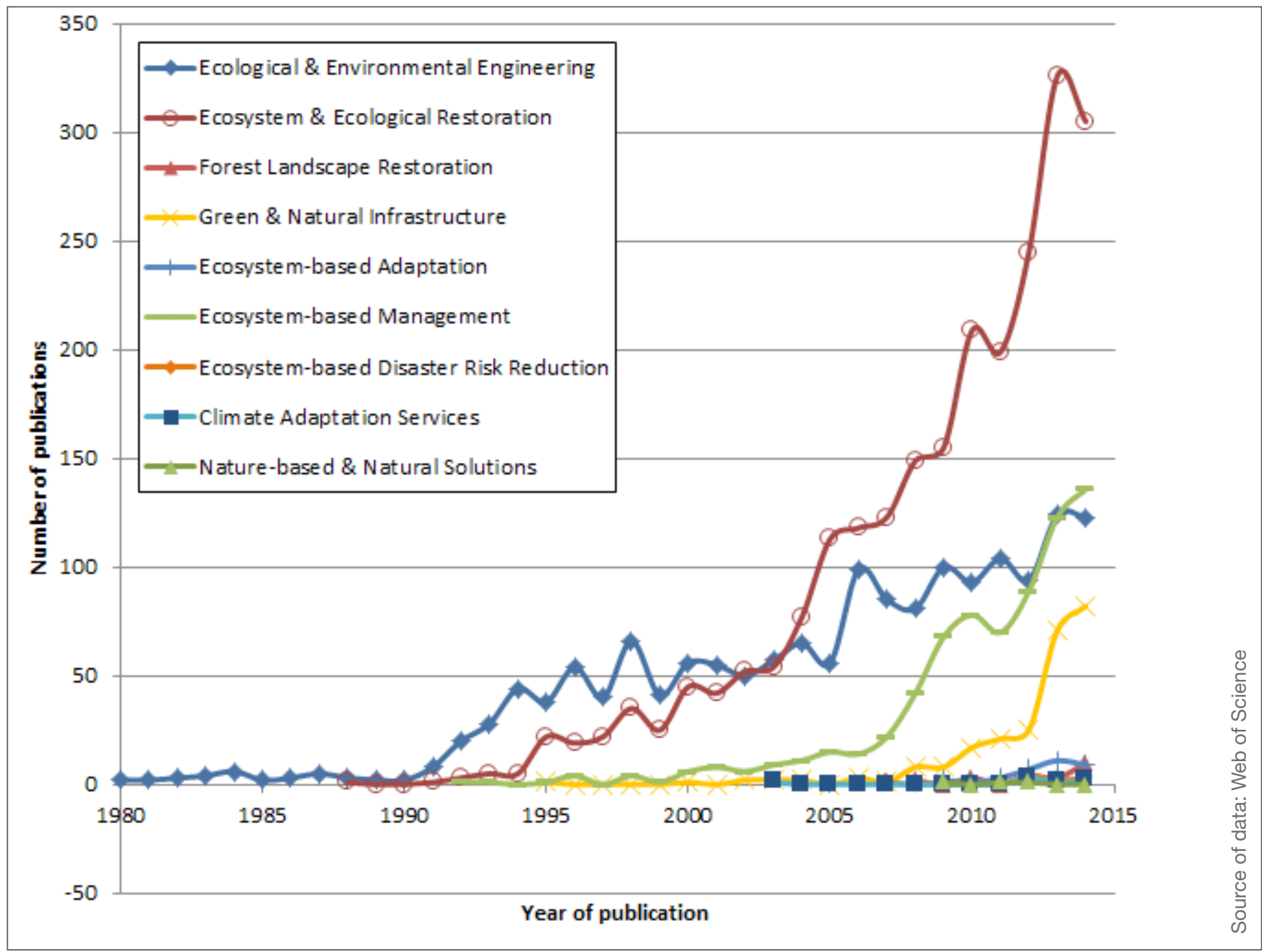

Figure 8. Trends in number of research papers mentioning NbS approaches (1980-2014)

level for example, one approach or concept may be described with reference to a different approach (see, for example, the definition of Eco-DRR in Annex 1). And the definitions of several different approaches may share similar terms (e.g. restoration, conservation, management). The term 'ecosystem services' also appears in many of the descriptions and discussions of the various approaches, reflecting its central place within these $\mathrm{NbS}$ approaches. Specifically, the terms restoration, conservation and management are variously present in the definitions of EbA, EbM, EcoDRR and ecological engineering. When compared, some $\mathrm{NbS}$ interventions have applications to specific societal needs (e.g. climate change in the case of EbA, EbM, CAS and sometimes Eco-DRR), or are applicable to a specific context (e.g. watersheds for natural infrastructure, for green infrastructure in urban areas, coastal and marine ecosystems for blue solutions) (see Annex 2). In addition to some $\mathrm{NbS}$ using other $\mathrm{NbS}$, some of the concepts attempt to address multiple societal issues together. For example, natural infrastructure can address water security, disaster-risk reduction amongst others (see Figure 7). This may be in response to increased recognition of complex global systems (Liu et al. 2015), or recognition of the role that nature can play in mitigating climate change or other societal challenges (Jones et al. 2012), but may also emerge from sustainability science and the Millennium Ecosystem Assessment (Wu 2013).

Alongside the common aspects seen in the definitions and descriptions of these approaches, there are a number of 
distinguishing factors that separate the approaches from each other. One such factor is their origin; approaches tend to emerge from one of three domains: practice, policy or research. For example, some of the approaches tend to originate in the policy sphere; these include EbA, EbM and EcoDRR, all of which have most of their earliest mentions in policy documents relating to UN conventions, such as the CBD and the UNFCCC. These concepts then moved from the policy sphere into practice, often without going through a scientific conceptualisation process or without any practical guidance being provided on how to implement them. By contrast, other concepts, notably ecological restoration, emerged out of practice, with a research component being developed later and making the practice much stronger. Finally, others, such as ecological engineering and CAS, have scientific foundations. For its part, ecological engineering, which emerged out of decades of research, now has a strong practical element.
In some cases, an approach has been developed by combining a number of preexisting approaches (e.g. Cornwall \& Brock, 2005). This process may result in the creation of new means to deal with societal issues and can facilitate the emergence of new concepts, much like what happens during scientific innovation (Uzzi et al., 2013). The new 'combination approach' may integrate a diverse set of complementary ideas and strategies and may therefore may be more likely to succeed, compared to its component approaches. A good example of this process is the combination of a number of approaches and tools in the development of Eco-DRR, which combines conservation, management and restoration of ecosystems to reduce the risk of disaster (Renaud \& Murti, 2013). However, for these combination approaches to be effective in practice, they require clear definitions, parameters and methodologies to guide their application (Brandt et al., 2013). 


\section{Lessons learned from the case studies}

\section{Janzen, M Fischborn}

Part B of this report presents 10 case studies from around the world that illustrate how NbS can be applied in different contexts, to address different issues. It is hoped that case studies such as these will allow for evidence-based learning to support widespread adoption of successful NbS approaches. The case studies also offer insights into the kinds of challenges encountered in implementing these approaches.

This section looks at some of the common lessons learned from these ten case studies, focusing particularly on what emerged as key elements that contributed to the success of these applications. Further details on lessons learned are found in the individual case study write-ups in Part B.

Inclusive, integrated approaches. Fostering integrated, cross-sectoral approaches is required for many $\mathrm{NbS}$ to be successful (Klimmek and van Ham, in press). This may involve a variety of training, capacity building and communication efforts. New and innovative partnerships and governance structures may also be required. In Jordan, for example (see Case Study 6), by bringing together three levels of governance (national and regional government, and local communities), effective strategies to combat desertification through land management were implemented. Multi-scale co-management designs are particularly valuable when managing resources across boundaries (such as the transboundary water issues addressed in Case Study 10).

\begin{abstract}
Stakeholder participation. Participatory
processes that support stakeholder empowerment facilitate the sustained success of projects. Community organisation is a longterm process that requires the ability to deal with any conflicts, issues, and constraints that may arise. Clarifying and addressing stakeholders' different values, interests, and knowledge levels will be key in building a strong foundation for strengthening natural resource governance. Community members require a clear understanding of the project, the implementation process, their rights and role in the project, and the benefits they may derive from participation in the project. Examples of cases which illustrate this point well include Case Studies 3 and 6.
\end{abstract}

Champions and leaders. Convincing decisionmakers of the value of investing in $\mathrm{NbS}$ is beneficial in the long term. To achieve this, it is important to identify and work with champions or leaders who can motivate, mobilise and guide their peers. Champions may originate in government, providing direction, technical expertise and institutional linkages, as was the case in Rwanda (see Case Study 4). In other cases, leaders may arise in a local community (e.g. an individual in Ecuador or a group of women in Costa Rica or local residents in the United Kingdom- see Case Studies 5, 7, and 3 respectively); these local leaders play a very important role in demonstrating commitment to, and success of, NbS to local decisionmakers.

Public and private sector roles. Fostering public-private partnerships may be needed in order to finance $\mathrm{NbS}$ at larger scales. Evidence 
is emerging of how facilitate such partnerships as a means of financing restoration (e.g. in Rwanda, see Case Study 4) and much can be learned from this approach for other types of $\mathrm{NbS}$ approaches. In other cases, private enterprises can work in parallel with government initiatives, in order to increase the scale of application of an $\mathrm{NbS}$, as was the case in Medmerry in the UK (see Case Study 3).

'Locally-grown' solutions. Using elements of traditional nature-based practices (such as customary resource management systems) may offer more appropriate and accepted solutions and be more successful than approaches that rely solely on bringing 'new' interventions in from outside. In Jordan (see Case Study 6), some elements of traditional practices relating to food security are being supported by the government, with a view to increase their usage outside of the area where the $\mathrm{NbS}$ originated. Furthermore, NbS can be initiated by individuals with no external funding or support, as was the case in Ecuador (see Case Study 5), offering a model for replication and scaling-up.

Addressing biodiversity and social benefits. Biodiversity and social impacts can be achieved together and increase the overall success of an NbS. A good example of this is found in the Medmerry case in the UK (see Case Study 3), where wetland restoration to address coastal flooding also resulted in the creation of a bird sanctuary. Barcelona's green infrastructure plan (see Case Study 9) aims to not only improve the quality of life of the city's residents, but also to increase biodiversity in the city through creation of green spaces and increased ecological connectivity.

Valuation and funding. Valuing ecosystem services is important in making a business case for investment in ecosystems. In the case of natural infrastructure, economic planning for water resources development at basin or national scales needs to account for ecosystem services. With the costs and benefits of ecosystem services valued, a business case can be made for investing in ecosystems and watersheds as natural infrastructure, as part of sustainable financing for river basin management (IUCN, 2011; Russi et al., 2013; Emerton \& Bos, 2004). It is also critical to make financing available to local initiatives for watershed management through decentralised funds and credit schemes that integrate clean and adequate water for all, ecosystem services, livelihoods and economic development (IUCN, 2011). The Rwanda case (Case Study 4) involved economic valuation of forest restoration options (Verdone, 2015), which later informed the development of a financing programme for this $\mathrm{NbS}$. 


\section{Toward an operational framework for $\mathrm{NbS}$}

\section{S Maginnis}

\subsection{The need for an operational framework for $\mathrm{NbS}$}

This section highlights some of the reasons why the development of an operational framework for $\mathrm{NbS}$ is a critical element to ensuring effective upscaling of this concept in practice. ${ }^{6}$

For new concepts such as $\mathrm{NbS}$ to endure, there needs to be a clear and widely accepted understanding of the foundations on which they are established, including not only definitions and principles but also parameters and methodological frameworks to guide their application (Davis, 2008; Brandt et al., 2013). NbS still remains, for many, a general metaphor without sufficiently clear guidelines to enable effective operationalisation. There is currently no accepted basis on which a government agency, municipality or private company can systemically assess the efficiency, effectiveness and sustainability of a particular nature-based intervention. This means that while the NbS concept continues to hold out real promise, there is a risk that poorly defined or ill-considered interventions fail to deliver, undermine government and investor confidence and further expose the very communities they are designed to protect.

It has already been highlighted in this report that many of the concepts and approaches that have emerged to address the relationship between people's well-being and ecosystem goods and services began life as a paradigm or narrative (i.e. within the research sphere). In other words, as they emerge, the efforts first focus on building a case as to why or how such an approach should be taken to meet specific societal needs. Indeed, it is not uncommon for the further elaboration of such approaches to continue to remain in the theoretical domain - teasing out for example issues such as aspirational principles and safeguards - until a time comes when there is actually a real operational need for more specific guidance.

Lack of operational clarity presents a major obstacle to wide-scale uptake of concepts and approaches since their proponents have, in effect, transferred the responsibility of interpreting how to put the idea into practice (often in several different circumstances) to the policy maker or the manager. An example of this was the 'Landscape Approach' which gained popularity in the 1990s. This approach emerged as a response to the fact that many land-use operations had significant off-site impacts that were never properly accounted for. The Landscape Approach became short-hand for integrating land-use decision-making in such a way that negative externalities from individual sites were minimised and positive synergies optimised. It took several years before practical ways to operationalise landscape-level thinking actually emerged as bodies of practice. This time lag in turn can result in a 'chilling effect', which further impedes progress.

Another undesirable scenario that can occur is when different practitioners or policy makers (often with different agendas) independently develop different operational criteria and standards for the same concept and principles.

6 Upscaling refers here to moving from a project-level implementation to national or sub-national policy response. 
This can open the way for fractious, almost ideological, debates amongst otherwise likeminded champions. Yet again, those wishing to implement such concepts will be reluctant to get drawn into a debate, and once again the promise of upscaling a conceptually attractive idea risks being stalled at the outset.

Currently there are several parallel exercises occurring which focus on specific $\mathrm{NbS}$ approaches, each developing a set of criteria (e.g. EbA, REDD+). However, many of these criteria could be useful in assessing other interventions and there is likely an overarching set of principles to guide implementation of all of these approaches. The reason why IUCN is promoting a single operational framework for $\mathrm{NbS}$ is because we believe practitioners, who are not necessarily conservationists or natural resource managers by training, prefer to spend their time putting in place effective and efficient measures rather than reviewing and comparing different approaches and methodologies.

\subsection{Ecosystem Approach as the basis for an NbS operational framework}

This section considers how the Ecosystem Approach can offer a useful 'conceptual foundation' on which an operational framework for NbS can be built. This conceptualisation is essential for the future development of $\mathrm{NbS}$. Without sufficient conceptual framing, there is a risk that a concept such as NbS will remain vague and aspirational, never truly getting off the ground or, even worse, be co-opted to be used in potentially undesirable ways for which it was never intended (Loughlin, 2002; Cornwall \& Brock, 2005).

The Ecosystem Approach was adopted in 1995 by the Convention on Biological Diversity (CBD), and later refined and defined as a "strategy for the integrated management of land, water and living resources that promotes conservation and sustainable use in an equitable way"
(Smith \& Maltby, 2003). The CBD later issued further operational guidance (Shepherd 2004) as well as a comprehensive list of tools and approaches was developed, to help implement the Ecosystem Approach and address CBD's objectives (CBD 2004). The Ecosystem Approach does not substitute for more traditional conservation approaches, which focus on single or rare species or protected areas, but rather comes as a holistic process to address natural resources in an integrated way. As such, the Ecosystem Approach lays the foundational thinking for the pursuit of the CBD's three key objectives: conservation, sustainable use of biodiversity, and equitable sharing of the resulting benefits (Maltby, 2000).

More generally, the adoption of the Ecosystem Approach fundamentally shaped the modern conservation and natural resource management agenda, and the approach sits as a solid foundation on which different, sector- or situation-specific operational frameworks can be built.

An operational framework for $\mathrm{NbS}$ would therefore benefit greatly from being grounded in the Ecosystem Approach. It is important to note, in this respect, that Nature-based Solutions are framed to deal with specific applications of the Ecosystem Approach, when the management or restoration of ecosystem functions can play a key role in helping address a societal challenge. It is also important to understand that the scope of the Ecosystem Approach is significantly more comprehensive than any NbS approach. The Ecosystem Approach is capable of guiding efforts to address a whole raft of conservation issues that $\mathrm{NbS}$ will never address - such as species conservation strategies or sectoral management strategies. Indeed, if one looks at the 20 Aichi targets, the Ecosystem Approach is relevant to all of them, whereas $\mathrm{NbS}$ really only provides the means to implement a sub-set of these targets (with particular, but not exclusive, emphasis on Targets 1-3, 6, 8, and 13-15). 
A helpful way of thinking about the relationship between the Ecosystem Approach and Naturebased Solutions is to use the analogy of national law. In this respect the Ecosystem Approach is like the constitution - laying the broad foundation on which individual laws must rest, adhere to and align with. NbS, under this analogy, is then equivalent to a class of laws (such as tax law or family law) which enables a consistent operational approach to a particular issue. In the same way that individual tax laws should be collectively coherent and consistently interpreted and applied, so it is important that we can be sure that the different $\mathrm{NbS}$ approaches are operationalised in a similar manner. A coherent NbS operational framework offers practitioners and policy makers an efficient and common way to understand, measure and improve the efficiency of different types of interventions that ultimately have the same design objectives: to help nations and individuals address major societal challenges by effectively maintaining or enhancing key ecosystem services.

\subsection{What should a single operational framework deliver?}

At the outset, it is important to highlight that a single operational framework is not the same as a single methodology or blueprint. NbS approaches are context specific and, consistent with the Ecosystem Approach's principles, and their implementation is fundamentally a matter of societal choice. These NbS approaches must not just be efficient ways of managing ecosystems to address particular problems, but equally must be compatible with cultural and jurisdictional norms and practices - all of which means that $\mathrm{NbS}$ approaches will be delivered through a multitude of interventions, methods and practices. However, that does not mean that the standards whereby $\mathrm{NbS}$ approaches are designed, measured, assessed and improved have to be equally numerous. Indeed, to the contrary, given our knowledge of ecosystem function and how people engage with them, it is possible to identify a limited set of parameters from which criteria could be derived.

Before looking at these parameters it is worthwhile to consider the utility of a single operational framework.

The first function of this framework is to be able to systematically distinguish whether an intervention actually meets the NbS definition as outlined earlier. For example, would it be possible to claim that an oil-palm plantation for biofuel production is an NbS? Or, would a technology that deploys a natural phenomenon such as wind or solar radiation be considered an $\mathrm{NbS}$ ? Or could an innovative design based on molecular arrangements that naturally occur in living organisms be considered an $\mathrm{NbS}$ ? Without a clear delineation of $\mathrm{NbS}$, it is impossible to distinguish whether an intervention is an NbS or not.

The second function is to provide a consistent way of assessing whether the NbS intervention is robust and sustainable, or weak and temporary. Weak or temporary NbS would potentially be those interventions which only minimally fulfil the principles and parameters. For example, an intervention that relies solely on planting a single, fast-growing, short-lived species, may quickly capture carbon as an $\mathrm{NbS}$ to climate change, but has little potential to store that carbon over the long term. All things being equal, this may still qualify as an $\mathrm{NbS}$ but only as a weak one.

The third function is an extension of the previous point - to provide a coherent basis to strengthen the viability of an intervention over time, by optimising the nature of the intervention against each individual parameter. This is particularly important where an NbS intervention is implemented in conjunction with another technical or policy intervention (see the food security example in Figure 1), and additional gains are available through fine-tuning the complementarity between 
these natural and conventional interventions. One could legitimately argue that the only parameter one should worry about is the one that directly accounts for the effectiveness of the solution. For example, the best option to sequester carbon, or to slow erosion, or purify water. Clearly it is important to account for $\mathrm{NbS}$ in these terms but we also need to recognise that in order to sustain an intervention over time, it would be short-sighted simply to focus on immediate gains. If $\mathrm{NbS}$ interventions are implemented correctly, they have the capacity to self-sustain over time, accumulating greater value as societal assets rather than depreciating as built infrastructure.

Finally, a framework will ensure that the socialecological system in which an NbS approach is implemented is fully considered (e.g. Waylen et al., 2015). This is important when bringing together the societal and environmental components of an NbS approach, enabling it to work across multiple disciplines and scales and offer informed societal choice (McGinnis \& Ostrom, 2014; Davies et al., 2015) from a variety of perspectives (Leach et al., 2010).

\subsection{Determining the key parameters of an NbS operational framework}

The thinking presented in this report is still a work in progress. However, there are a number of reference points that are worthwhile presenting here as useful considerations in the selection of key parameters for a single operational framework for $\mathrm{NbS}$. These include the following:

- The parameters should be underpinned by sound and reliable scientific knowledge that enables clear and robust criteria to be defined, and from which easily measured indicators can be derived.

- The parameters are essential components to ensure the effective and sustained functioning of a wide range of $\mathrm{NbS}$.
Often there is a temptation to include "nice to have" parameters which often qualify best practice but by themselves are not a fundamental determinant of the effectiveness and durability of the intervention. When these are framed as 'safeguards' they can be particularly difficult to effectively apply.

- The parameters as a whole should represent the basic determinants of an effective $\mathrm{NbS}$ across a range of different situations, avoiding redundancy. In defining a workable set of parameters we should exercise sufficient parsimony to avoid having specific parameters only to deal with occasional situations.

\subsection{Proposed operational parameters for $\mathrm{NbS}$}

Building on the above, the following five parameters are proposed. There has been some work already undertaken in the identification of these candidate parameters but IUCN's next phase of work will be to convene its network of scientists from its expert Commissions, to test each of these thoroughly and then to use the final agreed set as the building blocks from which to derive a robust operational framework and standard that can be used to assess any $\mathrm{NbS}$ intervention.

Candidate parameters for an NbS operational framework could include:

a. Ecological complexity. This parameter supports interventions that would maintain or promote complexity at different ecological scales.

b. Long-term stability. This parameter would support interventions that can persist over many years.

c. Scale of ecological organisation. This parameter would support implementation at a scale that helps mediate the 'upstream and downstream' relationships, dependencies and benefits. 
d. Direct societal benefits. This parameter would support the delivery of an attributable and substantial stream of direct societal benefits.

e. Adaptive governance. This parameter would ensure that the $\mathrm{NbS}$ intervention and the ecosystems on which it depends are supported by institutional and decisionmaking arrangements that can be flexible enough to adapt over time, to meet the changing needs of the people who manage and rely on these ecosystems. 


\section{Concluding remarks}

This report has presented:

- a definitional framework, to support a clear understanding of what $\mathrm{NbS}$ interventions are and what they seek to achieve;

- a discussion of how Nature-based Solutions relate to specific societal challenges;

- a review of the different approaches that can be considered $\mathrm{NbS}$;

- a set of case study applications of $\mathrm{NbS}$ and lessons learned from these projects;

- the rationale for developing an operational framework for NbS and some initial thoughts on what this framework would cover, in order to effectively operationalise the NbS concept and support best practice across a wide range of interventions.

In the coming years, and building on its existing work, IUCN will further amplify its efforts to develop and advance effective NbS to meet global societal challenges. These Nature-based Solutions will make a direct contribution to global efforts, will enable vulnerable societies around the world to better adapt to the adverse effects of water and food insecurity and climate change, and will help reduce the impacts of natural disasters. To ensure that its work is rooted in a strong evidence base, IUCN will undertake a comprehensive study of $\mathrm{NbS}$ applications to various challenges, drawing on the best available cases of $\mathrm{NbS}$ from across a representative set of geographies and ecosystem types, and using these case studies to test the $\mathrm{NbS}$ parameters under development.

By unifying $\mathrm{NbS}$ interventions under a single operational framework, it becomes possible to scale up implementation of these interventions and strengthen their impact in mitigating the world's most pressing challenges. 


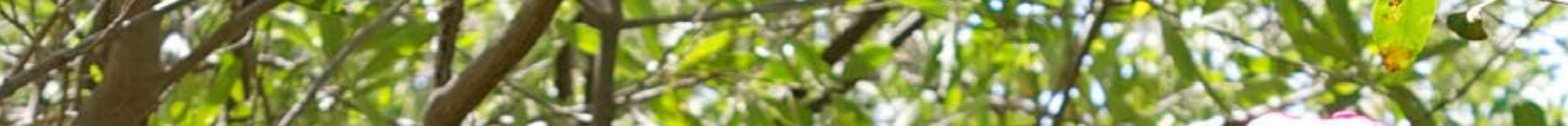

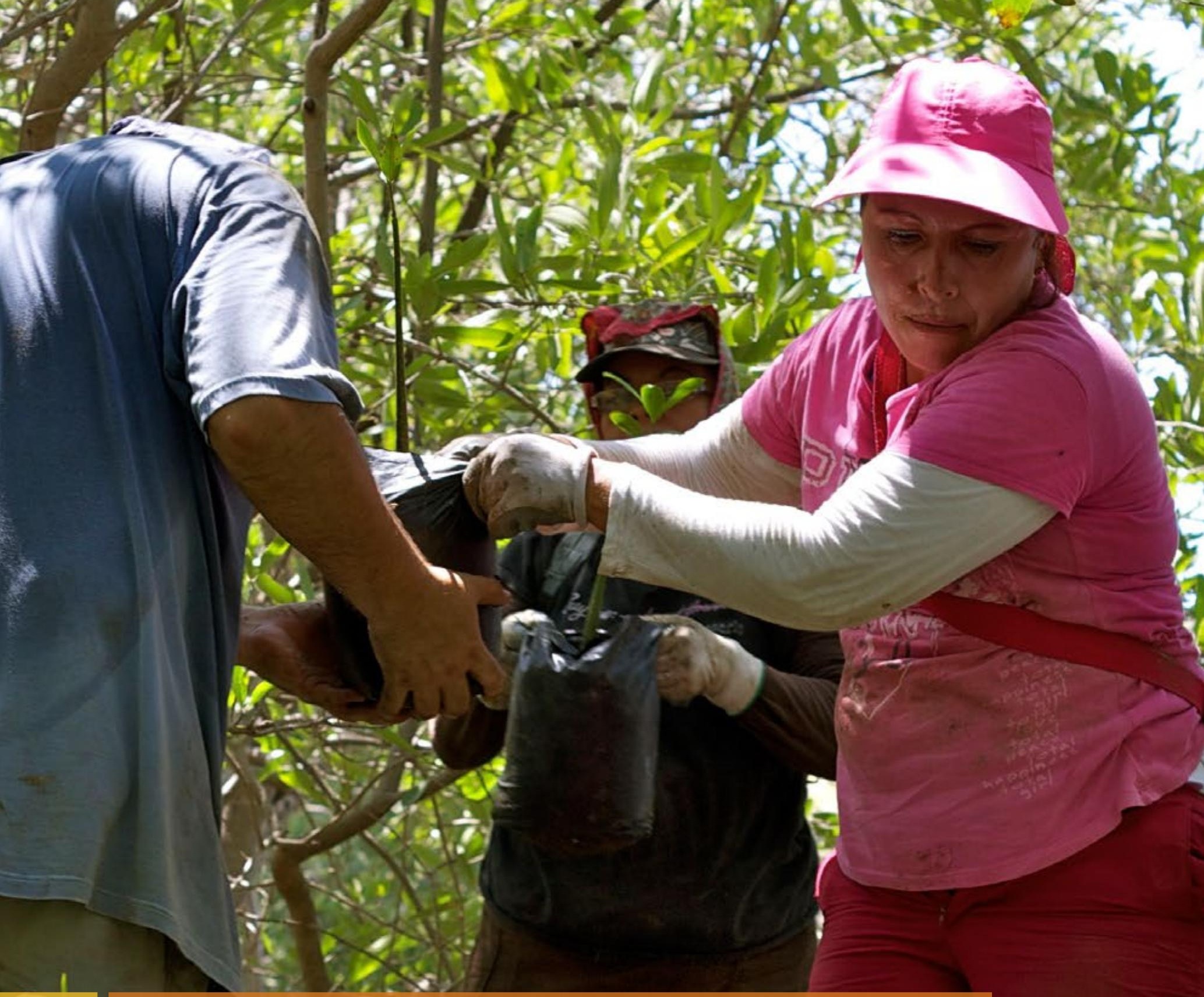

$\frac{+}{+\infty}$

Case Studies: Nature-

based Solutions on the

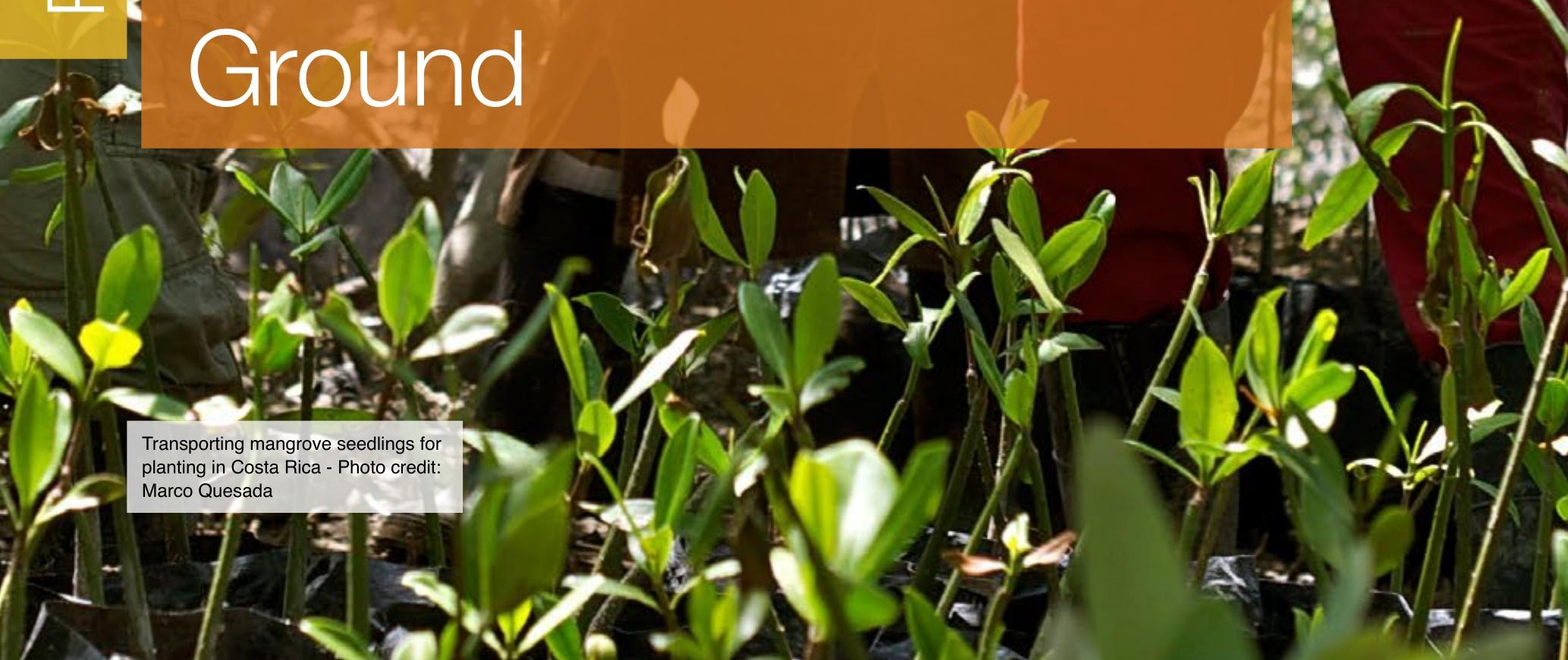




\section{Introduction to the case studies}

In order to demonstrate further the range of applications of the NbS concept, this section presents a suite of ten case studies. The initiatives described in these case studies have all employed at least one of the NbS approaches presented in Part A of this report, and have all aimed to address one or more societal challenges. The case studies have been selected to illustrate how NbS is being applied in different types of ecosystems and in different regions of the world (see Figure 9). Additional case studies will be published in a separate report.

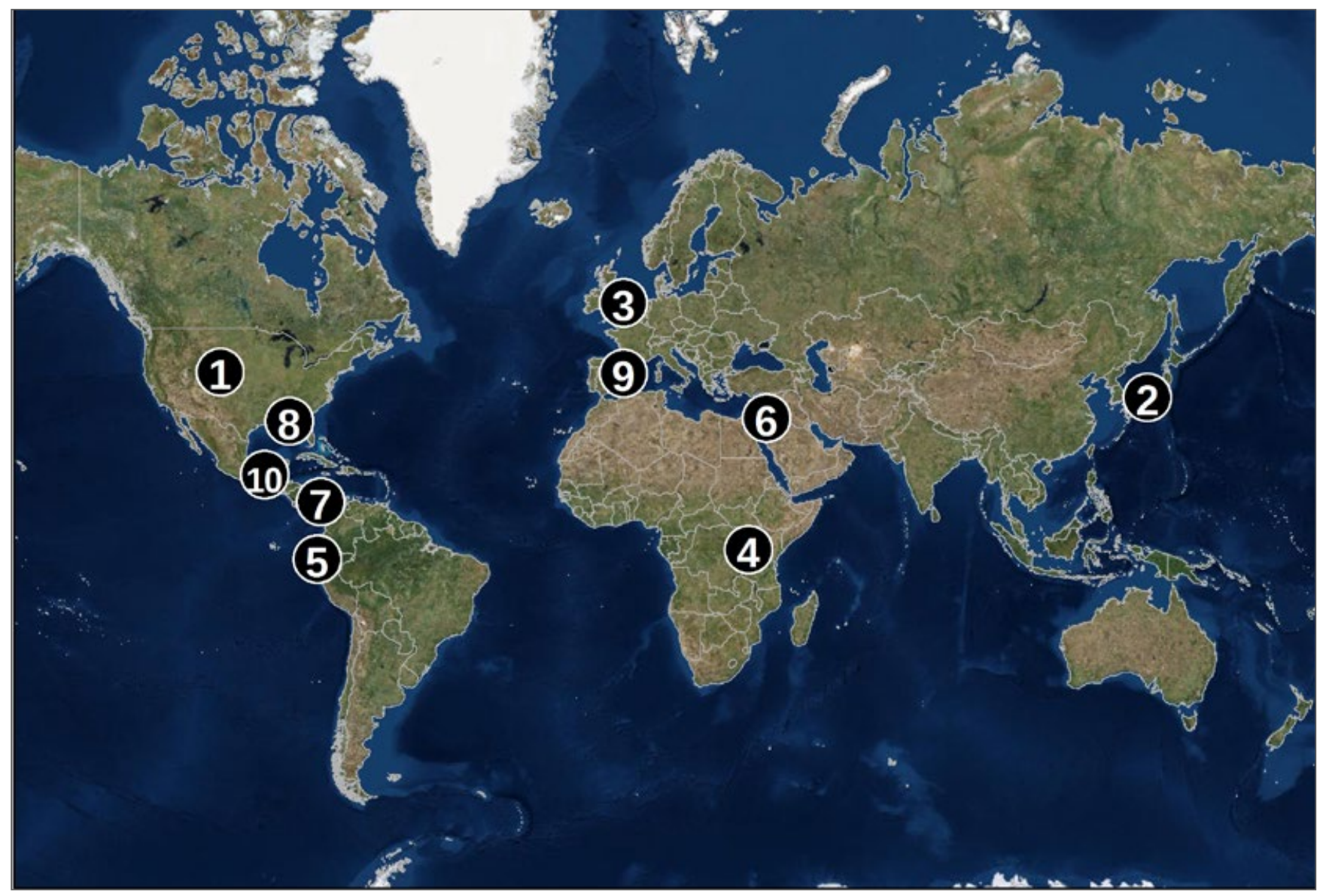

Figure 9. Map of case study locations

1- Colorado, USA

2- Japan

3- UK

4- Rwanda

5- Ecuador

6- Jordan

7- Costa Rica

8- Northern Gulf of Mexico, USA

9- Spain

10- Guatemala and Mexico 


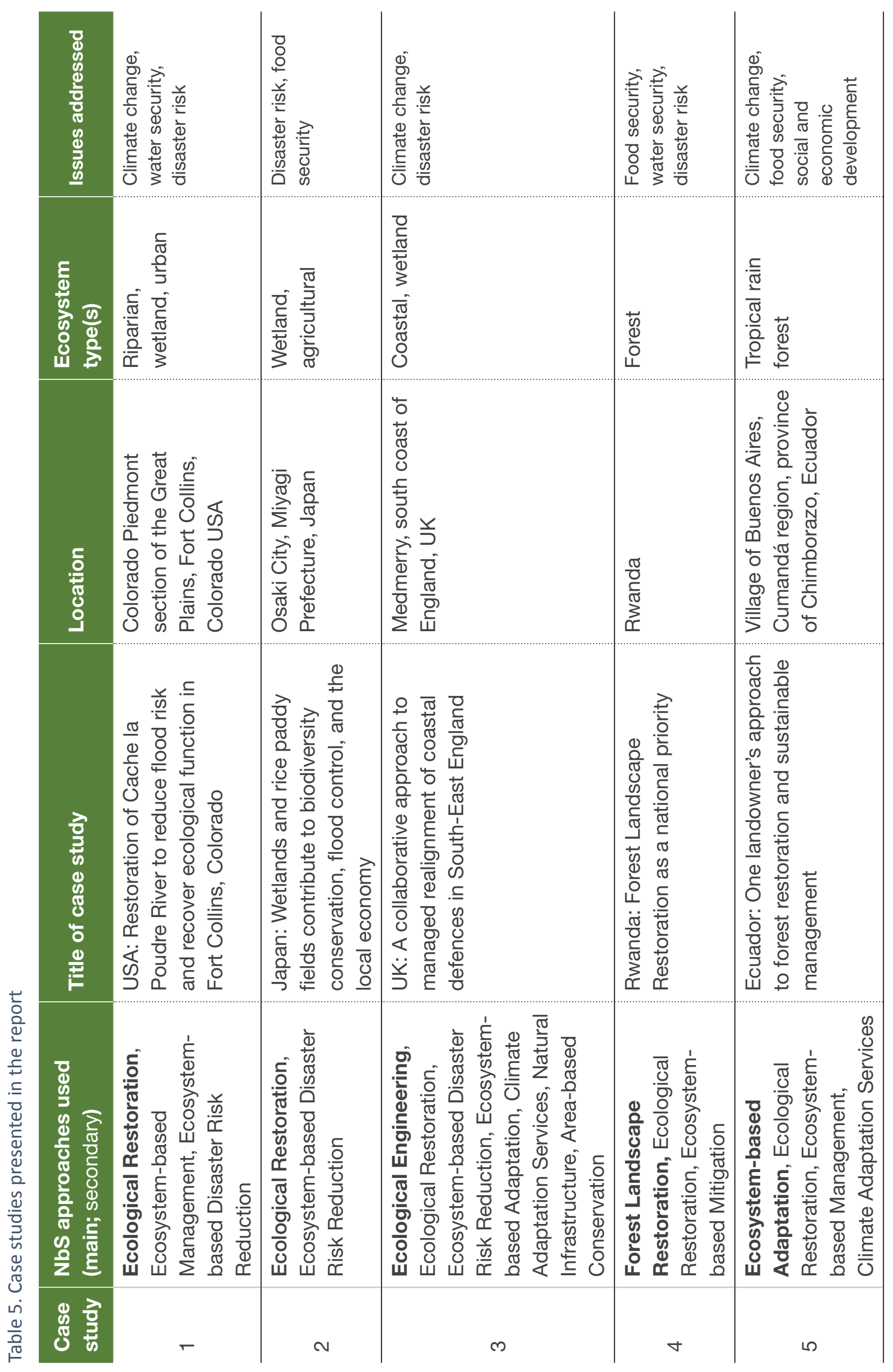




\begin{tabular}{|c|c|c|c|c|c|}
\hline 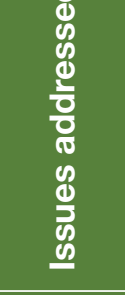 & 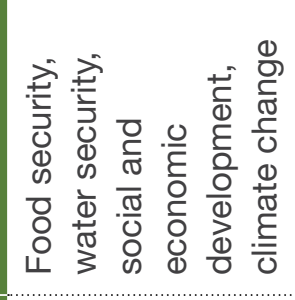 & 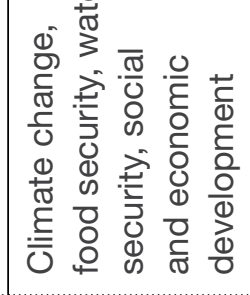 & 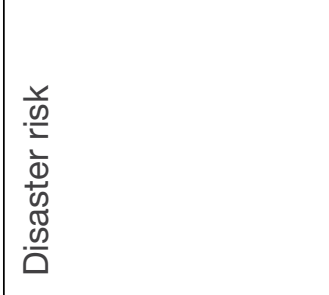 & 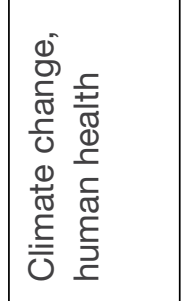 & 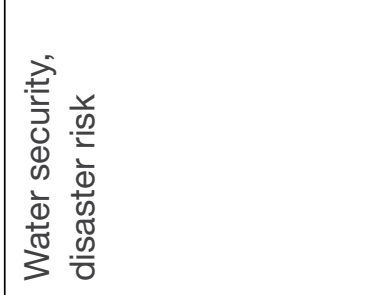 \\
\hline 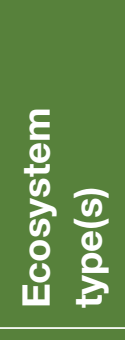 & 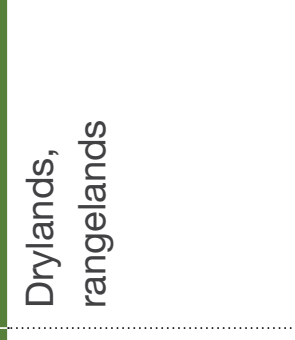 & 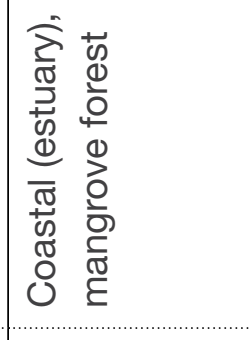 & 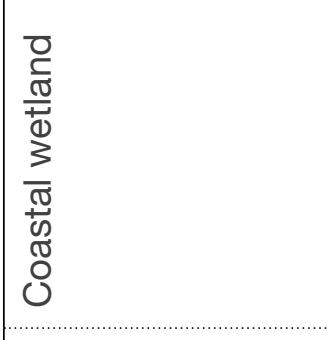 & \begin{tabular}{|l}
$\frac{5}{0}$ \\
$\frac{0}{5}$ \\
\multirow{2}{*}{}
\end{tabular} & 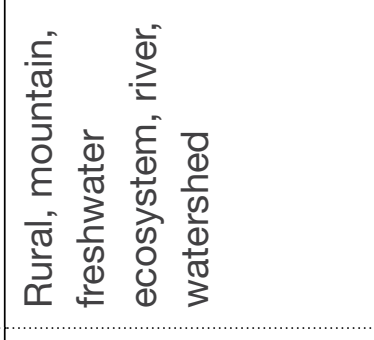 \\
\hline 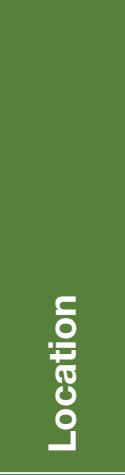 & 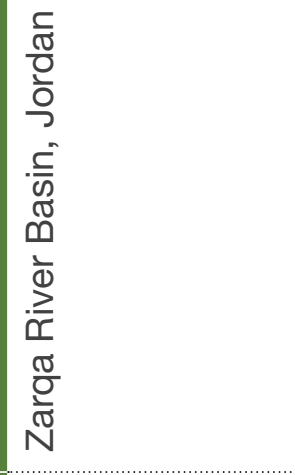 & 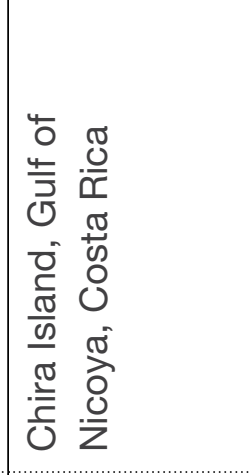 & 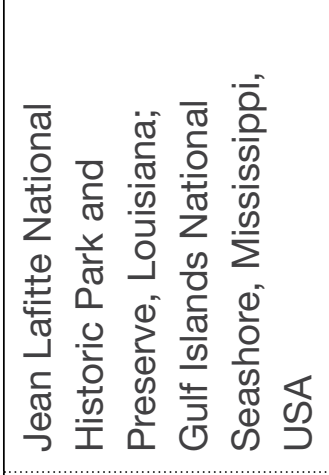 & 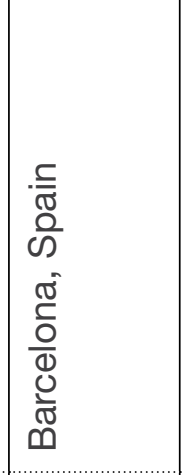 & 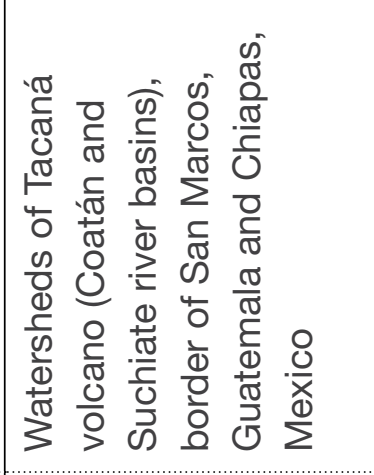 \\
\hline 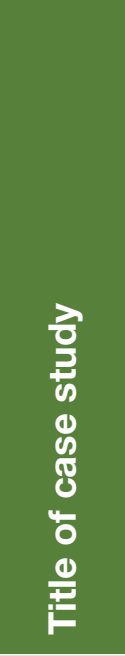 & 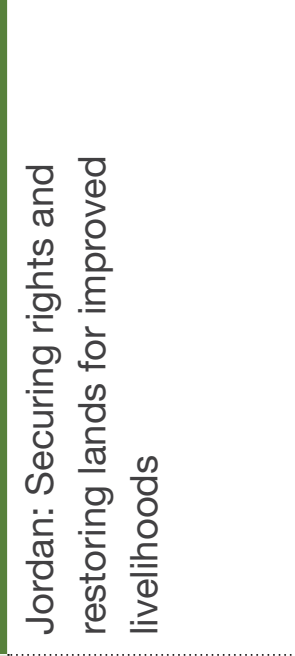 & 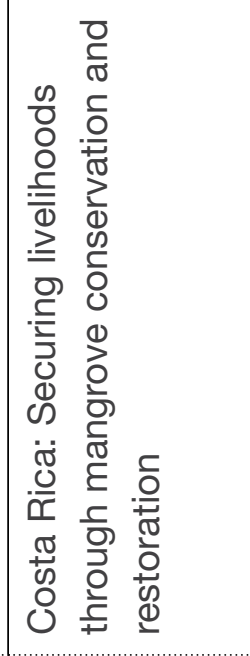 & 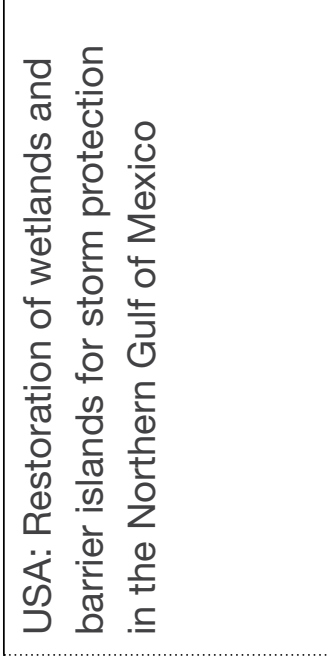 & 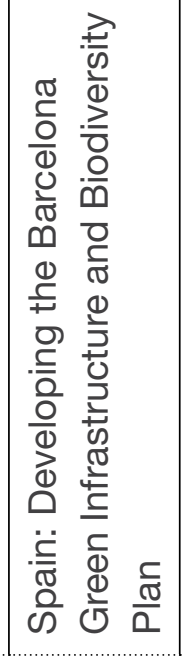 & 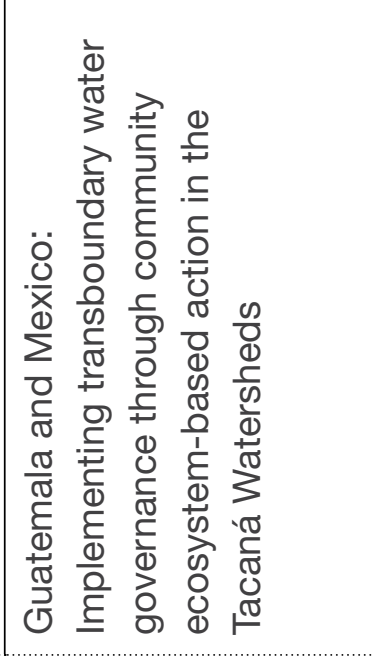 \\
\hline 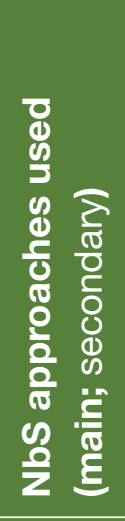 & 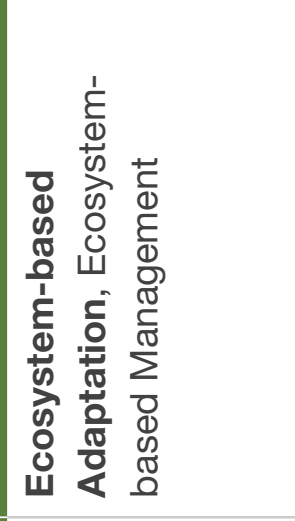 & 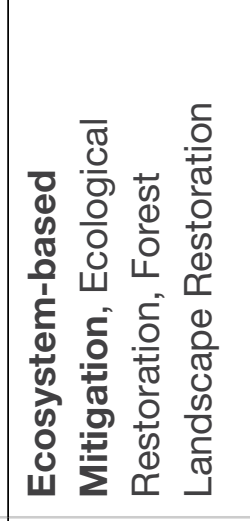 & 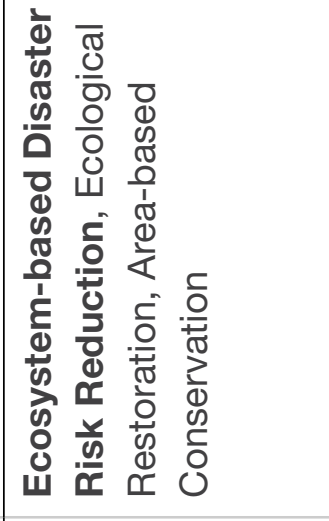 & 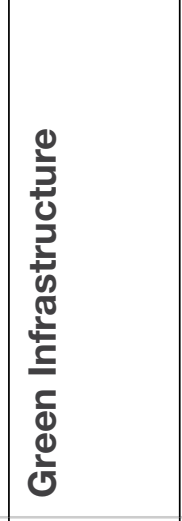 & 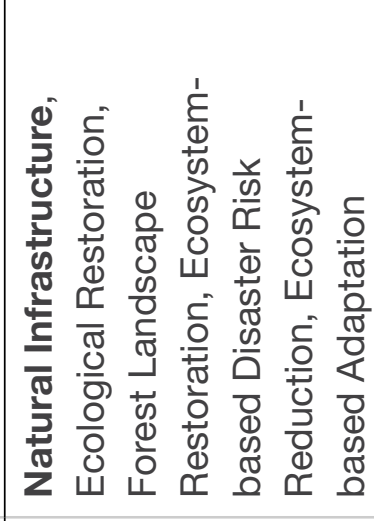 \\
\hline 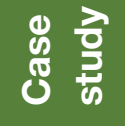 & $\theta$ & $r$ & $\infty$ & $\sigma$ & 우 \\
\hline
\end{tabular}




\title{
Case Study 1
}

\section{Restoration of Cache la Poudre River to recover ecological function and reduce flood risk in Fort Collins, Colorado}

\author{
Biohabitats, Southern Rocky Mountain Bioregion Office, Denver, USA (jnorris@biohabitats.com) \\ Rick BACHAND, City of Fort Collins Natural Areas
}

\section{UNITED STATES OF AMERICA}
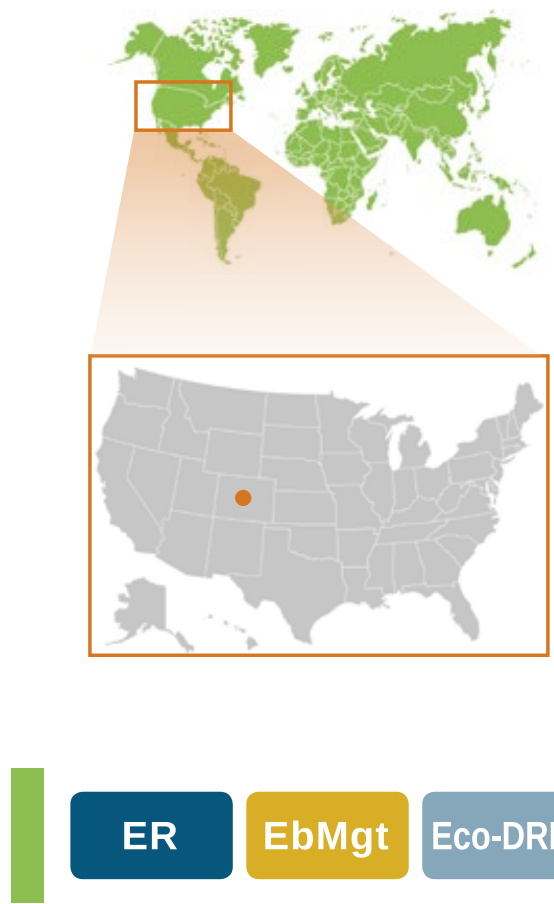

ER EbMgt Eco-DRR
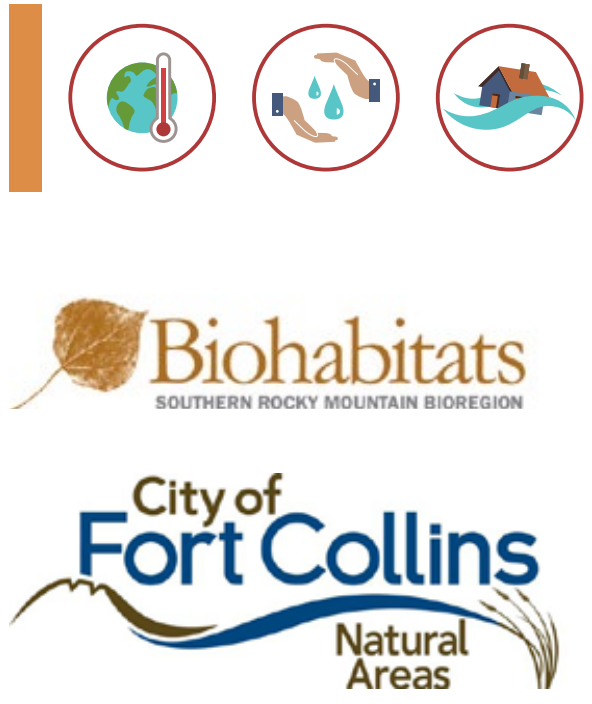

\section{General background}

Water resources in the semi-arid southwestern US are under increasing pressure from population growth and the demands of multiple users. Climate change models suggest that more extreme events will add to these pressures in the future (MacDonald, 2010). The Cache la Poudre River is a seasonal, snowmelt driven river originating in the Rocky Mountains running east into the lower-elevation plains. The River has played an important and historic role in the early settlement and growth of Fort Collins through the years, and supports the thriving urban centre it is today. City residents still consider the river central to the community's identity and rely on it as a source of drinking water, stormwater conveyance, and tourism (Bartholow, 2010).

Today, land use changes in the river's historic floodplain including gravel mining and urbanization diminish the river's ability to scour and deposit sediment within the river channel and constrain flooding events onto the floodplain that nourish riparian vegetation with water and vital nutrients. Likewise, growing water demands to support agricultural and municipal needs have modified the river's hydrology through alterations in base flow, timing and duration of flooding events, and negative physical and chemical changes in low flow periods ( $<0.85$ cubic metres/second). Finally, regional climate change predictions complicate our ability to understand how the river's hydrology and ecology may respond to warming climate scenarios.

For more than two decades the City of Fort Collins has invested heavily in this urban river through extensive planning efforts, purchase of approximately 700 hectares of lands within the river's floodplain, projects to address stormwater control and conveyance, water quality management, and acquisition of in-stream flow water rights.

More recently, in 2011 the City's Natural Areas Department published the Cache la Poudre River Natural Areas 

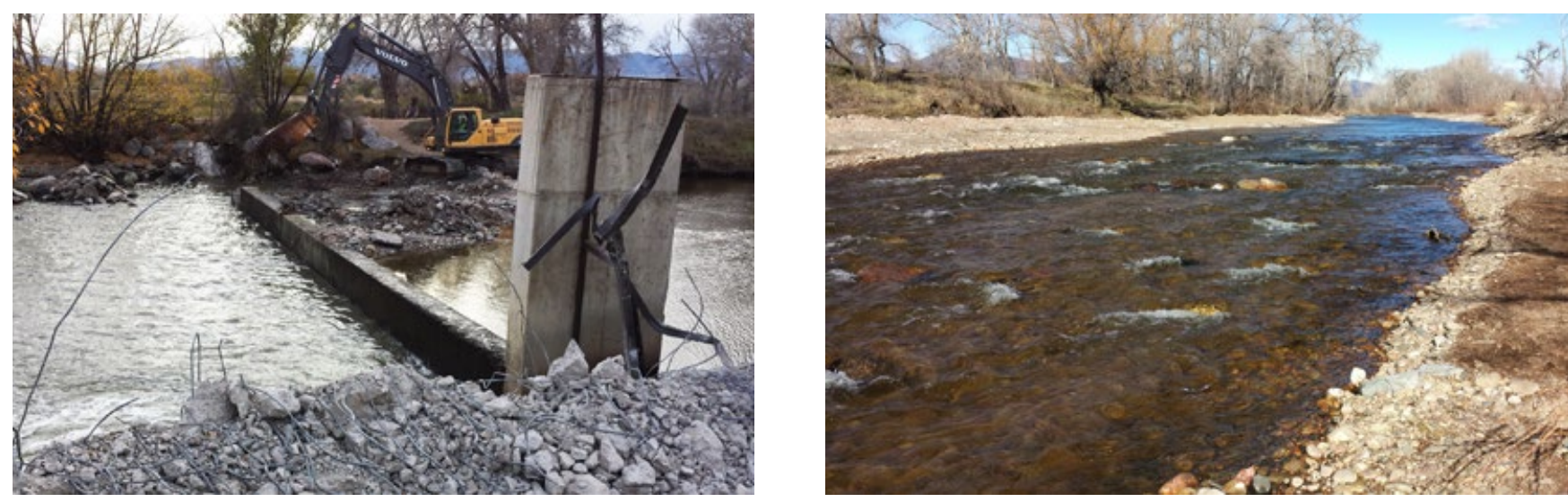

Before and after dam removal at Sterling Pond restoration site - Photo credit: Biohabitats

Management Plan (City of Fort Collins, 2011) outlining the opportunities and challenges in supporting the river's ecological function and reducing risks to life and property during significant flood events. The City is tackling these challenges by applying Nature-based Solutions (NbS) to support ecological function and reduce flood risk to adjacent properties. Since 2011, a suite of river restoration projects using NbS practices have been implemented by the City of Fort Collins and its partners under the 2011 management plan, two of which are described here: Sterling Pond Ecological Restoration, and the McMurry Natural Area Ecological Restoration. These projects are in neighbouring areas, just upstream of downtown Fort Collins

\section{Main activities}

The primary objective for the Sterling Pond and McMurry Restoration projects was to remove high, artificial banks created along the riverbank during gravel mining operations, which sought to prevent river flooding during mining activities. As a result, the river and its natural processes became highly modified and dysfunctional. Unnaturally elevated banks disconnected the river from its floodplain, increased bank erosion due to increased shear stresses resulting from channel confinement, and eliminated bankside vegetation and habitat. Recently, the formerly common approach of creating channelized rivers with armoured banks has given way to the idea that surface and groundwater interactions within the river ecosystem (river channel, riparian forests, and associated wetlands) is necessary to sustain river health and habitat while providing for optimal water quality (filtration) and increased water quantities.

\section{Sterling Pond (North Shields) Restoration \\ Project. This restoration project covers a} 600-metre stretch of the Poudre River that flows alongside artificial ponds created by historic gravel mining activities. On the downstream end of the project, the Josh Ames (water) Diversion Structure, a defunct concrete dam created for farmland irrigation, created a barrier to the ecological system and the river's physical processes. Restoring the Sterling site therefore involved three key strategies: lowering the high bank to widen the riparian zone and connect the river with its floodplains, creating additional shallow wetland habitat in the ponds, and removing the abandoned dam. The project was implemented in 2014 and 2015.

The Colorado Water Trust (a non-profit streamflow restoration organisation) and the City of Fort Collins partnered together to remove the concrete dam which spanned the river. The objective of the dam removal was to restore natural river flow, enable fish passage, and improve the riverbed as fish habitat. Once the structure was removed, the team modified approximately 150 metres of the river to mimic natural river features and gradation. The sediment that had built up behind the structure was excavated and redistributed in the channel and on the upstream banks for stabilisation. 


\section{McMurry Restoration Project. The McMurry}

Natural Area is an 18-hectare site that includes an 800-metre stretch of the Cache la Poudre River and two adjacent gravel ponds.

Restoration of the site began in 2010 and was completed in 2015. Like the Sterling project, lowering the riverbanks, creating wetlands in the gravel ponds, and revegetating the riparian area were primary objectives. This project included significant removal of concrete, debris, and old cars from the river bank placed there historically to prevent erosion.

Planting native wetland vegetation and floodplain trees and shrubs was included in the restoration plan, because the riparian forest had been nearly lost due to the lack of flooding flows which nourish the floodplain with water, nutrients and sediment. Five diverse vegetated zones were created - emergent wetland, wet meadow, willow, cottonwood, and upland grasslands, all intended to increase native species diversity and enlarge the riparian forest.

To facilitate public use and stewardship of the site, the project design included a pedestrian trail and designated fishing areas. Today, the property offers Fort Collins residents and visiting tourists a wealth of recreational opportunities.

\section{Results}

Together, the two projects restored two kilometres of the river's channel and riverbank, created over five hectares of riparian floodplain forest, and several hectares of wetlands. The projects planted an astounding 1,200 trees, 25,000 shrubs and 60,000 wetland grass plugs. Both projects included removal of hard infrastructure reconnecting more than 1,500 metres of river with its floodplain. Removing

\section{Key lessons learned}

Uncertainty of future hydrological conditions. The overarching challenge in transitional and semi-arid riparian systems is managing the uncertainty associated with future conditions and planning for increasing climatic and hydrological variability. Throughout the Rocky Mountains, upstream snowmelts are coming earlier and faster, and precipitation patterns are changing. These design challenges will become greater year after year. Restoration and flood control practices therefore need to be re-evaluated in light of the increasingly 'flashy' water flows. Lower-flow scenarios need to be examined during the design stage of restoration projects to better understand the interaction between the river and its floodplain. At a minimum, riparian restoration practices in this area need to carefully consider and plan for maintenance needs.

Establishing baseline data. The Cache la Poudre River is a highly manipulated system, with water use for drinking, irrigation and recreation as well as hydrological and geomorphic changes driven by mining, flood control, diversion structures and land-use change. In such systems, establishing critical baseline flows becomes more difficult and the system's hydrology is harder to anticipate. Approaching these challenges relies on experts with a historical knowledge of the area, incorporating appropriate variability in any modelling efforts, and establishing the river's baseline behaviour over a suitably long timeframe.

Partnership and collaboration. Although these specific projects did not draw in many partners and stakeholders, the projects are a subset of a much broader effort to fulfil the key goals of the Cache La Poudre Natural Areas Management Plan, and build on the broad coalition of stakeholders engaged in this overall planning process. 
the Josh Ames Diversion Structure resulted in multiple ecological benefits including lowering river water temperatures, eliminating fish barriers, and enhancing public safety for recreational float boating.

The projects also incorporated a number of recreational features. The City's Natural Areas Department was responsible for the location and development of trails and river fishing access points within the project area. At McMurry, a series of boulders placed at approximate water elevations were placed to help visitors understand the importance of functional floodplains, and the necessity of high river flows to spill out of its channel.

The City of Fort Collins continues to work in partnership with a broad and diverse range of partners to implement restoration projects that connect the river to its floodplain, improve base river flows, create rich wildlife habitat, improve aesthetics and offer recreational opportunities for the community.

\section{Acknowledgements}

City of Fort Collins, Natural Areas staff;

Colorado Water Trust (Project Partner),

Executive Director Amy W. Beatie, Esq.; Tessara

Water Llc.

\section{References}

Bartholow, J.M. (2010). Constructing an interdisciplinary flow regime recommendation. Journal of the American Water Resources Association (JAWRA) 46(5): 892-906.

City of Fort Collins. Cache la Poudre River: Natural Areas Management Plan Update [online report], (2011). www.fcgov.com/ naturalareas/pdf/poudre-managementplan2011.pdf._Accessed 20 April 2016.

MacDonald, G.M. (2010). Water, climate change, and sustainability in the southwest. PNAS 107(50): 21256-21262.

TNC (The Nature Conservancy) (2007). Groundwater and biodiversity conservation: a methods guide for integrating groundwater needs of ecosystems and species into conservation plans in the Pacific Northwest. Prepared by J. Brown, A. Wyers, A. Aldous and L. Bach. December 2007. 


\title{
Case Study 2
}

\section{Japan: Wetlands and rice paddy fields contribute to biodiversity conservation, flood control and the local economy}

\author{
Naoya FURUTA, IUCN Japan Liaison Office, Tokyo, Japan (naoya.furuta@iucn.org)
}

\section{JAPAN}

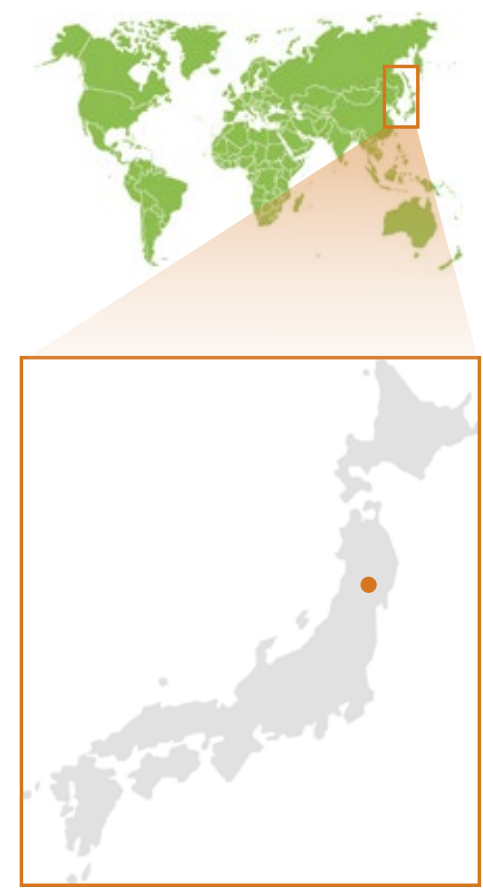

\section{ER Eco-DRR}
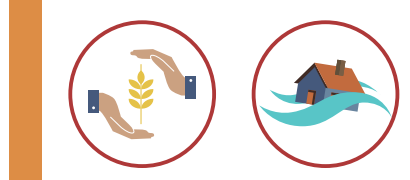

\section{General background}

Some $60 \%$ of Japan's wetlands have been degraded in the past 100 years due to the growth in intensive agriculture practices, driven by food security and development pressures; this loss of wetlands has significantly reduced ecosystem services and biodiversity (FAO, 2013). In the northern part of the Miyagi prefecture, the situation is acute $-92 \%$ of this area's wetlands have disappeared, converted to rice paddies or dry-fields for non-rice crops (Kurechi, 2007). In view of this extensive environmental degradation, policy makers are increasingly concerned about the longterm sustainability of conventional agricultural practices for the environment and communities (FAO, 2013). Policies may need to be revitalised to address agricultural-environmental issues as a means of sustainable community development. Furthermore, faced with declining domestic rice prices, farmers are seeking methods to add value to their produce in order to gain a competitive advantage (FAO, 2013).

The Kabukuri-numa wetlands, covering 100 hectares, comprise one of the few remaining wetlands in the area, their conservation assured because of their recognised function as a Nature-based Solution to managing disaster risk (Kurechi, 2007). As the prefecture's extensive lowland floodplain is often damaged by heavy rains, the government has developed and used the Kabukuri-numa wetlands and their surrounding rice paddies as a flood-control basin since 1970. The restoration of these wetlands has also boosted the population of white-fronted goose (a protected species in Japan) by providing significant over-wintering habitat (Osaki City, 2015). Migratory geese are now seen as an important indicator of the health of both the wetlands and the rice paddies. The government is committed to sustainable agricultural practices, not only through its continued protection of the Kabukuri-numa wetlands but also through the restoration of the wetland function of rice paddies by supporting the new practice of 'winter-flooded rice paddy'. 


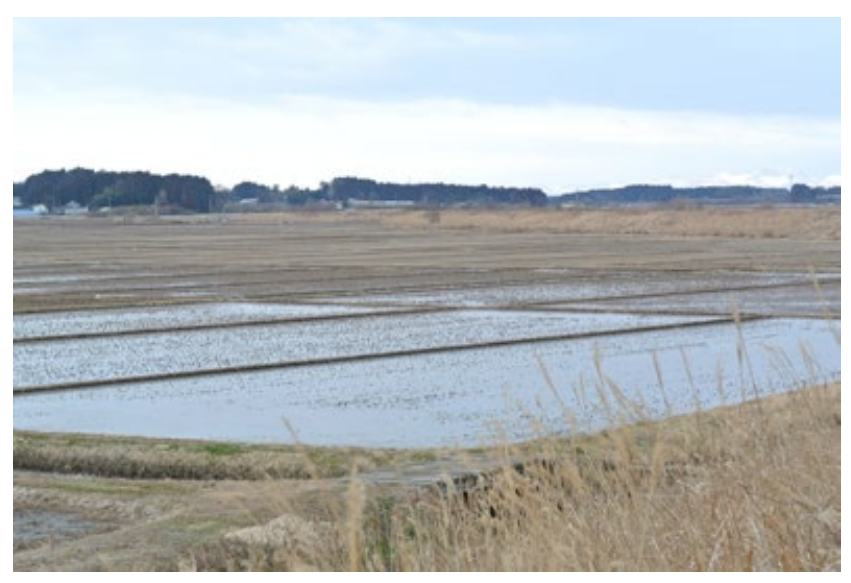

A flooded rice paddy - Photo credit: Naoya Furuta

\section{Main activities}

Sustainable agricultural practices. Because of the widespread wetland degradation and habitat loss, white-fronted geese gathered in large numbers in the Kabukuri-numa wetlands (Ministry of the Environment, 2010), leading to conflict between conservation organisations protecting the geese and local farmers angered over loss of their grain. In 1999 the local government sought to address this problem by compensating farmers for the goose-related agricultural losses they incurred. With this governmental support and increased awareness of wetland benefits, local farmers gradually started to change their practices. In 2003 a group of local farmers decided to implement a new practice of flooding their rice paddies in the winter (Furuta, 2016). Flooding rice paddies that are usually left dry in the winter creates more habitat for migratory birds in the winter season, thereby dispersing the roosts of the geese and improving the wetland function. Because of this practice, from 2009 to 2012 farmers did not need to apply for compensation for damaged agricultural lands or reduction in agricultural yields due to geese.

Sustainable agricultural practices such as this winter flooding of rice paddies, no-till farming and reduced pesticide use are marketed to consumers through certification and labelling programmes developed by the prefectural government and/or Japanese Agricultural

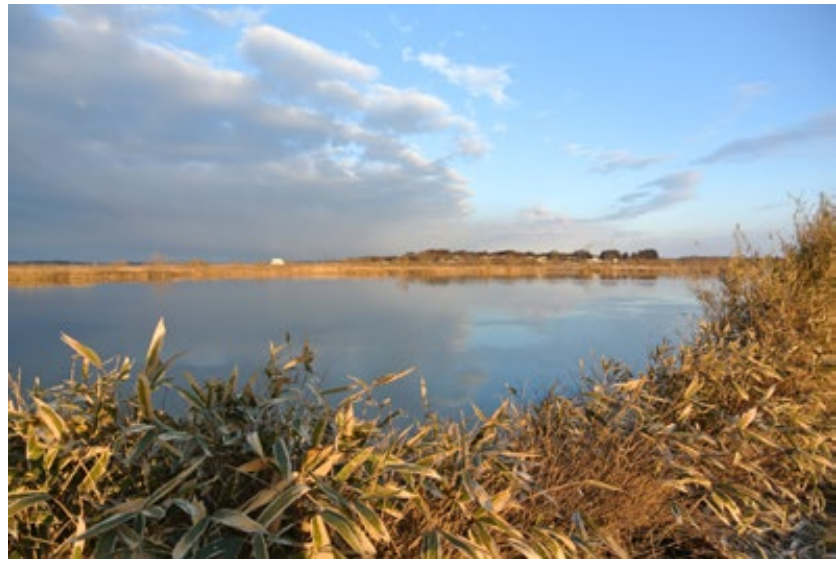

Part of the restored Kabukuri-numa wetlands - Photo credit: Naoya Furuta

Standards Association, to add value to agricultural produce (FAO, 2013). Since 1996, local municipal compensation is also available for farmers with rice paddies surrounding the Kabukuri wetlands who adopted practices that "contributed to restoration and continued management and conservation of rice paddies as substitute habitats of floodplain wetlands" (FAO, 2013, p. 3), such as reducing chemical fertilizer and pesticide use.

\section{Conservation and restoration efforts. In} 1997 the Miyagi prefectural government set up a roundtable for information sharing among relevant stakeholders (including local government officials, local farmers, academics and conservation organisations) to discuss important issues regarding the continued restoration of the Kabukuri-numa wetlands. Plans to create additional wintering sites for wild geese conflicted with government plans to increase the flood control capacity of the wetlands, since these plans would potentially negatively affect the wetland environment. Following collaborative discussions, measures were taken to improve flood control and conserve and restore the existing landscape (Furuta, 2016). For example, a clay overflow levee that took landscape and environmental factors into consideration was chosen instead of a concrete one (Osaki City, 2015). This is an uncommon practice in Japan. Embankments surrounding the Kabukuri-numa wetlands were 
to be kept unpaved and cars were banned from entering the embankments to avoid frightening the birds (Furuta, 2016). In this way, the roundtable played a significant role in the conservation of the Kabukuri-numa wetlands, providing space to build consensus among the different stakeholders and find innovative solutions to balance the need for flood control and conservation.

Education. The general public knew little about the benefits of the Kabukuri-numa wetlands and had little interest in conserving them. A non-profit organisation was formed thanks to the inspiration of Mr. Masayuki Kurechi, chairman of the Japanese Association for Wild Geese Protection, an organisation that has been instrumental in environmental education and awareness raising, particularly for the local people and school children.

\section{Results}

Conservation success. In 1997 farmers (landowners) jointly decided to restore the Shiratori district (a 50-hectare area of rice fields adjacent to Kabukuri-numa) to its original wetland status. The total area of the wetlands has therefore increased from 100 hectares to 150 hectares. Since 1999 the number of migratory geese in these wetlands and surrounding rice paddies has increased threefold, indicating a healthier landscape (FAO, 2013).

Income generation for farmers. According to local farmers, crop yields dropped about 20$30 \%$ following adoption of the new practice of winter-flooded rice paddies. At the same time however, successful branding and ecolabelling of the product (as 'premium rice') almost doubled the retail price and a local sake brewery purchases winter-flooded rice at premium cost, selling it as limited edition sake (titled "Winter-flooded Rice Paddy Sake"). Furthermore, the restoration efforts and the resulting increase in the area's goose population have provided farmers with alternative income- generating eco-tourism opportunities during non-farming months as visitors come to observe the migratory birds during winter (FAO, 2013). The geese are also being used as an effective marketing tool to capture the attention and support of consumers and society for purchase of environmentally friendly rice products (FAO, 2013). These economic benefits from the presence of the geese mean that the birds are now an important element assuring the future sustainability of agriculture in this area.

Up-scaling. Local government subsidies continue to compensate farmers for the costs involved in managing water in the rice paddies during the winter season. This compensation scheme attracted the national government's attention and in 2011 the Ministry of Agriculture, Forestry and Fisheries started a national Payment for Ecosystem Services scheme for environmentally friendly farming practices, based on this compensation system in the Kabukuri-numa wetlands area (FAO, 2013). Winter-flooding of rice paddies is now practiced in many parts of Japan. Currently the Miyagi prefectural government is planning to invest in agricultural infrastructure, upgrading projects in the area where the winter-flooded rice paddy practice is taking place.

\section{Model of biodiversity conservation within} an agricultural system. Registering with the Ramsar Convention in 2005 was a big step forward in accelerating and scaling up the efforts in the Kabukuri-numa wetlands. This was the first Ramsar site to intentionally include rice paddies within a wetland area (Ramsar Convention, 2016a). To disseminate the experiences and lessons learned from the Kabukuri-numa wetlands, a resolution was adopted at Ramsar COP10, which encourages parties to actively promote the planning, practices and management needed to enhance rice paddy biodiversity, and to help raise awareness of the potential role of rice paddies in biodiversity conservation at the global level (Ramsar Convention, 2016b). 


\section{Key lessons learned}

Collaboration. Productive and cooperative relationships are necessary among relevant stakeholders for information sharing and joint decision making, to balance the needs for farming, disaster risk reduction, and conservation. A willingness to listen to conflicting interests is necessary.

Policy. Policy should be built on stakeholder discussions and be flexible to modification in order to meet new and emerging challenges. Local efforts require policy support both at local and national levels for project continuation and up-scaling. In this case, recognition at the global level, i.e. Ramsar Convention, helped facilitate up-scaling of the project.

Income support for locals. Local farmers require governmental support in their efforts to implement practices that both support biodiversity and conservation, and provide sufficient income.

\section{Acknowledgements}

Mr. Masayuki Kurechi, for providing valuable data and information for this case.

\section{References}

FAO. Kabukuri Weltands Win-Win Solutions for Conservation and Development, Osaki City, Miyagi, Japan [online report], (2013). www. fao.org/3/a-bb130e.pdf. Accessed 22 April 2016.Furuta, N. (2016). Towards balancing needs for disaster risk reduction, farming and nature conservation in Kabukuri-numa Wetlands. Chiikijin 8: 60-65. (in Japanese)

Kurechi, M. (2007). Restoring rice paddy wetland environments and the local sustainable society - project for achieving co-existence of rice paddy agriculture with waterbirds at Kabukuri-numa, Miyagi Prefecture, Japan. Global Environmental Research, AIRIES 12: 141-152.

Ministry of the Environment of Japan. Payments for Ecosystem Services: Kabukuri-numa and Surrounding Rice Paddies [website], (2010). www.biodic.go.jp/biodiversity/ shiraberu/policy/pes/en/satotisatoyama/ satotisatoyama01.html. Accessed 22 April 2016.

Osaki City. (2015). Proceedings of Osaki Ramsar Festival - 10th anniversary of designation of Kabukuri-numa and the surrounding rice paddies as a Ramsar site (in Japanese). Ramsar Convention. Kabukuri-numa and the surrounding rice paddies [website], (2016a). www.ramsar.org/kabukuri-numa-and-thesurrounding-rice-paddies. Accessed 22 April 2016.

Ramsar Convention. Resolution X.31

"Enhancing biodiversity in rice paddies as wetland systems" [online report], (2016b). www.ramsar.org/document/resolution-x31enhancing-biodiversity-in-rice-paddies-aswetland-systems. Accessed 22 April 2016. 


\section{Case Study 3}

\section{UK: A collaborative approach to managed realignment of coastal defences in South-East England}

Nick GRAY, UK Environment Agency, Worthing, England (nick.gray@environment-agency.gov.uk) Joe PEARCE, UK Environment Agency, Worthing, England

Colin MAPLESDEN, UK Environment Agency, Worthing, England

\section{United Kingdom}

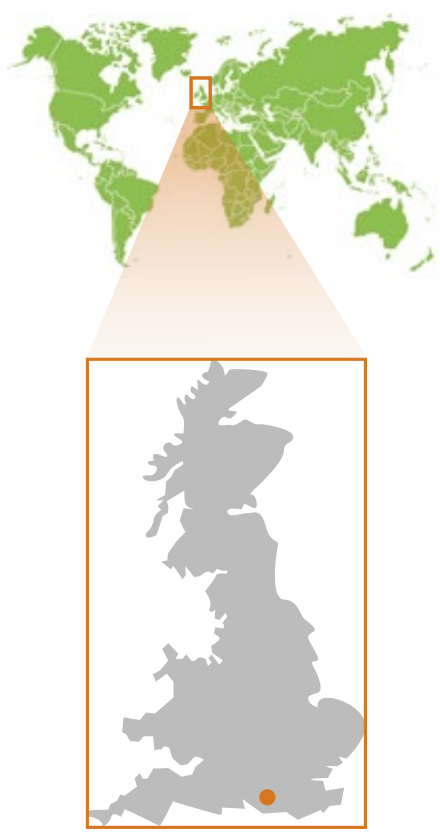

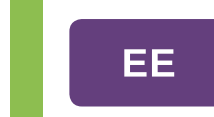

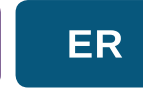

\section{EbA}

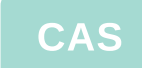

\section{NI}

\section{$\mathrm{AbC}$}

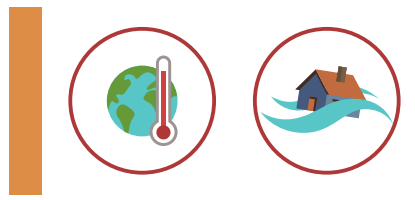

\section{Environment} Agency

\section{General background}

Worldwide, rising sea levels are intensifying flood risk (Woodruff et al., 2013). Ecosystem-based coastal defences can provide part of a solution to this growing problem (Temmermen et al., 2013). In northern Europe, managed realignment - the planned reconfiguration of river, estuary or coastal defences - has been used as a Nature-based Solution to avoid coastal flooding through the cost-effective creation of wetland habitat and the removal of seawalls (Turner et al., 2007).

Saltmarshes and intertidal mudflats have important biodiversity and cultural values (as recognised in the Ramsar Convention on Wetlands (Foster et al., 2013)). However, in England and elsewhere these ecosystems are being threatened by 'coastal squeeze', whereby erosion contributes to the loss of upper inter-tidal habitats (Morris, 2013). While creating new salt marsh can address flood risk and compensate for some habitat loss, rapid loss of existing habitat remains a continuing problem (Foster et al., 2013). In response to pilot initiatives in the UK and supporting policies, over 100 sites in northern Europe had undergone managed realignment by 2005 (Doody, 2013).

In the Solent area of England's southern coast, erosion has significantly reduced intertidal and mudflat habitat and the conservation and sustainable use of these intertidal mudflats and saltmarshes are of high concern. In contrast to earlier laws that supported the conversion of these habitats for development, new legislation now promotes their conservation. Many UK biodiversity policies provide standards that seek to integrate elements of biodiversity conservation into development projects. These policy instruments include for example the Ramsar Convention on Wetlands of International Importance, the UK Waterfowl Habitat, and the UK Biodiversity Action Plan, the last of which sets 'no net loss' targets for intertidal mudflats 


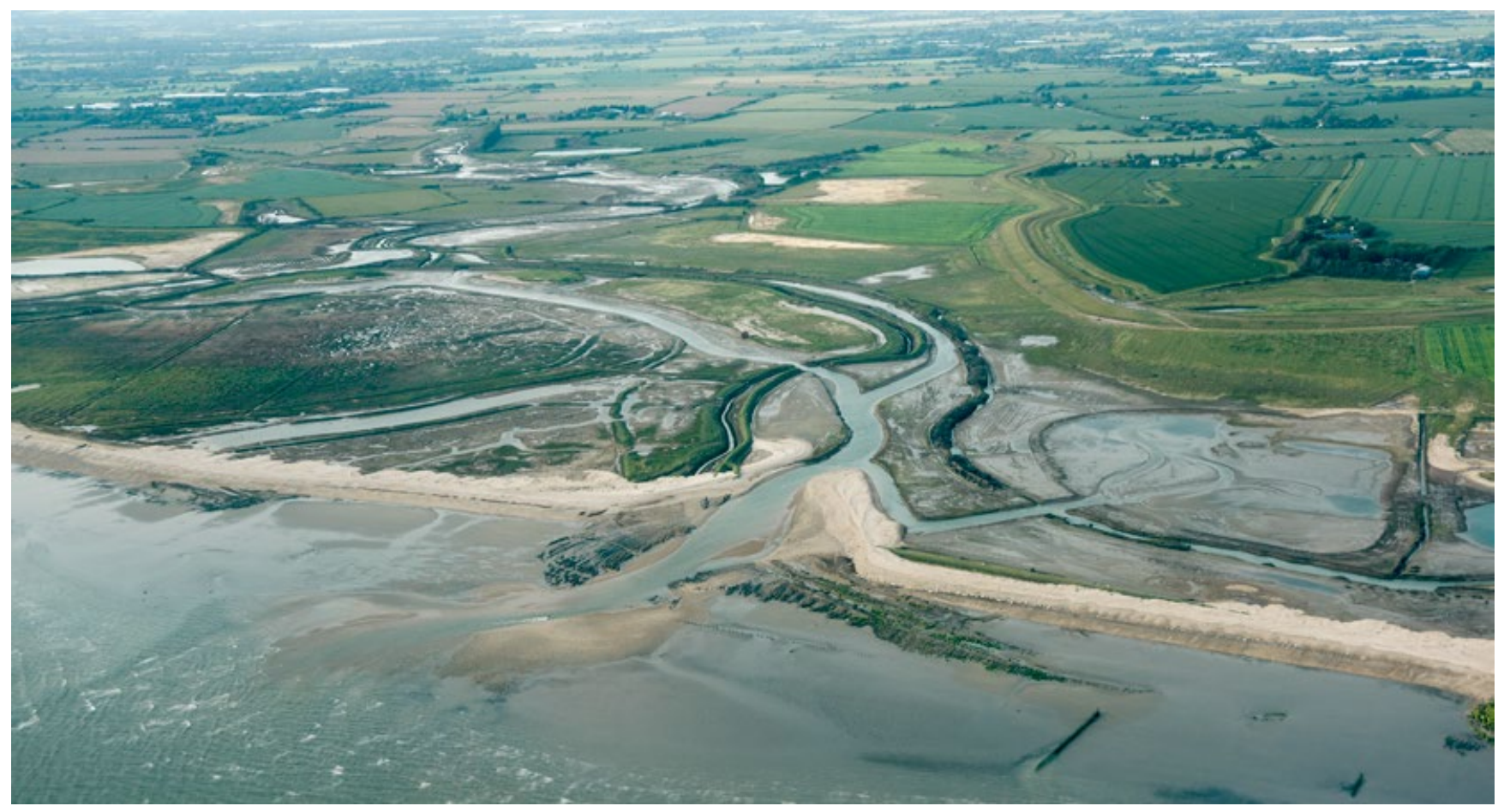

Aerial view of managed realignment at low tide - Photo credit: UK Environment Agency

and saltmarshes. Linked to these policies are numerous shoreline management and coastal habitat plans to mitigate flood risk (Foster et al., 2016; Thomas, 2014).

\section{Main activities}

Flooding from the sea and local streams had been a problem in the Solent for many years, prompting concerned local residents to act. In 2001, residents organised an international meeting, inviting Dutch coastal planning and management experts to help local communities understand the issues and to set out the options and implications to be considered (Cobbold \& Santema, 2001). As a result, the Manhood Peninsula Partnership (MPP) was formed, providing a forum for local people and statutory bodies to resolve how best to address flood risk in this section of the Solent.

\section{In 2007, the UK Environment Agency, the body} responsible for overseeing flood and coastal management in England, undertook wide public consultation on the draft recommendations for the 'Pagham to East Head Coastal Defence Strategy'. This strategy was the first document to recommend a managed realignment project at Medmerry, a coastal site at the tip of the Manhood peninsula where new defences would be built inland from the existing coastline. This option was initially not well received by the majority of local people. As part of the community response, local representatives were instrumental in raising further awareness and addressing community concerns by organising a second international event involving local people, management authorities and Dutch planning and coastal management experts (Cobbold \& Santema, 2008). In response to the initial public concern, the Environment Agency worked with a large group of concerned local people to form the Medmerry Stakeholder Advisory Group (MStAG), a group of self-elected representatives from among the wider group to represent local views, interact with the project team and report back to the community. In 2008, land was purchased for the realignment. Construction began in October 2011 and was completed in late 2013 (Maplesden et al., 2015).

The managed realignment project was a complex one to implement. Given that the site had environmental and cultural values, particularly for birds, water voles and 
archaeological remains, partnerships had to be created to ensure that habitat and ruins were properly managed. Although the Medmerry scheme would potentially offset coastal squeeze losses elsewhere in the Solent and so help meet England's biodiversity strategy targets, the scheme also had to reduce any habitat impacts that would occur during construction (Maplesden et al., 2015). To assist in decision making on biodiversity issues related to groundnesting birds, reptiles and water voles, a Habitat Creation Working Group was created. A further partnership with the RSPB (Royal Society for the Protection of Birds) helped manage construction during breeding times, particularly for rare birds. Efforts were made to relocate water vole populations and create habitat at the new site. Important Bronze Age settlements were also discovered in the site and were managed in collaboration with the Centre for Applied Archaeology at the University College London.

The project planning and development was governed by three groups: (1) the Core Team, comprised of engineers, environmental scientists and engagement specialists from the UK Environment Agency; (2) the Habitat Creation Group that included Natural England, RSPB, local wildlife groups, academics, local authority officers working with the Environment Agency and consultants; and (3) the Medmerry Stakeholder Advisory Group (MStAG). Before and during construction, the design team adopted a policy of sharing important design decisions with the MStAG, thereby creating a positive flow of information, fostering

\section{Key lessons learned}

Collaboration. The success of this project depended on close collaboration between a wide range of stakeholders which allowed for innovative problem-solving. This collaborative approach included citizens actively engaged in consultations, collaborations between Dutch and English planners, partnerships with environmental organisations and universities, a complementary coastal scheme conducted by the private sector, and an openness on the part of the Environment Agency and all public sector organisations involved to share and work in partnership with others.

Community action and engagement. Empowered local residents can bring about change and initiate action (Scholten \& Keskitalo 2015; Cunningham \& Cobbold 2015). Similarly, engaging with local residents early and often to answer questions and address concerns is critical to carrying out a successful project. Other considerations include using independent facilitation to move difficult conversations forward, involving communities in important decisions during construction, creating an environment of trust, bringing in conservation partners early for site management and design decisions, forming specialist groups to manage complex issues such as habitat management, understanding how archaeological finds may impact construction, and managing construction timelines to account for stakeholder concerns, habitat and species needs and archaeological finds (Maplesden et al., 2015).

Coastal squeeze risk. Coastal squeeze remains an issue for other managed realignment schemes, which can be subject to the same erosion processes as natural coastal wetlands. The contribution of managed realignment to address intertidal habitat loss or biodiversity loss therefore remains debated (Brady, 2015; Foster et al., 2013). In the case of Medmerry, changing dynamics were taken into account and so there is no ongoing concern for the intertidal habitat created at this site. 
local support for the design, and enabling construction to stay on target.

An extensive monitoring programme was established at the project site to track the evolution of the beach, intertidal and habitat areas. The data obtained from this monitoring will inform future coastal and habitat evolution. Monitoring of water voles is undertaken by the University of Brighton on behalf of the Environment Agency and includes engaging with a local wildlife group and volunteers.

\section{Results}

Flood protection. The Medmerry managed realignment scheme has proved successful. The winter of 2013-14 was one of the stormiest and wettest for the UK in the past 50 years. Whereas past storms of this scale in 2008 had caused 6 million GBP in damage, no damage was sustained in 2013-14. In feedback obtained from the MSTaG, the community appears to be happy with the results postproject, both for demonstrably reducing flood risk and for increasing wildlife habitat and tourism.

New wildlife habitat. Intensive monitoring of birds, water voles and fish all show that they are successfully using the new habitat. Continued monitoring is planned and will allow for a greater analysis of species usage of the habitats in the future. Furthermore, the environmental partnership created during the managed realignment project allows the RSPB to manage the site as a bird sanctuary and the site is expected to become part of the Natura 2000 network of European protected areas. Since Medmerry compensates for coastal squeeze, it is considered to be one of the most significant outcomes for conserving intertidal mudflat and saltmarsh habitat (Foster et al., 2016).

Private sector collaboration. Although the realignment scheme could not extend to protect an adjacent holiday park, the park self-funded a complementary scheme that was developed at the same time as the main scheme described here. It was also completed in 2013 (Pearce et al., 2013). As such, a positive collaboration between the public and private sector to protect the coastline was established.

\section{References}

Brady, A. (2015). Managed Realignment for habitat compensation: Contributing to nature conservation or furthering biodiversity loss? England's implementation of Article 6(4) of the EU Wild Birds and Habitats Directives at the coast. Master Thesis Series. Lund University.

Cobbold, C. and Santema, R. Going Dutch on the manhood peninsula. The Manhood Peninsula Partnership. [online book], (2001). www.peninsulapartnership.org.uk/abd/ wp-content/uploads/2012/12/Going-Dutchbook-a.pdf

Cobbold, C. and Santema, R. 'Going Dutch II. Towards a safe and sustainable future of the Manhood Peninsula'. The Manhood Peninsula Partnership 2001 [website], (2008). www.chichester.gov.uk/CHttpHandler. ash $x ? \mathrm{id}=5799 \& \mathrm{p}=0$

Cunningham, J. and Cobbold, C. (2015). How Anglo/Dutch collaboration produced radical long-term integrated coastal planning solutions for a vulnerable peninsula on Britain's south coast. Journal of Coastal Zone Management 18: S1-001.

Foster, N.M., Hudson, M.D, Bray, S. and Nicholls, R.J. (2013). Intertidal mudflat and saltmarsh conservation and sustainable use in the UK: A review. Journal of Environmental Management 126: 96-104.

Foster, N.M., Hudson, M.D, Bray, S. and Nicholls, R.J. (2016). Research, policy and practice for the conservation and sustainable use of intertidal mudflats and saltmarshes in the Solent from 1800 to 2016 . Environmental Science \& Policy 38: 59-71. 
Maplesden, C., Gilham, A. and Callaway, T. (2016). Medmerry Managed Realignment; Changing the Minds and Coast of Sussex - a Case Study. In Baptiste, A. (ed.) Coastal Management: changing coast, changing climate, changing needs, pp. 283-292. ICE Publishing.

Morris, R.K.A. (2013). Managed realignment as a tool for compensatory habitat creation: a reappraisal. Ocean and Coastal Management 73: 82-91.

Pearce, J., Khan, S. and Lewis, P. (2011). Medmerry managed realignment-sustainable coastal management to gain multiple benefits. ICE Coastal Management. In Schofield, A. (ed.) Innovative Coastal Zone Management: Sustainable Engineering for a Dynamic Coast. ICE Publishing.

Scholten, P., Keskitalo, E.C.H. and Meijerink, S. (2015). Bottom-up initiatives toward climate change adaptation in cases in the Netherlands and the UK: a complexity leadership perspective. Environment and
Planning C: Government and Policy 33: 1024-1038.

Thomas, K. (2014). Managed Realignment in the UK: The Role of the Environment Agency. In Esteves, L.S. (ed.) Managed realignment: a viable long-term coastal management strategy?, pp. 83-94. Springer Netherlands.

Temmerman, S., Meire, P., Bouma, T.J., Herman, P.M.J., Ysebaert, T. and de Vriend, H.J. (2013). Ecosystem-based coastal defence in the face of global change. Nature 504: 79-83.

Turner, R.K., Burgess, D., Hadley, D., Coombes, E. and Jackson, N. (2007). A cost-benefit appraisal of coastal managed realignment policy. Global Environmental Change 17: 397-407.

Woodruff, J.D., Irish, J.L. and Camargo, S.J. (2013). Coastal flooding by tropical cyclones and sea-level rise. Nature 504: 44-52. 


\section{Case Study 4}

\section{Rwanda: Forest Landscape Restoration as a national priority}

Charles KARANGWA, Forest Landscape Restoration Hub, IUCN Eastern and Southern Africa, Kigali, Rwanda (Charles.KARANGWA@iucn.org)

\section{RWANDA}
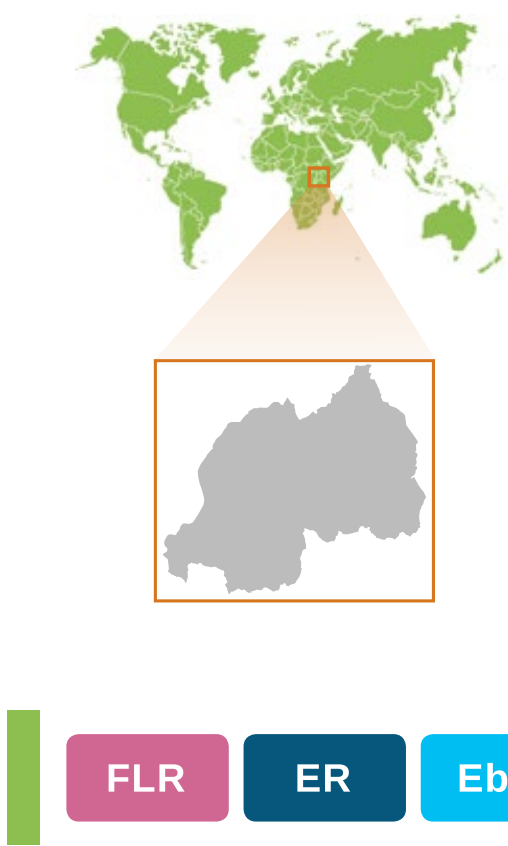

\section{FLR}

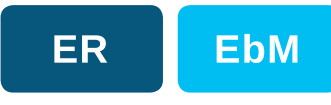

(
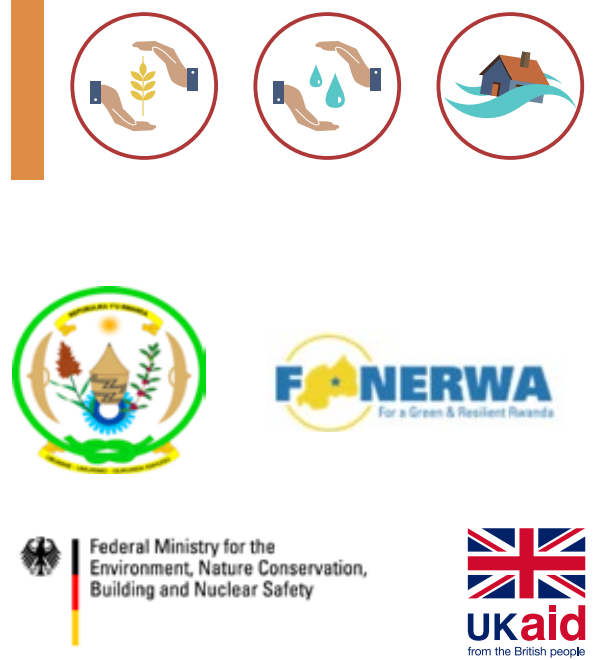

姆

NORWEGIAN MINISTRY OF NORWEGIAN MINISTRY OF
CLIMATE AND ENVIRONMENT

\section{General background}

Forests provide many ecosystem services such as supplying clean water, food and wood, reducing erosion and sequestering carbon; these services are important for the economies of many communities, including those in Rwanda. Most of Rwanda's population relies on subsistence agriculture for their livelihoods, and on wood as their main source of energy production (Ministry of Natural Resources, 2014). One of the primary challenges facing Rwanda is the management of its existing resources to meet the needs of an increasing population. Between 2002 and 2012, the country's population increased from 8.1 to 10.5 million people, making Rwanda Africa's most densely populated country (MINECOFIN, 2013). High population growth has put strong pressure on Rwanda's forest ecosystems, with natural forests being increasingly converted to agricultural land and small woodlots being overexploited for fuel wood. Alongside these problems, the country's forest plantations are becoming less productive (as most of them are at the end of their productive life) and are potentially vulnerable to pest and disease outbreaks, as they are largely dominated by a few species of Eucalyptus (Ministry of Natural Resources, 2014).

Although earlier efforts were made to restore degraded forests, the 1994 Rwandan genocide halted all such activities (Ministry of Forestry and Mines, 2010b). It was not until the mid-2000s that sustainable management was reinstated. The successful restoration of the Rugezi wetlands initiated in 2004 is a good example of a Naturebased Solution, providing a reference point for the use of ecosystem restoration to address societal challenges. The restoration of these wetlands and the surrounding watershed not only brought important livelihood benefits to local communities, but also enabled the Ntaruka hydropower station to return to full operational capacity after a steep decline in power generation, thereby easing what had been a national energy crisis for Rwanda (Hove et al., 2011). 


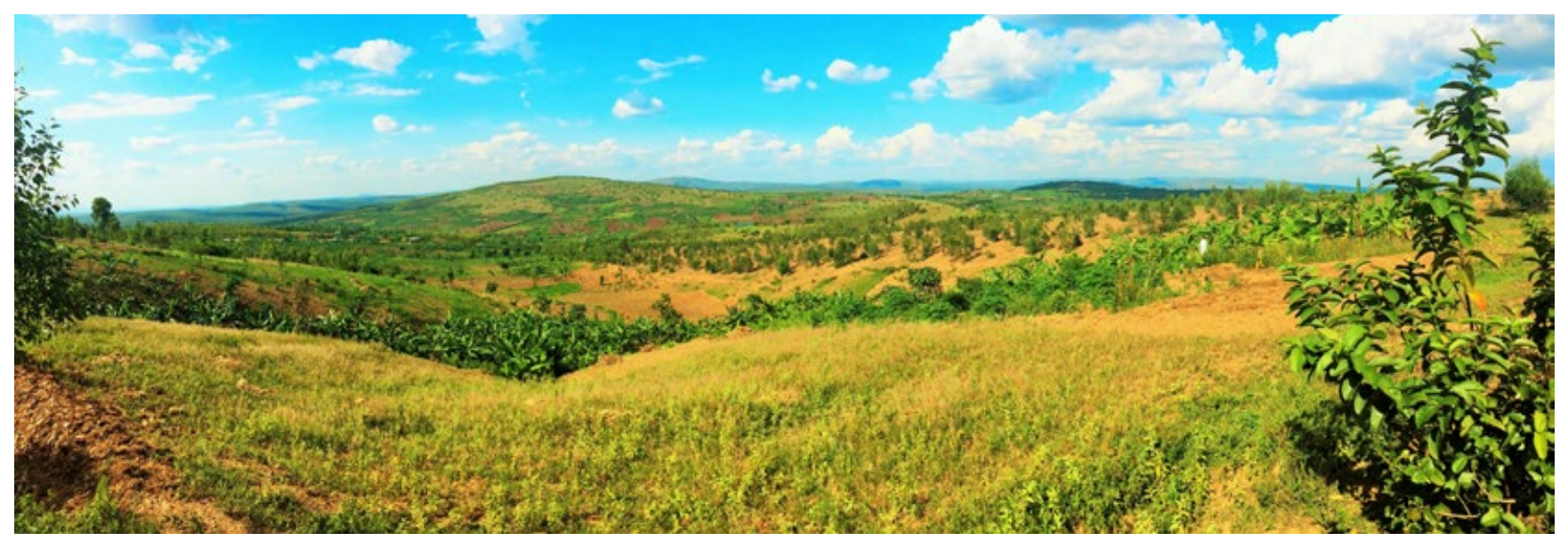

Forest Landscape Restoration site in Gatsiibo District, northeast Rwanda - Photo credit: Craig Beatty

\section{Main activities}

Enabling national policies. Several national policies have been very important in driving the forest landscape restoration work in Rwanda. The National Forest Policy, first established in 2004 and updated in 2010, promotes sustainable management, stakeholder involvement in decision-making, agroforestry on agricultural land, and protection of endangered species (Ministry of Forestry and Mines, 2010a). The updated version also includes a new 30\% national forest cover target to be achieved by 2020 (Ministry of Forestry and Mines, 2010a). Recognising the important role forestry plays in contributing to the GDP, the Economic Development and Poverty Reduction Strategy (EDPRS) advocates for the protection and maintenance of $10 \%$ of existing natural forests and reduction of wood energy consumption from $86 \%$ to $50 \%$ by 2020 (Ministry of Natural Resources, 2014). Rwanda's Vision 2020 policy for development was updated in 2012 to include the $30 \%$ reforestation target. Although forest cover has increased since these policies were put in place, only about $38 \%$ of it is natural forest (Ministry of Natural Resources, 2014).

The increased commitment to these reforestation targets has been motivated in part by Rwanda's commitment to the Bonn Challenge, a global forest restoration effort launched in 2011. Rwanda's pledge to restore two million hectares of degraded and deforested land aims to "restore forest landscapes to improve ecosystem quality and resilience, provide new opportunities for rural livelihoods, while securing adequate water and energy supplies and supporting low carbon economic development" (Ministry of National Resources, 2014, p. 1). The pledge built on existing commitments made by Rwanda and provided the motivation for the government to take the next step in conducting a countrywide restoration opportunity assessment.

\section{Launching Forest Landscape Restoration strategies. The Rwanda Natural Resources} Authority (RNRA), within the Ministry of Natural Resources (MINIRENA), used the Restoration Opportunity Assessment Methodology (ROAM) with support from IUCN and the World Resources Institute (WRI) to determine those areas and landscapes most in need of restoration (IUCN \& WRI, 2014), where benefits would be most immediate, and success most likely (Ministry of Natural Resources, 2014). The results of the national assessment provide a conceptual framework for decision-making on forest landscape restoration (FLR) at a national scale. They present a general overview of the opportunities available, as well as guidelines for action to deliver the Bonn commitment and the Vision 2020 and EDPRS targets.

The ROAM assessment followed a collaborative and iterative process. Not only was the project a collaborative effort between IUCN, WRI and the RNRA, but analyses were presented to district- 
level and national stakeholders for input and feedback before the final report was released in 2014 (Ministry of Natural Resources, 2014). Since the ROAM study built on existing policies and targets, it was able to gain support within cabinet from other Ministries. In 2015, the ROAM assessment was officially launched by the Government of Rwanda, which committed to implementing the five recommendations of the report: (1) improve coordination among government agencies, (2) improve delivery of high quality planting stock, (3) put in place conditions to increase demand for products from FLR, (4) prioritise FLR projects; and (5) improve financing resources for FLR (Ministry of Natural Resources, 2014).

\section{Results}

ROAM results. Rwanda currently has about $29 \%$ forest cover (Ministry of Natural Resources, 2014). The ROAM analysis indicates that approximately 2.5 million hectares of land and freshwater resources could directly benefit from FLR in terms of improved productivity, quality and functionality of forest ecosystems (Ministry of Natural Resources, 2014). Five types of intervention were identified: targeting agroforestry on both flat and sloping land, improving silviculture and rehabilitating managed woodlots, protecting and restoring existing natural forests, and establishing protective forests on steep sloping land and in riparian zones (Ministry of Natural Resources, 2014).

The main challenges involved in achieving the restoration objectives include: insufficient shared vision and coordination among ministries and agencies on the role of FLR in delivering national priorities; limited availability of quality tree seed and production of planting stock; significant gaps in knowledge and technical capacity on basic restoration approaches; lack of awareness and understanding of FLR among farmers, particularly on native species; and lack of emphasis on the potential role of the private sector (opportunities and models for publicprivate finance) (Ministry of Natural Resources, 2014).
Implementation of ROAM recommendations. Institutional changes and restoration projects have been put into place in response to the ROAM recommendations. For example, a Joint Sector Working Group was established to improve coordination between different government agencies and between the government, NGOs and international technical agencies (Clear Horizon Consulting, 2015).

To address the issue of tree seed availability, responsibility for the management of the national Tree Seed Centre was transferred from the Ministry of Agriculture to MINIRENA, since the latter is better able to expand and improve the seed stock. The Centre is responsible for the collection, preservation, certification and distribution of tree germplasm for agroforestry, reforestation and other tree planting programmes for Rwanda and other areas in the highland region of East Africa (Mugungu et al., 1996). IUCN worked with MINIRENA to develop a tree seed strategy in Rwanda which is now in its final stage. This strategy addresses the issues related to seed research, seed availability and management of the supply chain, as well as seed management infrastructure.

Two restoration projects were started in 2015: (1) RNRA is working with IUCN to determine carbon stocks and other ecosystem services in two Rwandan districts (East and North) and to implement restoration of degraded areas of about 18000 ha (Gatsibo and Gicumbi Districts) (Clear Horizon Consulting, 2015). This restoration project will generate employment for about 60,000 people, $70 \%$ of which are women; sequester 1,099,500 tonnes of CO2e; and increase crop productivity by $18 \%$ through agroforestry initiatives. (2) a World Bank-funded project, the Landscape Approach to Forest Restoration and Conservation (LAFREC), has been set up as a demonstration of landscape management for enhanced environmental services and climate resilience in the GishwatiMukura corridor of north-western Rwanda (World Bank, 2016). Goals of the project include increasing the number and diversity of trees to 
improve soil fertility, stabilize slopes, regulate stream flow and expand the resource base for local livelihoods (World Bank, 2014). The project also hopes to improve agricultural production through sustainable land management and agroforestry, improve flood forecasting and preparedness, and implement terracing to prevent land erosion (World Bank, 2014).

\section{In 2016, IUCN in partnership with the} government of Rwanda launched a Regional Hub on Forest Landscape Restoration that provides technical and policy support to countries in eastern and southern Africa. The hub is hosted by the government of Rwanda and focuses on innovation and accelerating restoration.

\section{Restoration financing opportunities.}

Government funding levels are not adequate to meet Rwanda's goal of reforesting two million hectares of trees. New sources of funding are therefore required. In 2013, the Government of Rwanda established the National Climate and
Environment Fund (FONERWA) as a primary financing mechanism for public and private environmental projects that have the potential to significantly contribute to Rwanda's climateresilient development needs. The centralised funding ensures that initiatives are consistent with national priorities and targets for FLR (FONERWA, n.d.). The private sector can apply for funding either through financing (they are required to provide $25 \%$ equity) or through a line of credit from the Rwandan Development Bank (Global Landscapes Forum, 2016). To date, eight calls for proposals have been completed, and funds have been granted to 31 projects (Global Landscapes Forum, 2016). Projects include integrated watershed management (involving FLR), alternative energy production, and development of green villages. This financing mechanism was established independently of the ROAM process, but is critical for guiding and prioritising FLR investment, and stimulating and supporting FLR activities. While there is still a gap between money holders and smallholder

\section{Key lessons learned}

Role of champions. The most important factor in gaining support for ROAM and FLR within the cabinet has been the presence of champions within government who have provided direction, technical expertise and institutional linkages.

National context. Framing of the ROAM assessment within a national context (i.e. building on existing policies) was critical to the adoption of the report by the Government of Rwanda.

Collaboration. Coordination among government agencies is needed for FLR implementation so that ministries work together to collaborate with the private sector and civil society. The identification of knowledge uptake pathways is also very important.

Economic considerations. In order to increase the demand for trees and products from FLR, support needs to be given to farmers to improve the return they receive from restoration activities and to make them aware of the benefits they can receive from FLR. In addition, a full range of opportunities, options and models for unlocking finances should be identified to support FLR activities.

Pilot activities. Early application of FLR in selected landscapes should be prioritised and supported to test how FLR interventions can be most effective through existing or planned initiatives. 
farmers, IUCN is working with the Fund to develop financing mechanisms and instruments to bridge this gap.

\section{Acknowledgements}

Government of Rwanda with special thanks to Minister Hon. Dr Vincent Biruta for his leadership and high-level support of the Forest Landscape Restoration movement; German Ministry for the Environment, Nature Conservation, Building and Nuclear Safety, for a financial contribution; UK Aid, for a financial contribution; Norwegian Ministry of Climate and Environment; FONERWA, for their collaboration and support.

\section{References}

Clear Horizon Consulting. (2015). Rwandan Forest Landscape Restoration Opportunity Assessment: Tracing the Influence. Prepared for IUCN.

FONERWA. What is Rwanda's Green Fund? [website], (n.d.). www.fonerwa.org/about/. Accessed 27 June 2016.

\section{Global Landscapes Forum. Removing barriers} for investing in forest landscape restoration. White Paper, 6 June 2016, Royal Society, London. [online report], (2016, June 6). www.landscapes.org/publication/removingbarriers-investing-forest-landscaperestoration-works/. Accessed 23 June 2016.

Hove, H., Parry, J-E. and Lujara, N. 'Maintenance of hydropower potential in Rwanda through ecosystem restoration'. World Resources Report, Washington DC [online report], (2011). www.wri.org/sites/ default/files/wrr_case_study_ecosystem_ restoration_rwanda.pdf. Accessed 22 June 2016.

IUCN and WRI (2014). A guide to the Restoration Opportunities Assessment Methodology (ROAM): Assessing forest landscape restoration opportunities at the national or sub-national level. Working Paper (Road-test edition). Gland, Switzerland: IUCN.
Ministry of Finance and Economic Planning (MINECOFIN). Economic Development and Poverty Reduction Strategy II [online report], (2013). www.rdb.rw/uploads/tx sbdownloader/EDPRS_2_Main_Document. pdf. Accessed 5 July 2016.

Ministry of Forestry and Mines. National Forest Policy [online report], (2010a). www.faolex. fao.org/docs/pdf/rwa149689.pdf. Accessed 5 July 2016.

Ministry of Forestry and Mines. Strategic Plan for the Forest Sector 2009-2012 [online report], (2010b). www.faolex.fao.org/docs/ pdf/rwa148251.pdf. Accessed 5 July 2016.

Ministry of Natural Resources. (2014). Forest Landscape Restoration Opportunity Assessment for Rwanda. MINIRENA (Rwanda), IUCN, WRI. viii + 51pp.

Mugungu, C., Atta-Krah, K., Niang, A. and Boland, D. 'Rebuilding the Rwandan Tree Seed Centre - Seeds of Hope Project'. Forest Genetic Resources n.24, Food and Agriculture Organization of the United Nations [online report], (1996).

www.fao.org/docrep/008/w3354e/W3354E17. htm. Accessed 5 July 2016.

World Bank. Landscape approach to forest restoration and conservation (LAFREC) [website], (2016). www.worldbank.org/ projects/P131464/landscape-approachforest-restoration-conservationlafrec?lang=en. Accessed 27 June 2016.

World Bank. Rwanda: World Bank to Support Forest Restoration and Conservation [online article], (2014, August 27). www.worldbank. org/en/news/press-release/2014/08/27/ rwanda-world-bank-to-support-forestrestoration-and-conservation. Accessed 22 June 2016. 


\title{
Case Study 5
}

\section{Ecuador: One landowner's approach to forest restoration and sustainable management}

\author{
Hugo CERDA, ESPOCH, Riobamba, Ecuador (hugocerda04@gmail.com) \\ Brian MCLAREN, ESPOCH, Riobamba, Ecuador
}

\section{ECUADOR}
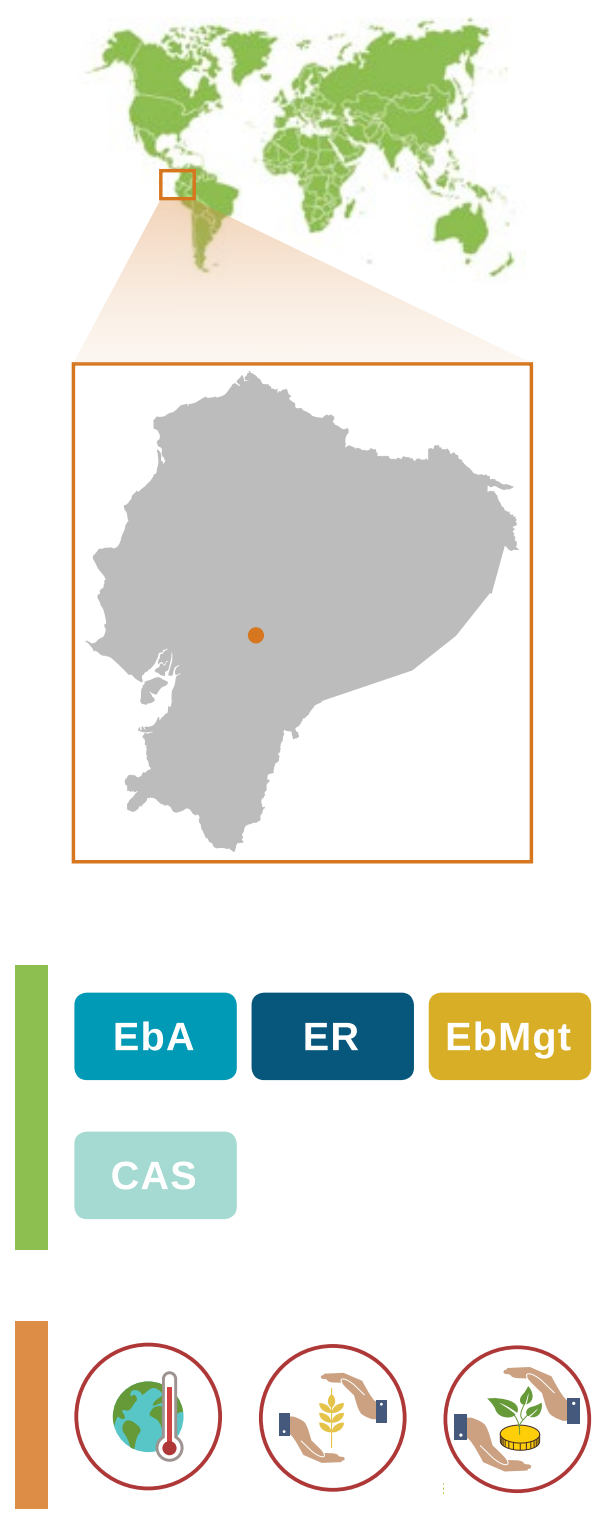

\section{General background}

Ecuador has one of the highest deforestation rates in South America (Blaser et al., 2011). Between 1990 and 2015, the country's forest cover was lost at an annual rate of about $0.6 \%$, due to expansion of agriculture (cropland and pastures), oil exploration, logging, mining as well as insecure land tenure, and weak public institutions (Blaser et al., 2011; FAO, 2015; REDD desk, 2016). Illegal and informal timber harvesting is widespread throughout the country. Furthermore, Ecuador is highly vulnerable to climate change, due to its economic reliance on resources that are affected by climate change, especially in its high-altitude ecosystems (including forests) (Blaser et al., 2011). Forest resources are especially important for those living in rural areas, many of whom rely on these resources for their livelihoods (e.g. timber products, hunting, land reserve for conversion to agriculture). Although Ecuador's overall poverty rate has declined from $37.6 \%$ in 2006 to $23.3 \%$ in 2015 , rural poverty rose in 2015 to $39.3 \%$ (World Bank, 2016). Rural smallholder farmers have limited access to credit, markets and technology, and are strongly impacted by degradation of ecosystems and the effects of climate change (IFAD, n.d.).

To combat deforestation and invest in social and economic development, the government of Ecuador developed various policies and pieces of legislation, including its National Plan for Good Living (Buen Vivir), which set a target of a $30 \%$ reduction rate in deforestation, recognized the rights of nature and the state's role in conservation, and promoted the sustainable use and restoration of fragile ecosystems (National Secretariat, 2010; 2013). In 2008, the Ministry of Environment also launched its SocioBosque programme which provides economic incentives to landowners who decide to protect their forests (Blaser et al., 2011). However, sustainable forestry laws and regulations are often contradictory and enforcement is weak, making implementation of sustainable practices less effective (Blaser et al., 2011). 


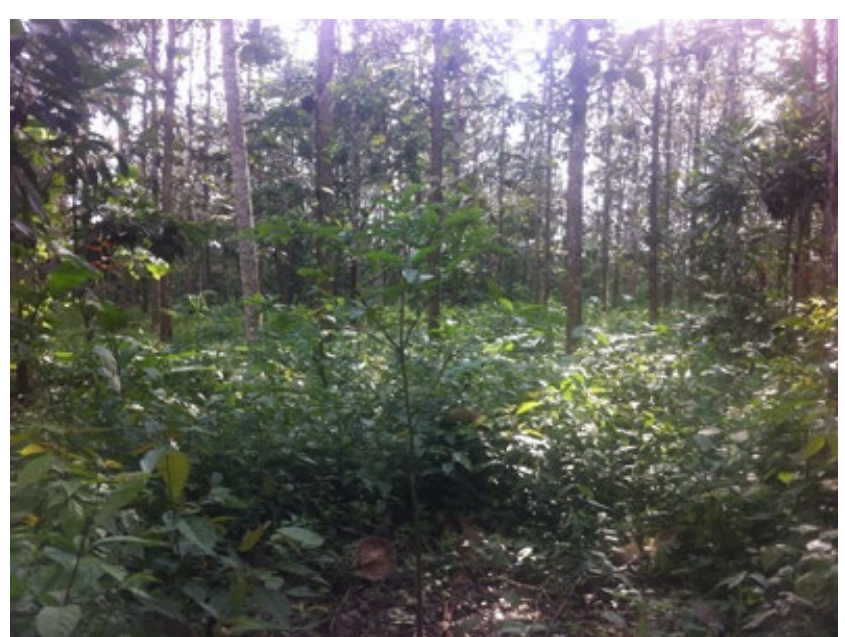

Two plots in an 'analogue forest' - Photo credit: Liette Vasseur

This case study describes how, with no external funding, one private landowner succeeded in restoring a 10-hectare area of forest in order to provide a sustainable source of income for his family and improve the resilience of this forest land to climate change impacts. Beginning in 2000, in the village of Buenos Aires (in the Province of Chimborazo), Mr. Manuel Ramon developed an 'analogue forest' from a disturbed and deforested area on his holding. Analogue forestry "uses natural forests as guides to create ecologically stable and socio-economically productive landscapes", and considers adaptation to, and mitigation of climate change (IAFN, 2016). After realizing that many timber species and the forest's ecosystem services were endangered, Mr. Ramon (having previously worked as a logger) became a sustainable forest manager to restore these species and ecosystem services.

\section{Main activities}

With limited knowledge and experience and through trial and error, the landowner discovered profitable and sustainable forest management techniques. The forest in Chimborazo is a humid tropical forest, with a great diversity of species.

Restoration. Instead of planting monocultures, Mr. Ramon created ecological associations between mahogany (Swietenia macrophylla) and Ecuador laurel (Cordia alliodora), and between

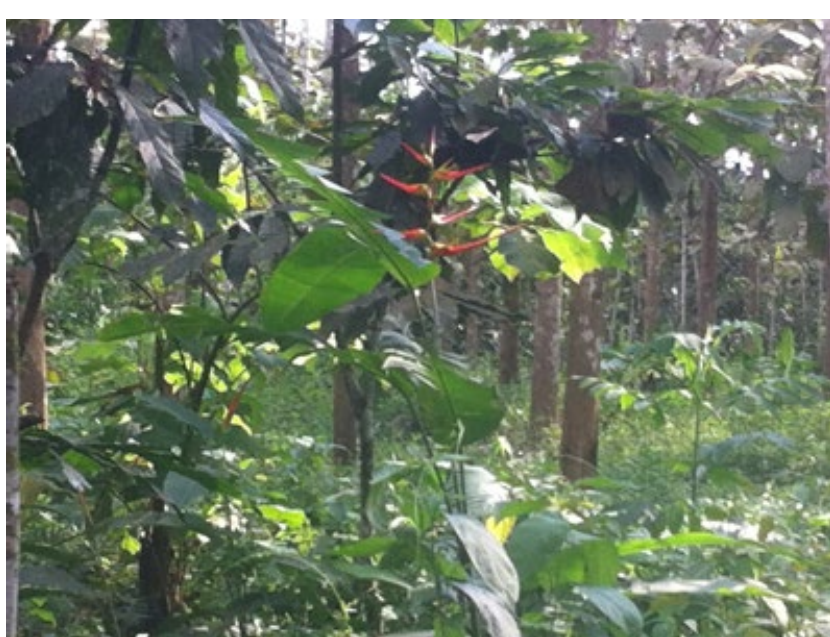

the Brazilian fire tree (Schizolobium parahybum), teak (Tectona grandis), mahogany, and Ecuador laurel. He used a number of ecological restoration techniques to improve soil moisture and fertility. He took note of optimal planting distances and planting times and observed the processes of ecological succession in the forest, identifying those species that did not adapt to the local ecosystem. In this way, he developed his own set of best practices for reforestation, climate adaptation and resilience.

Economic development. Not only did the landowner use his forest resources for subsistence, but he also identified the tree species that produced good quality commercial timber (e.g. for furniture making or cabin construction) and sold the wood to generate income. He collected the best seeds from the best trees and cultivated them in a nursery, transplanting the saplings in the forest to replace the harvested trees. Given the profitability of the forest, he was able to hire three employees for silvicultural work, thereby generating income for others in the community.

Collaboration and knowledge sharing. Mr. Ramon's formal engagement with government agencies began in August 2012, when the Chimborazo Ministry of Environment's Forestry Office of the Provincial Authority helped trace and classify the harvested wood to signify 


\section{Key lessons learned}

Individual commitment. This restoration succeeded due to the inspiration and innovation of one individual, his recognition of the value of natural resources and commitment to conservation.

Income generation. Conservation actions must be coupled with income in order to generate activities for long-term sustainability.

its legality. The Ministry also helped him establish scientific and educational tourism by determining the taxonomy and identification of seed trees, creating signage for the trees, and designing tourist trails. Domestic and international researchers have visited the forest to learn more about these forest conservation techniques.

\section{Results}

Environmental benefits. A resilient analogue forest has been established, which provides multiple ecosystem services to people, including a cooler climate, a refuge for fauna (reptiles, bats, birds, armadillos), retention of soil moisture via the accumulation of organic matter, recycled nutrients, pollination via the presence of bees, seed dispersal, and regulation of the hydrological cycle. Additionally, pest outbreaks are regulated and carbon is captured.

Livelihood benefits. Additional food sources, such as oranges, are generated. The forest also produces material for construction, good quality furniture as well as bi-products such as firewood and sawdust. Medicinal herbs and organic cacao can also be used by this family and sold to others. Finally, the beautiful forest environment also enhances health and wellbeing.

Biodiversity benefits. Over 15 forest species have been used in the reforestation, including the Black Manwood (Minquartia guianensis), mahogany (Swietenia macrophylla), cedar (Cedrela odorata), and Simira cordifolia, which were endangered.

\section{Policy alignment and institutional}

partnerships. The analogue forest contributes to Objective 7 of the Plan de Buen Vivir 20132017, which aims to "guarantee the rights of nature and promote environmental sustainability globally" (National Secretariat, 2013, p. 69). It also complies with the National Climate Change Strategy 2012-2025, and the National Forest Restoration Plan 2014-2017 (Ministerio del Ambiente, 2014). In addition to the Ministry's involvement in the initiative, the Polytechnic University of Chimborazo has also begun to participate through researchers' and students' work in the analogue forest.

Long-term impacts and expected results. It is hoped that this model will be replicated across Ecuador and that it will become widely adopted as a Nature-based Solution to address climate change adaptation and mitigation as well as poverty alleviation.

\section{Acknowledgements}

Manuel RAMÓN; Lady Abigail QUITO; Marcelo PINO, Director Provincial del Ministerio del Ambiente de Chimborazo; Alberto Paul CASTELO, Director Patrimonio Natural de Chimborazo.

\section{References}

Blaser, J., Sarre, A., Poore, D. and Johnson, S. (2011). Status of tropical forest management 2011. ITTO Technical Series No 38. International Tropical Timber Organization, Yokohama, Japan. 
FAO (Food and Agriculture Organization of the United Nations). Global Forest Resources Assessment 2015 [online report], (2015). www.fao.org/3/a-i4808e.pdf. Accessed 18 July 2016.

International Analog Forestry Network (IAFN). Analog Forestry [website], (2016). www. analogforestry.org/about-us/analog-forestry/. Accessed 18 July 2016.

IFAD (International Fund for Agricultural Development), United Nations. Rural poverty in Ecuador [website], (n.d.). www. ruralpovertyportal.org/country/home/tags/ ecuador. Accessed 19 July 2016.

Ministerio del Ambiente. Plan Nacional de Restauración Forestal 2014-2017 [online report], (2014). www.sociobosque.ambiente. gob.ec/files/images/articulos/archivos/ amrPlanRF.pdf. Accessed 19 July 2016. (In Spanish).

National Secretariat of Planning and Development. National Plan for Good Living, 2009-2013: Building a Plurinational and
Intercultural State. Summarized Version [online report], (2010). www.unosd.org/ content/documents/96National\%20Plan\%20 for\%20Good\%20Living\%20Ecuador.pdf. Accessed 19 July 2016.

National Secretariat of Planning and Development. National Plan for Good Living, 2013-2017. Summarized Version [online report], (2013). www.planificacion.gob.ec/ wp-content/uploads/downloads/2013/12/ Buen-Vivir-ingles-web-final-completo.pdf. Accessed 19 July 2016.

The REDD desk. REDD in Ecuador [website], (2016). www.theredddesk.org/countries/ ecuador. Accessed 18 July 2016.

World Bank. Ecuador Overview [website], (2016). www.worldbank.org/en/country/ecuador/ overview. Accessed 18 July 2016. 


\section{Case Study 6}

\section{Jordan: Securing rights and restoring lands for improved livelihoods}

Fidaa F. HADDAD, IUCN-Regional Office for West Asia, Amman, Jordan (fida.haddad@iucn.org)

\section{JORDAN}
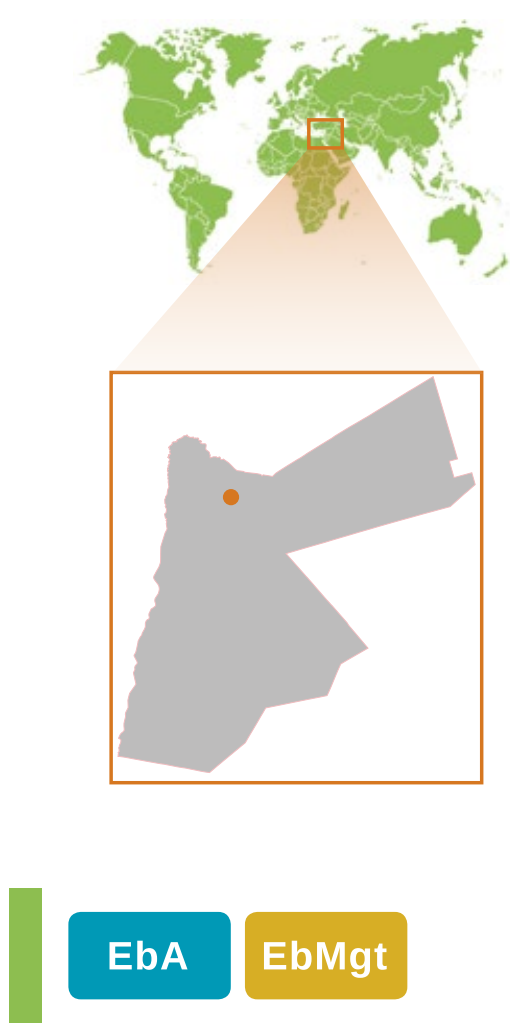

\section{EbA EbMgt}
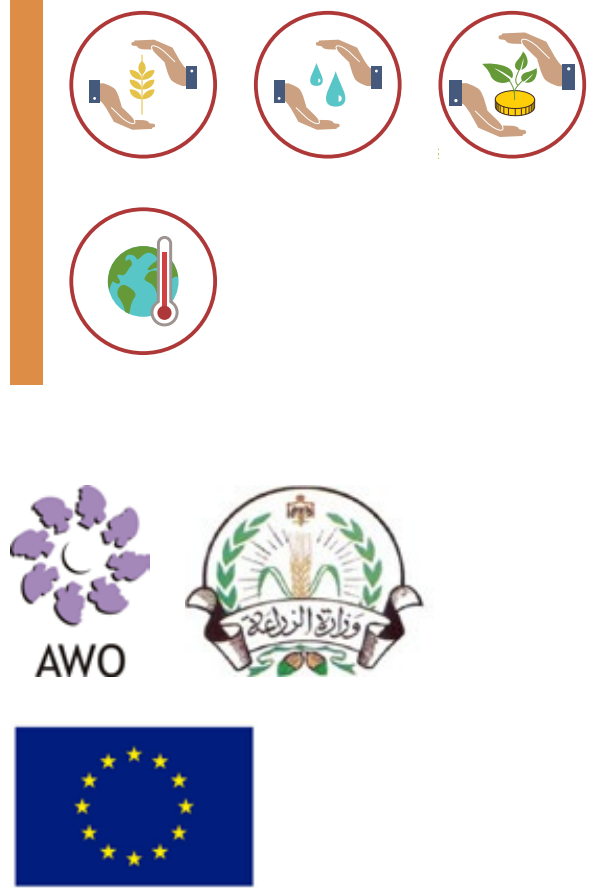

\section{General background}

The Zarqa river basin in northern Jordan, where about half of the country's population live, has seen severe land degradation, which has in turn resulted in high levels of poverty and unemployment. The biodiversity loss, landuse changes and ground water extraction can be traced to unsustainable development and mismanagement of natural resources (Haddad, 2014). Grazing land is now very scarce and range management for grazing has become a marginal activity (Haddad, 2014). The contribution of natural rangelands to livestock feeding in Jordan has decreased from $85 \%$ in the 1950 s to less than $10 \%$ in 2011 (Haddad, 2014). Livelihood strategies have shifted to high-intensity agriculture - including poultry, cattle and irrigated crop production - which now uses most of the available water resources (Haddad, 2014). In addition, the region is subject to desertification and unpredictable precipitation, further increasing the pressures on the ecosystems and people of the river basin (Hima Management Committee, 2012). A number of factors have contributed to the overexploitation of the natural resources, including insecure and contested land tenure, the departure from tribal land ownership to private ownership, and the introduction of government subsidies for dry season cropping. These trends have reduced the incentives for farmers to practice sustainable resource management and encouraged overstocking and overgrazing of the rangelands (Haddad, 2014).

Traditionally, land management followed the Hima ('community conserved area') system. Used by the Bedouin tribes since ancient times, this grazing system seasonally sets aside heavily grazed rangeland for regeneration and recovery. Tribes wandered across political borders, migrating through Jordan, Syria, Saudi Arabia and areas around the Iraqi borders to allow for this regeneration (Ministry of Agriculture, 2013). Sites were thus governed and managed by a particular village, clan or tribe through consensus rather than through legislation or institutional control (Haddad, 2014; Hima Management Committee, 2012). However, this traditional grazing system has declined over the years, and 


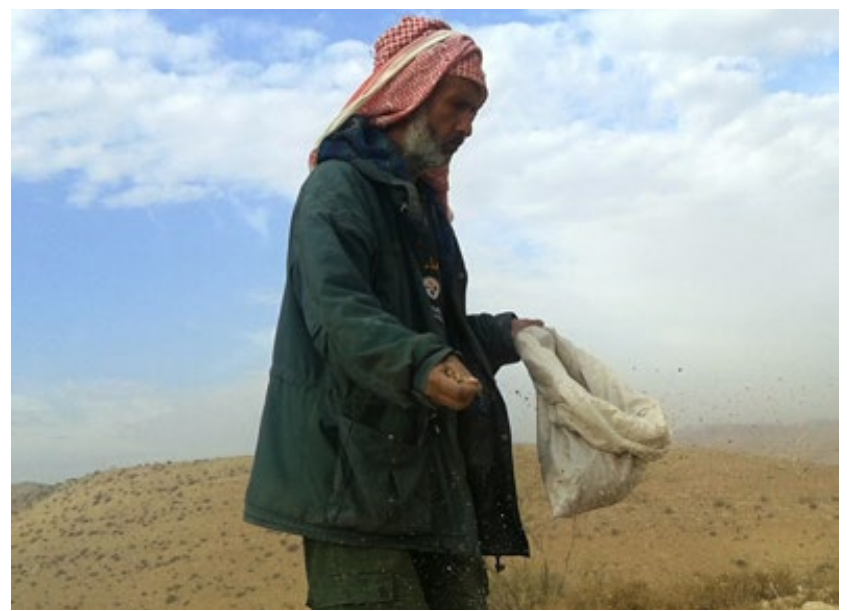

Planting native vegetation - Photo credit: IUCN ROWA

Bedouins in Jordan now live permanently within the country's borders (Ministry of Agriculture, 2013). The revival of Hima is seen as a means to strengthen local community capacities and customary laws, to protect and manage land resources for social economic growth and conservation of natural resources in the Zarqa River Basin (Haddad, 2014).

\section{Main activities}

In collaboration with the Ministry of Agriculture and the Arab Women Organization (AWO) in Jordan, the IUCN Regional Office for Western Asia implemented a four-year project to sustainably restore and manage dryland/ rangeland ecosystems in the Zarqa River Basin as a Nature-based Solution to address poverty reduction and biodiversity protection (IUCN, 2012g). The objectives of the project included securing the rights to private and common ecosystem services (with special attention to women and vulnerable groups), creating economic and income generating options for rural communities, and influencing policies at all scales (IUCN, 2012a).

Stakeholder dialogue and a participatory management cycle were used to develop and implement a series of action plans.

These approaches brought together national, regional and community levels of society to determine how to work together to address local issues of shared concern. They also provided the framework for discussions and

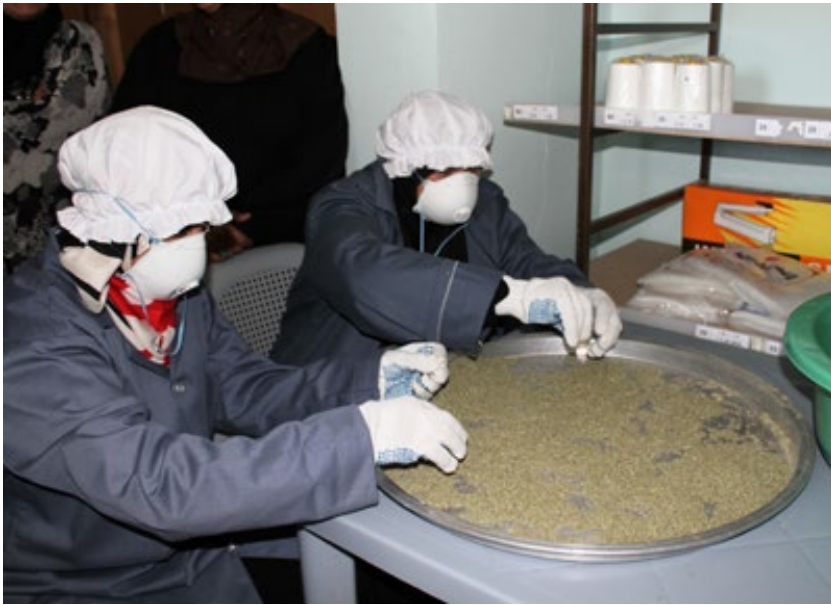

Processing medicinal herbs - Photo credit: IUCN ROWA

implementation of outcomes (Local Dry Lands Resources, 2012). In this way, the needs of local communities were integrated with the objectives of the local governorate and natural resources ministries, and location-specific, long-term land management visions and strategies were developed for combating desertification (Local Dry Lands Resources, 2012). Through this process the Hima system was defined as "representing a simple, practical, and resourceful approach to [...] activate the power of change at the local level, and empower people to make local initiatives that can help themselves and the government to raise their living standards and take control of their land resources" (Haddad, 2014, p11). Although the Hima system is implemented on a smaller scale than in the past, this project employs grazing plans and designates land to be used solely for rangeland management (i.e. not for crop production) to mimic traditional practices.

\section{Results}

Baseline studies. An environmental economic valuation of the rangelands in Jordan was conducted to help decision makers implement the Hima concept. The total value of natural pastures in Jordan was estimated to be approximately US\$192 million and the total economic losses incurred between 1990 and 2011 from grazing-related land degradation was calculated to be over US\$ 1 billion (IUCN, 2012b). A baseline study was also conducted outlining local resource and land tenure 
rights, dryland degradation, legal and policy frameworks, and stakeholder and governance issues (Badia Research Program, 2011).

\section{Conservation and management. Through} government approval and the transfer of management rights to communities in the project area, land was allocated by the government as Hima rangelands to the communities (Haddad, 2014; IUCN, 2012c; 2012d; 2012e). Various government and community partnerships thus emerged in support of sustainable rangeland management.

For example, in Bani-Hashem community an official Tribal Charter was drafted that included the restoration of indigenous plants (IUNC, 2012g). Another community, named Halabat, worked with the Ministry of Tourism and Antiquities to revive sustainable rangeland management and cultivation practices, and livestock grazing (Haddad, 2014; IUCN, 2012d).
Capacity building. Capacity building workshops focused on rangeland strategy preparation and management, lobbying and negotiating with higher-level decision makers, gender mainstreaming, and financial, administrative, and communication skills development (IUCN, 2012c; IUCN, 2012f). Exchange visits between local community members and NGOs took place to share accomplishments, lessons learned and challenges of similar projects in Jordan. In BaniHashem, government ministries trained local people to identify indigenous and economically beneficial plants and to evaluate land restoration, after two years of community-based protection (IUCN, 2012d; 2013a).

Awareness and education. In 2012, the Ministry of Agriculture, in collaboration with Jordan Television, created a TV programme to disseminate the idea of revitalising the Hima

\section{Key lessons learned}

Requirements for participatory approach. A participatory approach was fundamental to involving local people in the decision-making process and helping define roles and responsibilities of the local community. However, this cannot be achieved unless suitable skills are acquired (e.g. negotiation, appreciation of information, acceptance of others, patience, understanding of local customs and power relations). Good facilitation skills, as well as trust and respect, are required to build links between stakeholders.

Information sharing. Exchange of information is needed to build capacities in planning and implementation of project actions, so that communities are involved in decision making and can take the lead.

Partnerships. Achievement of real and lasting benefits is not something that can easily be achieved by one agency operating alone. There is a need for new and innovative partnerships including government, civil society, the private sector and donor agencies. A particular emphasis on the involvement of community-based organisations allows these groups to have more authority and empowerment, and thus a more effective role in the community.

Conditions for developing economic opportunities. Several challenges must be addressed to ensure success of new marketing endeavours, such as the revision of legislation and procedures for infrastructure specifications and standards, and the need for marketing and sales skills within the local community (IUCN, 2012a). 
system (IUCN, 2012e; IUCN, 2013b). Other awareness raising campaigns promoted the value of natural resources and the benefits of alternative livelihood opportunities (IUCN, 2012f). Participatory video tools documented local messages for decision makers regarding challenges and solutions in reviving drylands and managing rangelands.

Income generation. A revolving fund was established at two of the sites to offer loans for income-generating projects to improve community livelihoods (IUCN, 2012e; 2013c). Employment opportunities were created for Hima participants, as technical veterinarians or assistants (IUCN, 2013b). In Bani-Hashem, a marketing study identified several microenterprise development opportunities, such as in the spice market (IUCN, 2012a). Local women were hired to organise the collection, drying and packaging of indigenous medicinal herbs, providing additional income for their families (IUCN, 2013b; IUCN, 2013c).

Policy initiative. In 2013, the National

Rangeland Strategy of the Ministry of Agriculture was updated to incorporate the Hima concept as a basic approach in the governance of Jordan's rangelands (Ministry of Agriculture, 2013). The strategy was launched in 2014 at the Regional Hima Forum under the patronage of $\mathrm{HRH}$ Prince Hassan. HRH Prince Hassan also endorsed the Amman Declaration on Innovating Hima for the regional up scaling of the Hima system (Al Hima, 2014).

\section{Acknowledgements}

The project is a result of the cooperation of IUCN, the Ministry of Agriculture, the Ministry of Environment, and the Arab Women Organization. We are especially grateful to Dr. Radi Al-Tarawneh, Secretary General of the Ministry of Agriculture and the rangeland department for the leadership and insights on updating the Jordanian rangelands strategy.

\section{References}

Al Hima: Possibilities are Endless Conference. The Amman Declaration on Innovating Hima - May 2014 [online report], (2014). www. cmsdata.iucn.org/downloads/the_amman_ declaration_on_innovating_hima_signed_by_ hrh.pdf. Accessed 8 February 2016.

Badia Research Program, National Centre for Research and Development. Securing Rights and Restoring Range Lands for Improved Livelihoods in the Badia of the Zarqa River Basin, Jordan [online report], (2011, November). www.cmsdata.iucn.org/ downloads/baseline_study__securing_ rights_and_restoring_land_for_improved_ livlihoohs.pdf. Accessed 8 February 2016.

Haddad, F. (2014). 'Rangeland Resource Governance - Jordan'. In Herrera, P., Davies, J., \& Baena, P.M. (eds.) Governance of Rangelands: Collective Action for Sustainable Pastoralism 2. London: Routledge, pp. 45-61.

Hima Management Committee, Bani Hashem Him Society. Community Management Plan for Hima Bani Hashem, 2013-2017 [online report], (2012). www.cmsdata. iucn.org/downloads/bani_hashem_hima_ cemp2012_2017.pdf. Accessed 8 February 2016.

IUCN. Market chain analysis: Artimessia and Germandar in Bani Hashem [online report], (2012a). www.cmsdata.iucn.org/downloads/ marketing_analysis.pdf. Accessed 8 February 2016.

IUCN. Natural Resource Economic Valuations: Environmental Economic Valuation of the HIMA System, the Case of Zarqa River Basin- Jordan [online report], (2012b). www.cmsdata.iucn.org/downloads/iucn econmicvaluation_final.pdf. Accessed 8 February 2016. 
IUCN. Securing Rights \& Restoring Lands, 1 [online newsletter], (2012c). www.cmsdata. iucn.org/downloads/drylands_newsletter_ no_1__final.pdf. Accessed 8 February 2016.

IUCN. Securing Rights \& Restoring Lands, 2 [online newsletter], (2012d). www.cmsdata. iucn.org/downloads/drylands_newsletter_ no_2__english.pdf. Accessed 8 February 2016.

IUCN. Securing Rights \& Restoring Lands, 3 [online newsletter], (2012e). www.cmsdata. iucn.org/downloads/drylands_newsletter_ no_3_english.pdf. Accessed 8 February 2016.

IUCN. Securing Rights \& Restoring Lands, 3 [online newsletter], (2012f, December). www. cmsdata.iucn.org/downloads/drylands_ newsletter_english.pdf. Accessed 8 February 2016.

IUCN. The Zarqa River Basin, Jordan: Reviving Hima Sites [online report], (2012g). www. cmsdata.iucn.org/downloads/iucn_aug_30. pdf. Accessed 8 February 2016.

IUCN. Securing Rights \& Restoring Lands, 1 [online newsletter], (2013a). www.cmsdata. iucn.org/downloads/drylands_newsletter_ english_1.pdf. Accessed 8 February 2016.

IUCN. Securing Rights \& Restoring Lands, 2 [online newsletter], (2013b). www.cmsdata. iucn.org/downloads/english_newsletter sep_2013.pdf. Accessed 8 February 2016.

IUCN. Securing Rights \& Restoring Lands, 3 [online newsletter], (2013c). www.cmsdata. iucn.org/downloads/newsletter_english_dec_ final.pdf. Accessed 8 February 2016.

Local Dry Lands Resources Management Committee. Local Strategic Plan for Integrated Management of Dry Lands in Hashmiyha Area [online report], (2012). www.cmsdata.iucn.org/downloads/local_ strategic_plan_for_integrated_management_ of_drylands_in_hashmiyha_2011.pdf. Accessed 8 February 2016.

Ministry of Agriculture. Updated Rangeland Strategy for Jordan [online report], (2013). www.moa.gov.jo/Portals/0/pdf/English_ Strategy.pdf. Accessed 7 July 2016. 


\section{Case Study 7}

Costa Rica: Securing livelihoods through mangrove conservation and restoration

Marco QUESADA, Conservation International, Arlington, USA (mquesada@conservation.org)

\section{COSTA RICA}
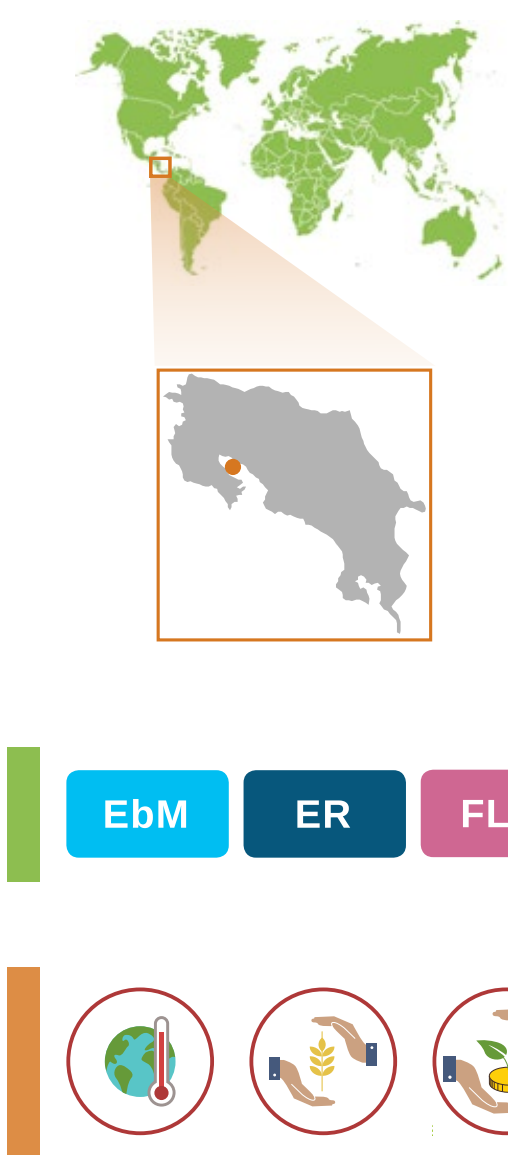

\section{EbM}

\section{ER FLR}
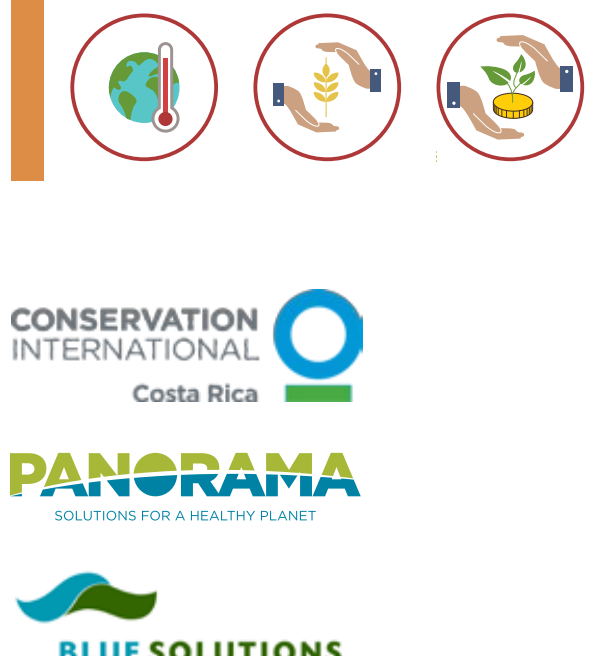

\section{General background}

Mangrove forests in Costa Rica, especially in the Gulf of Nicoya, are important ecosystems at local, national and global levels because of the many ecosystem services they provide. These forests protect the shoreline from erosion, support the health of estuarine ecosystems, and provide habitat for invertebrate species such as clams and molluscs that local women rely on for their livelihoods. Fisheries are even more dependent on the health of mangrove forests, and more than 6,000 fishers live in the gulf and rely on fisheries for their livelihoods (Bluetubetv, 2014). Finally, mangrove forests offer large amounts of carbon storage in above-ground vegetation and in sediment around mangrove roots, and so are important contributors to climate change mitigation. Despite these benefits, by the 1960s many of Costa Rica's mangrove forests were degraded as a result of their overexploitation for firewood and their conversion to salt evaporation and shrimp ponds. Analysis of 2010 satellite images has shown that approximately $34 \%$ of the Gulf of Nicoya's mangroves had been illegally converted to these ponds (Venegas-Li et al., 2013). In addition, encroachment of agricultural land continues to threaten the country's mangrove forests.

\section{Main activities}

In response to these issues, Conservation International began a pilot mangrove restoration project in 2014, as a Nature-based Solution to the socio-economic impacts of mangrove degradation in two coastal communities located on the island of Chira in the Gulf of Nicoya. This project consisted of establishing baseline measures and assessments of carbon sequestration for policy making, replanting of mangrove forests by local stakeholders, building local capacity for sustainable use of mangroves and livelihood diversification, and creating a local education programme.

Baseline measurement of mangroves and carbon sequestration. Blue carbon (i.e., carbon stored in 


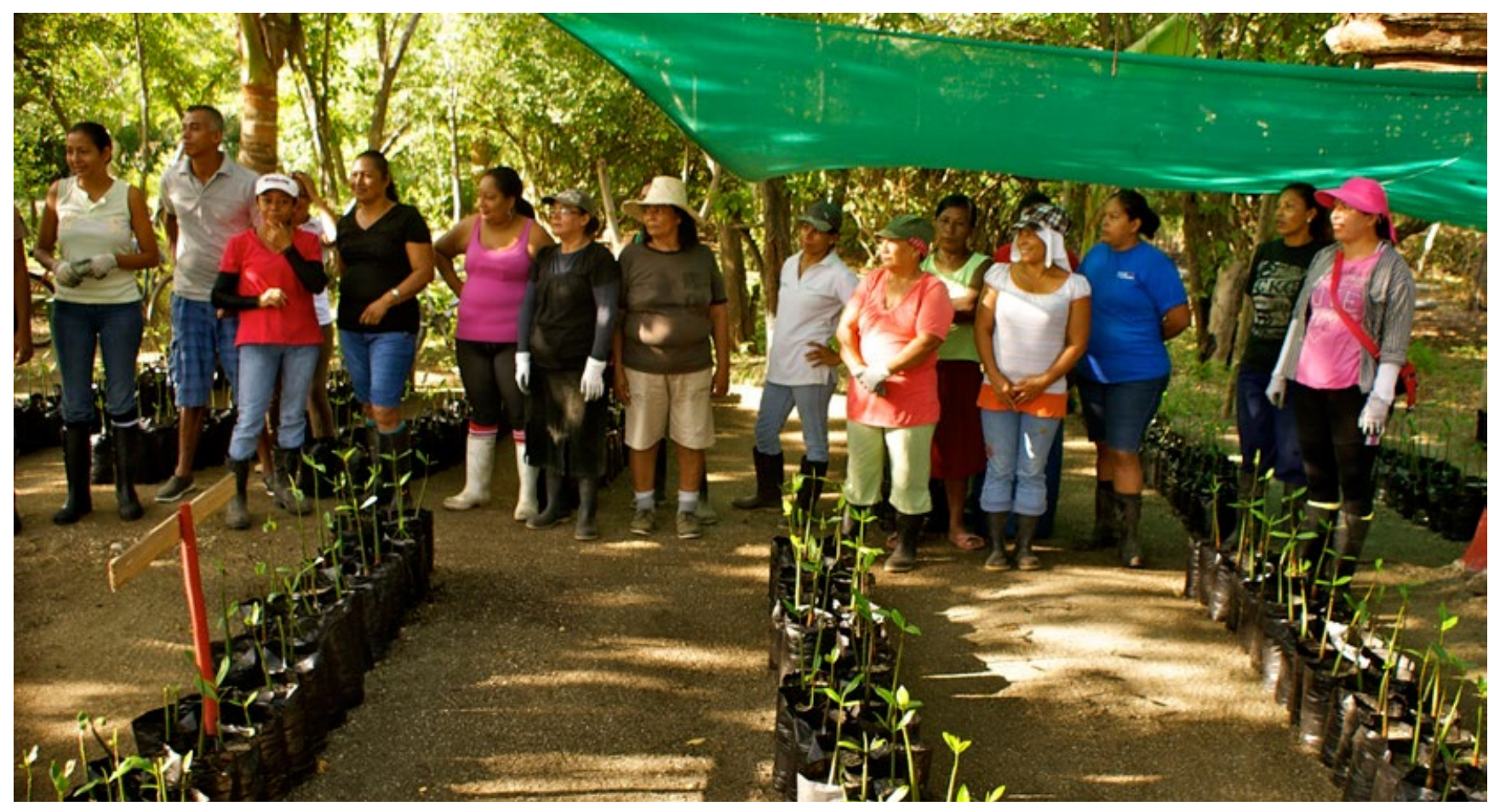

A mangrove nursery - Photo credit: Marco Quesada

mangroves, salt tidal marshes and seagrass meadows) represents substantial carbon storage, not only in the living biomass aboveand below-ground but also in soil and nonliving biomass such as litter and dead wood. The anaerobic conditions of coastal soils prevent carbon from being released back into the atmosphere and so allow a continuous build-up of carbon over time. These coastal ecosystems therefore play an important role in climate change mitigation (Howard et al., 2014). Howard et al. (2014) note that "Blue carbon offers the possibility to mobilise additional funds and revenue by combining best practices in coastal management with climate change mitigation goals and needs" (p. 20). To this end, blue carbon estimates for the Gulf of Nicoya's mangroves were established in 2014, based on methods agreed upon by an international group of blue carbon scientists, through the Blue Carbon Initiative (Howard et al., 2014). Local scientists measured the diameter and height of mangroves and all living plant material to determine the amount of carbon stored above ground. Sediment samples were extracted for below-ground measurements. Samples were extracted from 120 sampling plots established across the Gulf. The results of this research were presented to local policy makers to inform policy on broader climate change mitigation strategies.

Replanting mangrove forests. Mangroves in Costa Rica have been protected by law since the late 1970 s and this legislation has reduced, though not eliminated, ecosystem degradation. To aid these efforts, Conservation International designed and implemented a replantation programme during 2014 and 2015, utilising the expertise of a botanist to direct mangrove restoration. Women from Montero, a fishing community on Chira island, were the first to agree to implement the programme since they realised that the success of their husbands' fishing depended on healthy mangrove ecosystems. In addition to replanting mangroves, two successful mangrove nurseries were established and operated by local stakeholders. Few employment opportunities exist on the island, and the restoration of the mangroves (and subsequent increase in biodiversity) has the potential to attract tourists as well as the attention of the government who could pay for this work. 


\section{Key lessons learned}

Collaboration. The combined knowledge of scientists, local stakeholders and policy makers is necessary for feasible and sound projects. Trust and long-term working relationships between local stakeholders and outside organisations (in this case Conservation International) facilitates community engagement, knowledge sharing, and collaboration.

Stakeholder assessment. Clarification of values and interests that motivate local stakeholders is key in project design and implementation to achieve lasting results.

Local commitment. Strong local commitment to project implementation increases success. The strong commitment of local women, who volunteered their time in the midst of caring for their families and searching for alternative sources of income, was especially crucial to the success of this project.

\section{Education and capacity building. An}

education programme focusing on mangroves and their ecosystem services was launched at elementary schools to present the mangroves' value and importance to local children. Children from these schools also helped develop the previously mentioned mangrove nurseries for restoration efforts. Training on marine tourism management was provided for potential micro-entrepreneurs; this included providing information on the birds and other mangrove species that exist on the island, as well as strategies for managing tourism groups.

\section{Results}

Carbon sequestration. Since the blue carbon estimates followed internationally recognised scientific methods, these estimates can be published and shared with international audiences. Carbon stocks at the Gulf of Nicoya were estimated for the first time and vary between 413 and 1,335 MgC/ha. Conservation International has since designed a blue carbon project that could use carbon credits to finance community development activities and the organisation continues to work on the necessary policy to implement such a project.

Mangrove replanting. One year after the start of the project, local stakeholders had planted more than 8,000 mangrove saplings, which had a survival rate of over $90 \%$. This pilot project serves as a model for other communities on the island, some of which have also started replanting mangroves.

Education and capacity building. Children are involved in monthly classes on mangrove and marine biology. Capacity building of adults started with 30 local stakeholders, out of which 14 finalised the training modules. Six of them currently run small businesses related to tourism (mangrove tours, food, lodging).

A second stage of the project is currently being planned.

\section{Acknowledgements}

Ana Gloria GUZMÁN, Marine Programme Manager, Conservation International Costa Rica; Miguel CIFUENTES, Tropical Agricultural Research and Higher Education Center (CATIE); Maguil CÉSPEDES; Blue Solutions, as part of the Panorama partnership.

\section{References}

Bluetubetv. The Salt Forest and Its People English [Video File], (2014, May 14). www. youtube.com/watch?v=qyyytklgUEl. Accessed 2 June 2016. 
Howard, J., Hoyt, S., Isensee, K., Pidgeon, E. and Telszewski, M. (eds.). (2014). Coastal Blue Carbon: Methods for assessing carbon stocks and emissions factors in mangroves, tidal salt marshes, and seagrass meadows. Conservation International, Intergovernmental Oceanographic Commission of UNESCO, International Union for Conservation of Nature. Arlington, Virginia, USA. www.thebluecarboninitiative. org/manual/
Venegas-Li, R., Barquero, L.M. and MartínezFernández, D. (2013). 'Mapping mangrove species composition with Rapideye satellite images in the Nicoya Gulf, Costa Rica: How far can we go?', paper delivered at Association for Tropical Biology and Conservation (ATBC) Conference, San José, Costa Rica, 23 June 2013. 


\title{
Case Study 8
}

\section{USA: Restoration of wetlands and barrier islands for storm protection in the Northern Gulf of Mexico}

\author{
Mark FORD, National Park Service, Atlanta, USA (mark_ford@nps.gov)
}

\section{UNITED STATES OF AMERICA}

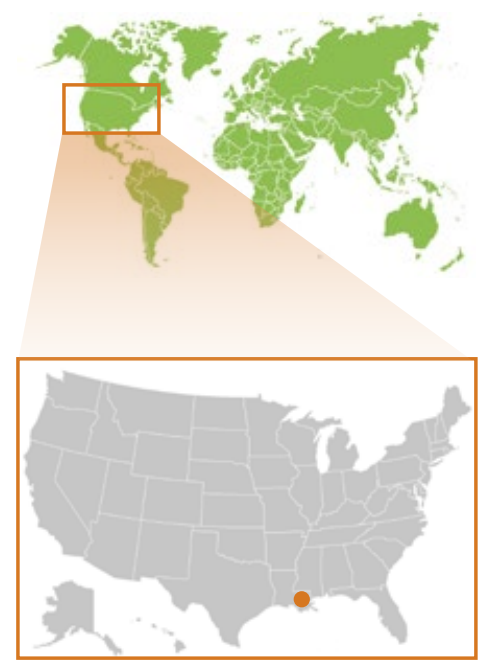

ECO-DRR

ER

$\mathrm{AbC}$

\section{General background}

Hurricane Katrina hit the Louisiana and Mississippi coasts in August 2005, causing 1,836 deaths and costing about US\$ 81 billion worth of damage (Ford, 2014). Although this was one of the costliest storms in US history, the northern Gulf of Mexico frequently experiences smaller tropical storm surges.

Wetlands and barrier islands play a key role in reducing wave energy, and so help protect coastal communities from the effects of these storm surges (Barbier et al., 2013; Costanza et al., 2008; USACE, 2009). In addition to their contribution to risk reduction, wetlands decrease salinity in estuarine areas that are important habitat for economically valuable species such as oysters, shrimp, and critically threatened species such as gulf sturgeon; these wetlands therefore support the local fisheries industries in Mississippi and Louisiana, which are important economic sources for both these states (USACE, 2009). Given the benefits provided by wetlands and barrier islands, Louisiana and Mississippi have focused on the restoration of these natural features in order to protect against future flooding and storms. Restoration of wetlands in Jean Lafitte National Historic Park and Preserve in Louisiana, and restoration of offshore barrier islands in the Gulf Islands National Seashore in Mississippi are currently underway. These parks were not originally established for storm protection, but rather to preserve the rich cultural, historical (e.g. military) and natural heritage of the area. However, it became clear after Hurricane Katrina that these parks could also act as a Nature-based Solution to coastal flooding. Although these restoration projects require considerable cost (estimated at over US\$450 million), the expenses incurred are minor compared to the huge costs of damage from storm surges along this coast.

\section{Main activities}

A) Wetland restoration in Jean Lafitte National Historic Park and Preserve 

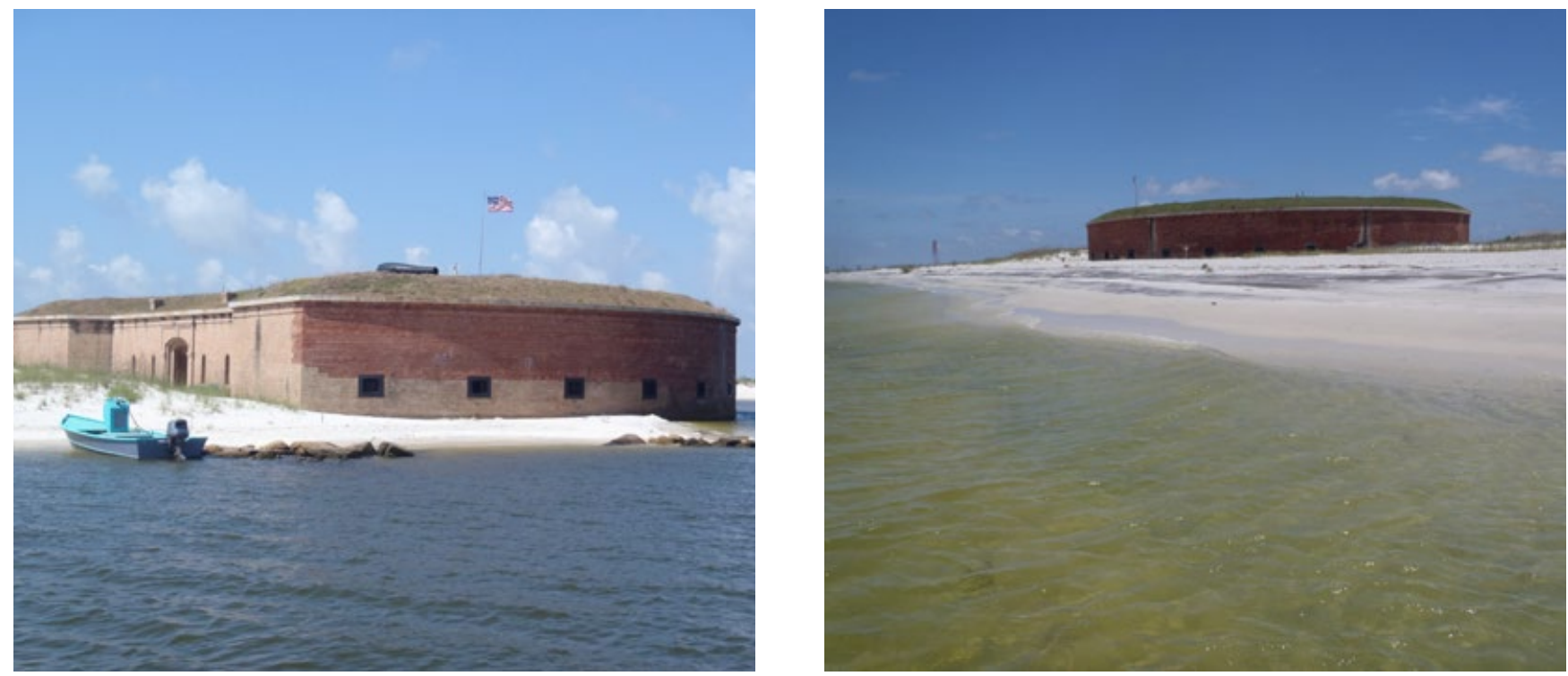

Before and after beach nourishment on Ship Island - Photos credit: Mark Ford

Canal reclamation. Before this property became part of the National Park system, canals were dug for oil and gas exploration and navigation throughout the Barataria Preserve of the Jean Lafitte National Historic Park and Preserve (National Park Service, 2009). These canals and their associated spoil banks contribute to the loss of wetlands in the park by altering hydrology, turning marsh into open water, restricting water flow above and below the marsh surface, causing increased flooding and drying of the marsh behind them, and creating habitat for exotic species (National Park Service, 2009).

In 2009, the National Park Service initiated a canal reclamation project to reclaim more than 20 miles of canals in the Barataria Preserve. The objectives of this project were to restore the functions, resources and values related to hydrology in the park, and to increase the resiliency of park ecosystems to subsidence, sea-level rise, and storm events (National Park Service, 2009). Using floating excavators, old spoil banks were pushed into canals and invasive trees were felled, while native species such as oaks and bald cypress were preserved (Biohabitats, 2016). The final elevation of the spoil banks was similar to that of the surrounding marsh (Biohabitats, 2016; Ford, 2014).
Removal and control of exotic plant species. In addition to removing invasive trees during backfilling, about 1,000 hectares of mature and growing Chinese tallow (Sapium sebiferum) trees were removed by park rangers to allow native bald cypress to replace them (Delta Dispatches, 2012). Since 2011, the park has also employed a suite of approaches to clear floating aquatic vegetation from parts of the waterways in order to facilitate recreational boating and fishing.

Planting of desired species. In 2011, volunteers teamed up with park staff and planted more than 700 bald cypress trees along the Bayou Segnette Waterway (Delta Dispatches, 2012). Cypress trees hold sediment within their extensive root systems to prevent erosion, and so "play a strong role in the protection of the hurricane levee system that borders the park and the adjacent human communities" (Ford, 2014, p. 146).

\section{Mississippi River water and sediment} diversions. The Davis Pond Freshwater Diversion Structure, upstream from New Orleans, releases fresh river water into the Barataria Basin to help regulate salinity and sediment load in the Barataria Preserve (Ford, 2014). This in turn decreases the deterioration of the marshes and loss of land around New 
Orleans, and maintains habitat for commercial and recreational fisheries (USACE, n.d.).

\section{B) Mississippi Coastal Improvements Program (MsCIP): Gulf Islands National Seashore Restoration}

Restoration of Ship Island. Ship Island, part of a chain of sandy barrier islands off the Mississippi coast, currently exists as two parts (East Ship and West Ship) separated by a shallow sandbar, Camille Cut (USACE, 2016). This splitting of Ship Island (i.e. the creation of Camille Cut) was the result of Hurricane Camille in 1969. Camille Cut will now be reconfigured as a low-level dune system, filled in with sand, stabilised with sand fencing and planted with native dune vegetation to restore stable dune habitat (USACE, 2016). Sand will also be added to the east end of East Ship Island to recreate Ship Island as a single elongated barrier island.

\section{Results}

\section{A) Wetland restoration in Jean Lafitte National Historic Park and Preserve}

To date, five miles of canals have been reclaimed, more than 700 native trees have been planted and invasive species are being removed in Jean Lafitte Park. Furthermore, abundant freshwater and nutrient input into the preserve from the Mississippi River diversion has increased the volume and abundance of submerged aquatic vegetation, which can decrease wave energy (Poirrier et al., 2010). At the same time however, an increase of the exotic species, Giant Salvinia, throughout the Preserve was also noted which may damage the habitat quality for fish and wildlife (Poirrier et al., 2010).

\section{B) Mississippi Coastal Improvements Program (MsCIP): Gulf Islands National Seashore Restoration}

The US Army Corps of Engineers modelled storm surge attenuation to determine the effectiveness of the restoration of Ship Island. Modelling suggests that wave height will be reduced in the lee of the island, and surge height from major storms at the mainland beach will be reduced by as much as 1.25 metres (Ford, 2014). Not only will restoration of this barrier island provide a first line of defence against storm surges, it will also (i) provide nesting habitat for threatened and endangered sea turtles and over-wintering waterfowl; (ii) help maintain salinity levels in the Sound and habitat for oysters, fish and crustaceans essential for commercial and recreational fishing; and (iii) protect historical and cultural sites within the Gulf Islands National Seashore (USACE, 2016). An Environmental Impact Statement for restoration of Ship Island was released in 2016 and planning and implementation are soon to follow.

\section{Acknowledgements}

Julie WHITBECK, Jean Lafitte National Historic Park and Preserve, National Park Service;

\section{Key lessons learned}

Importance of monitoring. Continued monitoring is necessary to ensure the success of the restoration projects. The management of floating aquatic vegetation requires consistent effort and monitoring of the extent of this vegetation and the prevalence of invasive species. Without regular and repeated effort, physical removal, physical restraint and herbicide treatments are effective only for short periods until the vegetation regrows or is reintroduced.

Roles of protected areas. Although parks and protected areas are originally meant for one management or conservation objective, they can serve in other capacities as well - in this case, as a Nature-based Solution to coastal flooding. 
Haigler "Dusty" PATE, Jean Lafitte National Historic Park and Preserve, National Park Service.

\section{References}

Barbier, E.B., Georgiou, I.Y., Enchelmeyer, B. and Reed, D.J. (2013). The value of wetlands in protecting southeast Louisiana from hurricane storm surges. PLOS ONE 8(3): e58715

Biohabitats. Jean Lafitte National Historic Park and Preserve Wetland Restoration [website], (2016). www.biohabitats.com/projects/ chinese-tallow-tree-removal-wetlandrestoration-in-barataria-preserve/. Accessed 29 January 2016.

Costanza, R., Pérez-Maqueo, O., Martinez, M.L., Sutton, P., Anderson, S.J. and Mulder, K. (2008). The value of coastal wetlands for hurricane protection. Ambio 37(4): 241-248.

Delta Dispatches. CRCL volunteers plant more than 700 cypress trees at Jean Lafitte National Historical Park and Preserve [blog], (2012, Jan 4). www.mississippiriverdelta. org/blog/2012/01/04/crcl-volunteers-plantmore-than-700-cypress-trees-at-jean-lafittenational-historical-park-and-preserve/. Accessed 29 January 2016.

Ford, M. (2014). Hurricane Katrina, the role of US National Parks on the northern Gulf of Mexico and post storm wetland restoration. In Murti, R. and Buyck, C. (eds.) Safe Havens: Protected Areas for Disaster Risk Reduction and Climate Change Adaptation (chapter 16). IUCN, Gland, Switzerland and Cambridge, UK.
National Park Service, US Department of the Interior. Canal Reclamation at Barataria Preserve: Environmental Assessment Jean Lafitte National Historical Park and Preserve [website], (2009). parkplanning.nps.gov/document.cfm? parkID=387\& \&roject|D=25944\&document ID=31179. Accessed 29 January 2016.

USACE (U.S. Army Corps of Engineers). Davis Pond Freshwater Diversions [website], (n.d.). www.mvn.usace.army.mil/About/Projects/ DavisPondFreshwaterDiversion.aspx. Accessed 29 January 2016.

USACE (U.S. Army Corps of Engineers), Mobile District. Mississippi Coastal Improvements Program (MsCIP) Comprehensive Barrier Island Restoration Hancock, Harrison, and Jackson Counties, Mississippi: Final Supplemental Environmental Impact Statement [website], (2016). parkplanning. nps.gov/projectHome.cfm?projectID=39288. Accessed 29 January 2016.

USACE (U.S. Army Corps of Engineers), Mobile District. Mississippi Coastal Improvements Program (MsCIP) Hancock, Harrison, and Jackson Counties, Mississippi: Comprehensive Plan and Integrated Programmatic Environmental Impact Statement Volume 1 - Main Report [online report], (2009). www.sam.usace.army.mil/ Portals/46/docs/program_management/ mscip/docs/MSCIP\%20Main\%20 Report\%20062209-Errata.pdf. Accessed 29 January 2016 


\title{
Case Study 9
}

\section{Spain: Developing the Barcelona Green Infrastructure and Biodiversity Plan}

\author{
Marga PARÉS, Cap del Programa de Biodiversitat (mparesr@bcn.cat) \\ Coloma RULL, Tècnica del Programa de Biodiversitat \\ Montse RIVERO, Adjunta a Gerència de MASU
}

\section{SPAIN}

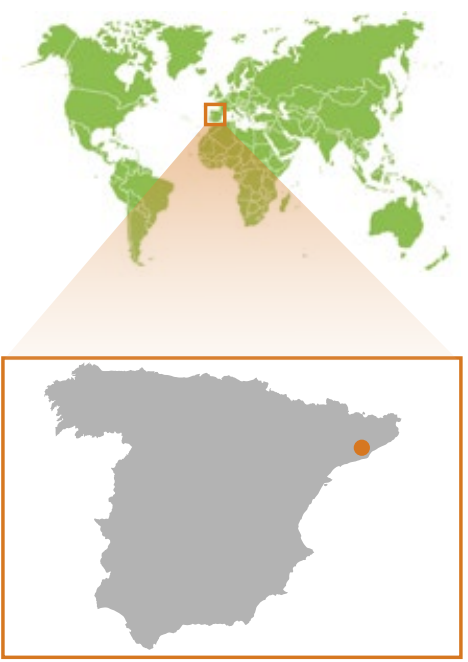

G
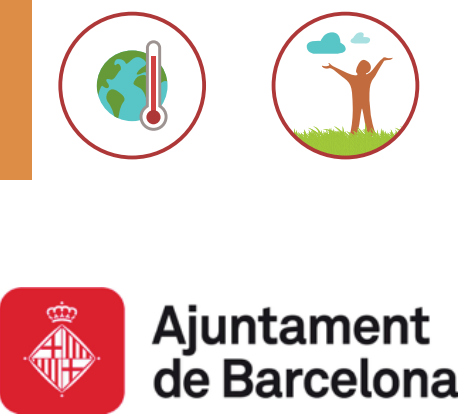

\section{General background}

Barcelona is one of the most densely populated European cities with about 1.62 million people living in an area of just over $100 \mathrm{~km}^{2}$ (Baró et al., 2014). Air pollution has become a major concern for residents as the city has regularly exceeded the European Union's limits for average annual concentrations of nitrogen dioxide and particulate matter over the past decade (Baró et al., 2014). In addition, changing land use has reduced the city's green space and biodiversity and limited the connectivity of its natural areas. During the past five decades, the city has converted rural land to urban use at a rate of about 1,000 hectares per year (Marulli \& Mallarach, 2005). Rapid urban and industrial sprawl in the Barcelona Metropolitan Area, together with traffic infrastructure development, has caused habitat and landscape fragmentation, resulting in thousands of patches of isolated natural areas with minimal ecological function (Muarulli \& Mallarch, 2005). Furthermore, municipal land-use and urban plans often do not consider functional ecological processes when incorporating protected natural areas in city plans (Marulli \& Mallarach, 2005). To address these problems of decreased environmental quality within the city, the Barcelona Green Infrastructure and Biodiversity Plan 2020 was developed for city planning and released in 2010. The 2020 Barcelona Plan aims to create a city where natural heritage and biodiversity are preserved and enhanced, where maximum green infrastructure (Gl) and connectivity are achieved as well as maximum social and environmental services from $\mathrm{Gl}$, and a city that is more resilient in the face of climate change (Ajuntament de Barcelona, 2013).

Restoring and enhancing Gl through this plan provides the inhabitants of Barcelona with many ecosystem services such as air purification, noise reduction, regulation of urban climate and temperature, reduction in energy consumption and $\mathrm{CO} 2$ emissions, water cycle regulation, recreation, improvement in mental health and general well-being. 


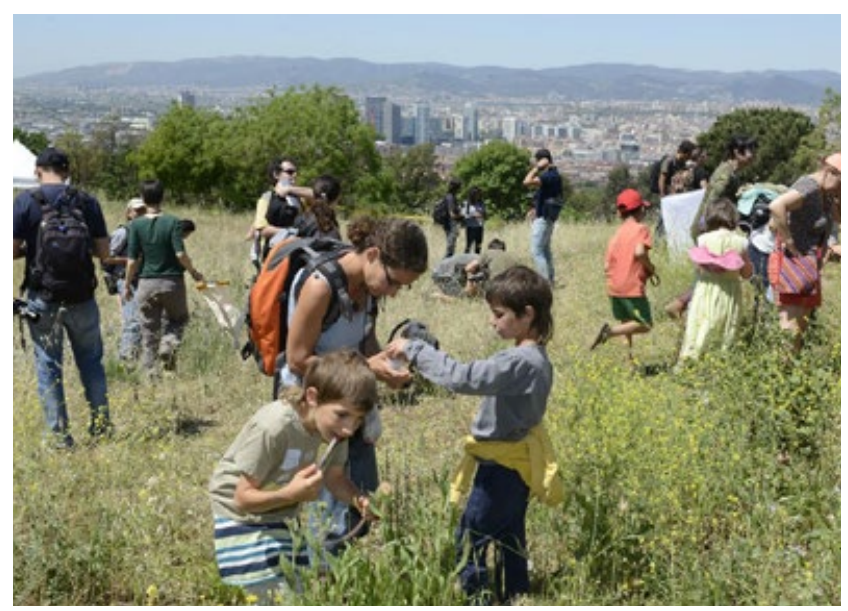

BioBlitz event in Barcelona - Photo credits: Ajuntament de Barcelona

In addition to these benefits to humans, GI supports biodiversity, provides habitat for flora and fauna, and creates ecological connectivity (Ajuntament de Barcelona, 2013; URBES, 2014; Baró et al., 2014).

\section{Main activities}

An assessment of the city's existing green spaces was conducted prior to developing the Green Infrastructure and Biodiversity Plan. As of 2010, the city of Barcelona had about 3,611 hectares of Gl covering $35 \%$ of city land, with one large natural park (Collserola Park) accounting for about half of this area (Ajuntament de Barcelona, 2013). In the city, parks and gardens generally cover small areas and there is very little connectivity between them. Street trees also make up a large part of the GI, there being a total of almost 200,000 trees (Ajuntament de Barcelona, 2013). These trees play an important role in mitigating climate change and maintaining air quality; in 2008, it was estimated that the city's trees removed, on an annual basis, about 5,000 net tonnes of CO2 and more than 305 tonnes of pollutant compounds (Ajuntament de Barcelona, 2013).

\section{Barcelona Green Infrastructure and}

Biodiversity Plan 2020. Barcelona City Council developed the plan using a participatory approach. Several meetings were held in early 2009 to discuss the assessment of Gl in the city, agree on long-term challenges and goals, and

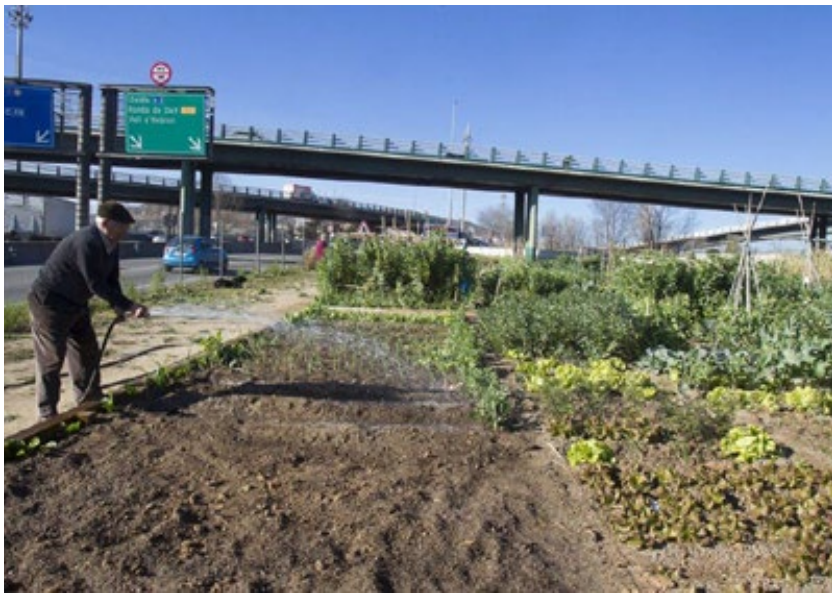

One of the city's community gardens - Photo credits: Ajuntament de Barcelona

gather proposals on a way forward for enhanced biodiversity and Gl (Ajuntament de Barcelona, 2013). Participants included multi-level government representatives, researchers and social, environmental and private institutions.

A 2008 citizen opinion survey also determined that green areas were associated with health, freedom, nature and relaxation and that citizens wanted to see more flowers, trees and lawns as well as increased cleanliness and security in these areas (Ajuntament de Barcelona, 2013).

A number of different strategies were developed to achieve the goals set out in the Plan. Examples of these strategies include: managing parks, gardens and other green spaces to reduce the demand for water, control for pests and disease, and use suitable soils; improving knowledge of how climate change is transforming the environment; developing a communication strategy to spread knowledge of Gl, biodiversity and their values; promoting citizen involvement in the creation and conservation of green spaces for health and enjoyment; and building strong local leadership, networks and commitment to conservation of $\mathrm{Gl}$ (Ajuntament de Barcelona, 2013).

Challenges. Implementing the Barcelona Green Infrastructure Plan presents several challenges. For example, management of the city's small and fragmented green spaces needs to allow for heavy use of these areas, given the high 
population density. The urban trees also pose several challenges for future management.

Three predominant tree species account for about half of all trees in the area, indicating that a pest or disease outbreak could have a major impact on Gl. Two of these species (Aleppo pine and holm oak) are also considered vulnerable to climate change. Furthermore, street trees often have little space for roots, little organic matter and compacted soil with poor structure and deficient nutrition. Finally, the tree species in the city present problems for those with pollen allergies; some $98 \%$ of the pollen present in Barcelona is of the type that can set off respiratory allergies.

\section{Results}

To date, the Plan has launched numerous education and outreach initiatives as well as GI activities. Positive impacts have already been seen as a result of these actions.
Education and outreach initiatives. Several programmes have been launched to improve public knowledge and appreciation of the benefits of $\mathrm{Gl}$ and biodiversity, and the need for conservation. Annual gardening workshops for families are offered in parks and gardens in the city. Schools use parks to learn about sustainability through the city's 'Come to the Parks' programme (Ajuntament de Barcelona, 2013). Scientists facilitate exploration of the city's flora and fauna every year through an event called "BioBlitzBcn". The goal of this event is to identify and count as many species as possible in a specified area (Museu de ciències naturals de Barcelona, 2015). During the most recent BioBlitz in April 2016, almost 1,000 scientists, naturalists and volunteers identified 249 species at Montjuïc Hill and Barcelona's Botanical Garden (Let It Grow, 2016).

\section{Key lessons learned}

Challenges. It is difficult to balance the intensive use of green space with its maintenance and conservation. City officials noted that integrating urban greenery into densely built urban environments and obtaining ownership of the required land is challenging (Hansen, 2015). Developing green infrastructure is a slow process in a city of Barcelona's size.

Keys to success. Political support and willingness are essential for implementation to be successful (Hansen, 2015). Successful management of biodiversity and ecosystem services must be based on multi-scale, multi-sectoral, and multi-stakeholder involvement (Schewenius et al., 2014). Regular dialogue with urban policy makers and planners in the research process facilitates knowledge transfer (Schewenius et al., 2014).

Impact of GI. Gl strategies at the municipal level have only limited effects on local air quality and greenhouse gas emissions offsets, but could complement other policies intended to meet air quality and climate change mitigation policy targets. Strong coordination between municipal and regional governments dealing with environmental quality and urban planning is needed (Baró et al., 2014).

Public awareness. Citizens need to be aware of the important ecosystems services that green infrastructure provides, such as temperature regulation, storm water runoff mitigation, and recreational opportunities, to create buy-in and participation in conservation activities (Baró et al., 2014). 
GI activities. Many GI initiatives are underway. For example, the designation of maintenance levels for various green spaces is under review to optimize resources and maintenance. More resources need to be allocated for maintenance instead of regeneration or full renewal of areas (Ajuntament de Barcelona, 2013). Controlling leaks in pipes, use of groundwater, automated irrigation, and the use of plants with lower water demands has decreased the pressure on drinking water (Ajuntament de Barcelona, 2013). Ten thousand tonnes of plant material from pruning and maintenance activities have been transformed into mulch and compost, which are reused in green spaces (Ajuntament de Barcelona, 2013). Through the 'Plan of Vacant Urban Plots' programme launched in 2012, NGOs are converting vacant city-owned areas to places for $\mathrm{Gl}$ activities such as gardening and urban horticulture to provide spaces for recreation, social integration, maintenance of cultural heritage and access to food (Ajuntament de Barcelona, n.d.).

\section{Acknowledgements}

Medi Ambient i Serveis Urbans (MASU);

Ecologia Urbana (EU); Ajuntament de Barcelona; Francesc Baró, Researcher and PhD candidate, Institute of Environmental Science and Technology, Barcelona.

\section{References}

Ajuntament de Barcelona. Barcelona Green Infrastructure and Biodiversity Plan 2020 [online report], (2013). www.ajuntament. barcelona.cat/ecologiaurbana/sites/ default/files/Barcelona\%20green\%20 infrastructure\%20and\%20biodiversity\%20 plan\%202020.pdf. Accessed 20 January 2016.

Ajuntament de Barcelona, 'Ecologia, Urbanisme i Mobilitat' Pla BUITS [website], (n.d.). www. ajuntament.barcelona.cat/ecologiaurbana/ ca/pla-buits (in Catalan). Accessed 19 May 2016.
Baró, F., Chaparro, L., Gómez-Baggethun, E., Langemeyer, J., Nowak, D.J. and Terradas, J. (2014). Contribution of ecosystem services to air quality and climate change mitigation policies: the case of urban forests in Barcelona, Spain. Ambio 43(4): 466-479.

Hansen, R. Barcelona, Spain. Case Study Portrait [online report], (2015). www. greensurge.eu/products/case-studies/Case_ Study_Portrait_Barcelona.pdf. Accessed 20 January 2016.

Let It Grow. Brilliant Seventh Edition of BioBlitzBcn [online article], (2016, May 9). www.letitgrow.eu/2016/05/09/brilliantseventh-edition-of-bioblitzbcn/. Accessed 19 May 2016.

Marulli, J. and Mallarach, J.M. (2005). A GIS methodology for assessing ecological connectivity: application to the Barcelona Metropolitan Area. Landscape and Urban Planning 71: 243-262.

Museu de ciències naturals de Barcelona. BioBlitzBcn [online report], (2015). www. letitgrow.eu/wp-content/uploads/2016/03/ Bioblitz-Barcelona-Report-2015-DEF.pdf. Accessed 19 May 2016.

Schewenius, M., McPhearson, T. and Elmqvist, T. (2014). Opportunities for increasing resilience and sustainability of urban social-ecological systems: insights from the URBES and the cities and biodiversity outlook projects. Ambio 43(4): 434-444.

URBES (Urban Biodiversity and Ecosystem Services). Green Infrastructure, a wealth for cities. Factsheet 6 [online report], (2014). www.mistraurbanfutures.org/sites/default/ files/urbes_factsheet_06_web.pdf. Accessed 20 January 2016. 


\title{
Case Study 10
}

Guatemala and Mexico: Implementing transboundary water governance through community ecosystem-based action in the Tacaná watersheds

\author{
Rebecca WELLING, IUCN Global Water Programme, Gland, Switzerland (rebecca.welling@iucn.org)
}

\section{GUATEMALA AND MEXICO}

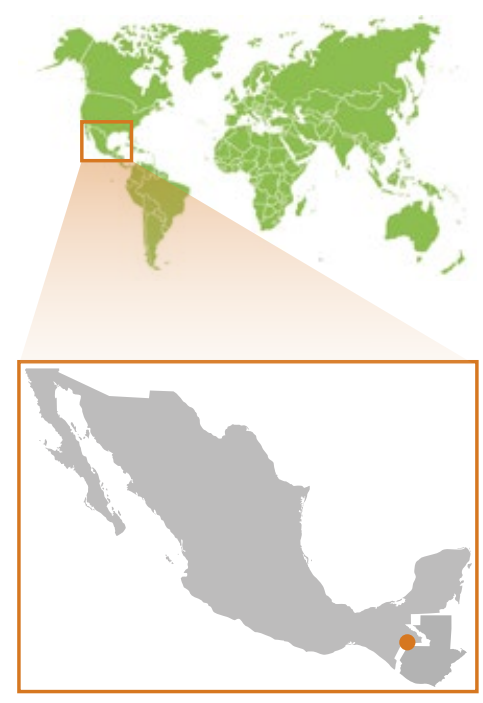

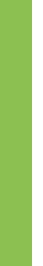

\section{NI}

ER

FLR

\section{EbA}
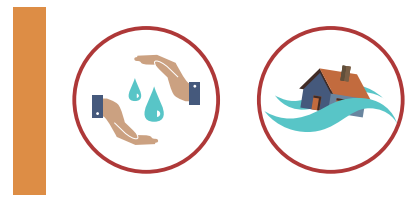

\section{General background}

The watersheds of the Tacaná volcano (including the Coatán and Suchiate river basins) are of great strategic importance for both Guatemala and Mexico since they supply water to the cities located downstream, irrigation water for agriculture and, in the lower reaches, fishing. Despite this potential, the area is vulnerable to both ecological and political pressures. The climate is tropical humid and there is a high occurrence of hurricanes as well as volcanic activity. Deforestation and degradation of the river banks and upper watersheds has exacerbated erosion and flooding and reduced the water absorption capacity of the watersheds. The area is also exposed to a number of socio-political shortcomings such as lack of coordination between the different governmental institutions responsible for the area, marginalisation of indigenous people, high illiteracy and mortality rates, very high population growth, and complex land tenure rights.

In response to these challenges, IUCN (through its Water and Nature Initiative, WANI) and partners set up a demonstration water governance project in the Tacaná watershed in Guatemala and Mexico. This initiative combined pilot livelihood projects and bottom-up integrated governance of water resources management. Increased collaboration through changes in water governance was also an explicit objective of this demonstration project. Focusing on a grassroots approach to water management, increased knowledge and information, and the improvement of environmental health and livelihoods, the Tacaná project has demonstrated a way forward in scaling up locallevel initiatives to national-level approaches. The project has also shown how a region's adaptive capacity can be strengthened by employing watershed restoration as a Nature-based Solution to improve water security and make local livelihoods less vulnerable to climate change.

\section{Main activities}

The Tacaná watersheds demonstration project was developed based on WANI's main goal - to "mainstream an 


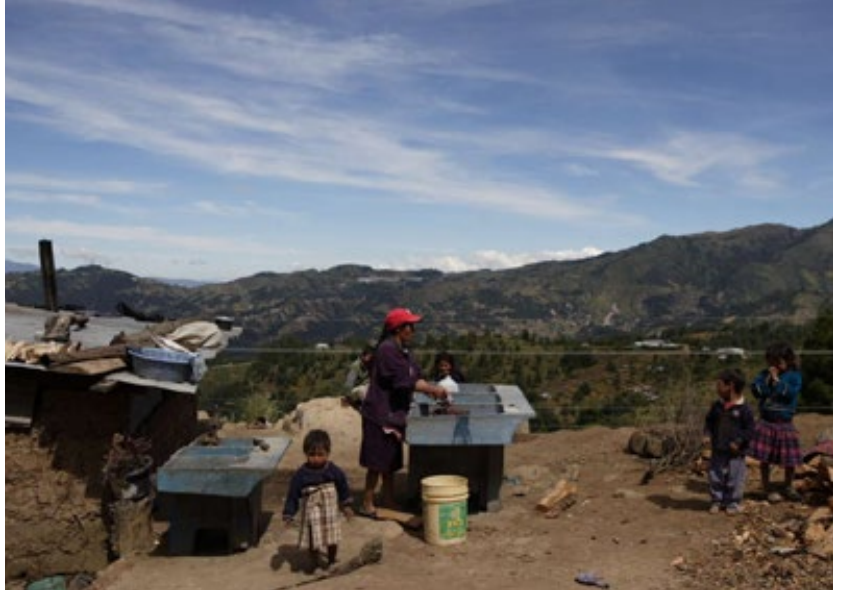

Tacaná watershed - Photo credits: Taco Anema

ecosystem approach into catchment policies, planning, and management". Activities to meet this goal as well as the initiative's core strategic objectives were carried out from 2008-2012 (Smith \& Cartin, 2011).

Ecosystems and livelihoods. Unregulated land-use change in the upper watershed had been especially damaging on steep hillsides, and erosion from deforestation and roaming livestock had greatly increased the risk of floods and mudslides. As a response, numerous community pilot projects were prepared in order to address particular water, soil and environmental conservation issues. These projects were the basis for the self-organisation of communities into micro-watershed councils, which encompass 10 to 20 communities who share water resources in the watersheds of tributary streams (Cartin et al., 2012).

Knowledge mobilisation. Mobilisation was achieved through economic valuation of water resources, provision of locally available information, and capacity building for learning and leadership. For example, in 2008 the project's Living Water Partnership established a Payment for Ecosystem Services scheme in Guatemala to protect and restore the Tacaná watersheds' natural resources, focusing primarily on water. In Mexico, 'water resource virtual libraries' in municipal town halls now provide up-to-date information on water

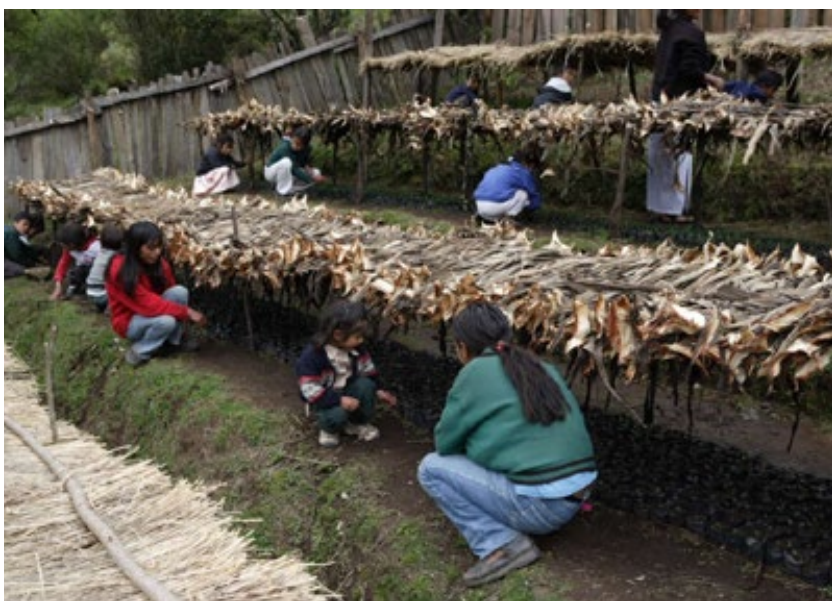

Community members tend a seedling nursery - Photo credits: Taco Anema

resources and the regional environment. These libraries are used in awareness-raising and educational programmes, and as a means of increasing political openness over water management at the municipal and state levels. Lastly, learning from the pilot projects has been incorporated into the University of San Carlos's academic studies in Guatemala. These programmes are creating a critical mass of trained professionals who will eventually work in various institutions and organisations with influence on the country's water resources, thereby creating an influential feedback loop.

\section{Self-organisation for improved governance.}

The Tacaná project developed a water planning and community management model that is inclusive, highly participatory (including community and local political authorities) and based on strategic collaborations with government and NGOs to resolve the more complex environmental and social problems. In Guatemala, micro-watershed councils coordinate the management of shared water and land resources and determine how this can be integrated with community development. Since these councils in Guatemala are interconnected, there is potential for their actions to include watershed management at different scales in future management activities.

Integration and collaboration at local to national levels. At the local level in 
Guatemala, collaborations between Community Development Committees and coordination with Municipal and National Development Councils enabled integration of microwatershed planning and management with community-led action on development. Projects developed by communities rather than external institutions address the real demands of communities, not just institutional goals. At the department level in San Marcos, Guatemala, an alliance was created between government organisations and NGOs to form CORNASAM (the Inter-Institutional Coordination for Natural Resources and the Environment). At the national level in Guatemala, the country's National Micro-Watershed Commission, comprised of government ministries and non-governmental or inter-governmental organisations, was established to lead governance reform through country-wide micro-watershed management.

Transboundary governance. WANI and partners convened the first bi-national forum of mayors to jointly analyse and identify environmental problems in the Coatán and Suchiate river basins. More generally, a key objective of WANI's involvement in this project was to promote and facilitate national and transboundary governance approaches, specifically through the establishment of codes of conduct - a set of shared principles or guidelines that will guide the behaviour of a set of actors. Two draft Codes of Conduct were prepared in 2008 for the Tacaná watersheds (Cartin et al., 2012).

\section{Results}

By 2011, a total of 107 activities had been implemented in the Tacaná watersheds, tackling issues related to conservation and environmental restoration, food security, income generation and basic social services - and cutting across the private, public and civil sectors of society (Cartin et al., 2012). The micro-watershed model was central to the achievement of the project's objective of building the adaptive capacity of the watershed and local livelihoods through empowerment of community-owned institutions. With support from the Tacaná project, communities built micro-watershed councils to lead watershed restoration and development that met their priorities. Some examples of these projects and governance work are summarised below.

\section{Governance work. Governance-related}

outcomes have been seen at the local, national and transboundary levels. At the local level in Guatemala, CORNASAM adopted the micro-watershed as the unit of planning for water and the environment, and coordinated outreach and training in the micro-watershed approach. Micro-watersheds were mapped, and a database developed identifying the most vulnerable areas. In Mexico, the Cahoacan River Basin Commission was created and basin municipalities are working to develop risk management approaches. At the national level in Guatemala, in 2011, the 'Mi Cuenca' project, operating in conjunction with the Tacaná watershed project, organised the Presidential Forum on Environment and Development, the first such event to be held in the country. In Mexico, the implementation of water councils as outlined in the new Water Law of 2003 was nationally supported. At the transboundary level, the 'Tapachula Declaration of Intent' was signed in 2006 by Mexican and Guatemalan mayors to cooperate in joint actions on watershed management and to provide a platform for information sharing by governmental agencies at the very local level. As a result, forest conservation actions are now being coordinated to prevent and control forest fires.

Livelihood pilots. Several livelihood projects were initiated, covering a wide range of activities. These included, for example, the development and networking of community enterprises and cooperatives, construction of septic systems, protection of springs for domestic water supply and installation of piped distribution, and support for the construction of a water treatment plant and advice on water recycling in the processing of coffee beans to reduce wastewater. Women made up $90 \%$ 


\section{Key lessons learned}

Local governance. Developing local governance and organisational structures benefits and complements Integrated Water Resource Management (IWRM) actions. Integrating local communities and their social structures into micro-watershed councils led to greater cohesion and unity. These councils give members control over their resources and, as more are formed, the influence spreads across the basin. Successful local models can be scaled up to national level and lead to the formation of national institutions or processes, which can then extend the model to other watersheds.

Community engagement. Community-level participation in transboundary water resource management is achievable and adds value to conventional transboundary approaches. Planning and implementation of IWRM can be successfully shared between communities across boundaries.

Collaboration. Strengthening community-based alliances and integrating them with municipal and national development institutions increases coordination between administrative levels. This promotes integrated and coordinated water resource planning across the watershed and shared experiences with other community groups and networks.

Ecosystem approach. Using an ecosystems approach (focusing on environmental restoration for livelihood security) to IWRM enables small-scale initiatives to energise communities to selforganise and enhance their development opportunities. These activities build resilience and support livelihoods through restoring ecosystem services.

Livelihood benefits. Poverty reduction and increased livelihood opportunities are major concerns at both local and national levels. Combining income generation and environmental conservation can be achieved through a variety of options that fully integrate the community. Both technical and business training is required in order for pilot projects to be viable and sustainable.

Risk management. Developing disaster risk management planning should be integral to the overall watershed management planning and not just as an emergency response (as demonstrated by Tropical Storm Stan). This ensures that measures to combat risks such as climate change are part of integrated water resource planning for the micro-watershed.

of those implementing the projects, thereby empowering them to take a more proactive role in the development of their communities - a domain that has conventionally been dominated by men.

\section{Drinking water systems rehabilitation} and disaster preparedness. To rehabilitate, reconstruct and redesign drinking water systems damaged by Tropical Storm Stan in 2005, the Tacaná project facilitated communications, damage assessment and the organisation of donor coordination. WANI coordinated the rehabilitation and reconstruction of 72 drinking water systems and four small irrigation systems (Cartin et al., 2012). The devastation caused by this tropical storm alerted the authorities and communities 
to the area's vulnerability to climate change impacts and the need to increase resilience to tropical storms and flooding through improved infrastructure and restored ecosystems.

Disaster preparedness plans and mechanisms were therefore developed alongside the drinking water systems reconstruction work.

\section{Acknowledgements}

Stefano BARCHIESI, Project Officer, IUCN Global Water Programme; Mark SMITH, Director, IUCN Global Water Programme.

\section{References}

Cartin, M., Welling, R., Córdoba, R., Rivera, O., Rosal, C. and Arrevillaga, F. (2012).
Tacaná Watersheds Guatemala \& Mexico: Transboundary water governance and implementation of IWRM through local community action. Gland, Switzerland: IUCN. Retrieved from www.portals.iucn.org/ library/efiles/documents/2012-011.pdf

Smith, M. and Cartin, M. (2011). Water Vision to Action: Catalysing Change through the IUCN Water and Nature Initiative. Gland, Switzerland: IUCN. Retrieved from www. cmsdata.iucn.org/downloads/final_wani_ results_report_Ir.pdf 


\section{References}

ALTER-Net. Nature and Urban Wellbeing. Nature-Based Solutions to Societal Challenges. International conference, 18 - 20 May 2015, Ghent, Belgium [online resources] (2015) www.alter-net.info/outputs/conf-2015

Ammar, A.A., Dargusch, P. and Shamsudin, I. (2014). Can the Matang Mangrove Forest Reserve provide perfect teething ground for a blue carbon based REDD+ pilot project? Journal of Tropical Forest Science 26(3): 371-381.

Arkema, K.K., Abramson, S.C. and Dewsbury, B.M. (2006). Marine ecosystem-based management: from characterization to implementation. Frontiers in Ecology and the Environment 4(10): 525-532.

Aronson, J. (2011). Sustainability science demands that we define our terms across diverse disciplines. Landscape Ecology 26(4): 457-460.

Baird, R.C. (2005). On sustainability, estuaries, and ecosystem restoration: The art of the practical. Restoration Ecology 13(1): 154-158.

Balian, E., Eggermont, H. and Le Roux, X. (2014). Outputs of the Strategic Foresight workshop "Nature-Based Solutions in a BiodivERsA context", Brussels June 11-12 2014.

Barot, S., Lata, J.-C. and Lacroix, G. (2012). Meeting the relational challenge of ecological engineering within ecological sciences. Ecological Engineering 45: 13-23.

Barrow, E. (2014). 300,000 Hectares Restored in Shinyanga, Tanzania - but what did it really take to achieve this restoration? S.A.P.I.EN.S [Online periodical] 7(2). www.sapiens. revues.org/1542.

Barton, H. and Grant, M. (2006). A health map for the local human habitat. The Journal for the Royal Society for the Promotion of Health 126(6): 252-253.

Benedict, M.A. and McMahon, E. (2002). Green Infrastructure: Smart Conservation for the 21st Century. Sprawl Watch Clearinghouse Monograph Series. Washington DC: Sprawlwatch Clearinghouse.

Borsje, B.W., van Wesenbeeck, B.K., Dekker, F., Paalvast, P., Bouma, T.J., van Katwijk, M.M. and de Vries, M.B. (2011). How ecological engineering can serve in coastal protection. Ecological Engineering 37(2): 113-122.

Bowler, D.E., Buyung-Ali, L.M., Knight, T. and Pullin, A.S. (2010) Urban greening to cool towns and cities: a systematic review of the empirical evidence. Landscape and Urban Planning 97(3): 147-155.

Brandt, P., Ernst, A., Gralla, F., Luederitz, C., Lang, D.J., Newig, J., Reintert, F., Abson, D.J. and von Wehrden, H. (2013). A review of transdisciplinary research in sustainability science. Ecological Economics 92: 1-15.

Bronstert, A. (2003). Floods and climate change: interactions and impacts. Risk Analysis 233: $45-558$. 
Cárcamo, P.F., Garay-Flühmann, R. and Gaymer, C.F. (2013). Opportunities and constraints of the institutional framework for the implementation of ecosystem-based management: the case of the Chilean coast. Ocean Coastal Management 84: 193-203.

CBD (Convention on Biological Diversity). Ecosystem Approach Sourcebook [website] (2004). www.cbd.int/ecosystem/sourcebook/.

CBD (Convention on Biological Diversity) (2010). X/33 Biodiversity and climate change, Decision Adopted by the Conference of the Parties to the Convention on Biological Diversity at its Tenth Meeting; UNEP/CBD/COP/DEC/x/33; 29 October 2010, Nagoya, Japan.

CBD (Convention on Biological Diversity) (2016). Recommendation adopted by the Subsidiary Body on Scientific, Technical and Technological Advice XX/12. Ecosystem Restoration. Montreal, Canada, 25-30 April 2016 Agenda item 1.

Coates, D. and Smith, M. (2012). Natural infrastructure solutions for water security. In R. Ardakanian and D. Jaeger (eds.) Water and the Green Economy Capacity Development Aspects. UN-Water Decade Programme on Capacity Development (UNW-DPC). Bonn, Germany: UNW-DPC.

Colfer, C.J., Sheil, D. and Kishi, M. (2006). Forests and human health: assessing the evidence. Bogor, Indonesia: Center for International Forestry Research.

Colloff, M.J., Lavorel, S., Wise, R.M., Dunlop, M., Overton, I.C. and Williams, K.J. (2016). Adaptation services of floodplains and wetlands under transformational climate change. Ecological Applications 26(4): 1003-1017.

Corcoran, E., Nellemann, C., Baker, E., Bos, R., Osborn, D. and Savelli, H. (eds) (2010). Sick Water? The central role of wastewater management in sustainable development. United Nations Environment Programme, UN-HABITAT, GRID-Arendal.

Cornwall, A. and Brock, K. (2005). What do buzzwords do for development policy: a critical look at "participation", "poverty reduction" and "empowerment." Third World Quarterly 26(7): 1043-1060.

Costanza, R., de Groot, R., Sutton, P., van der Ploeg, S., Anderson, S.J., Kubiszewski, I., Farber, S.and Turner, R.K. (2014). Changes in the global value of ecosystem services. Global Environmental Change 26(1): 152-158.

Covington, W., Niering, W.A., Starkey, E and Walker, J. (1998). Ecosystem Restoration and Management : Scientific Principles and Concepts. In Humans as Agents of Ecological Change, pp.599-618.

Dalton, J. and Murti, R. (2013). Utilizing Integrated Water Resource Management Approaches to Support Disaster Risk Reduction. In K. Sudmeier-Rieux and M. Estrella (eds.) The Role of Ecosystems in Disaster Risk Reduction. Bonn, Germany: United Nations University Press.

Davies, K.K., Fisher, K.T., Dickson, M.E., Thrush, S.F. and Le Heron, R. (2015). Improving ecosystem service frameworks to address wicked problems. Ecology and Society 20(2): 37.

Davis, K. (2008). Intersectionality as buzzword: A sociology of science perspective on what makes a feminist theory successful. Feminist Theory 9(1): 67-85. 
Davies, N. (1996). Europe. New York: Oxford University Press.

Doswald, N. and Osti, M. (2011). Ecosystem-based approaches to adaptation and mitigationGood practice examples and lessons learned in Europe, Bonn: Bundesamt für Naturschutz.

Dudley, N., Stolton, S., Belokurov, A., Krueger, L., Lopoukhine, N., MacKinnon, K. Sandwith, T. and Sekhran, N. (eds.) (2010) Natural Solutions: Protected areas helping people cope with climate change, IUCNWCPA, TNC, UNDP, WCS, The World Bank and WWF, Gland, Switzerland, Washington DC and New York, USA.

Duncan, J.M.A., Dash, J. and Tompkins, E.L. (2014). Mangrove forests enhance rice cropland resilience to tropical cyclones: evidence from the Bhitarkanika Conservation Area. In R. Murti and C. Buyck (eds.) Safe Havens: Protected Areas for Disaster Risk Reduction and Climate Change Adaptation. Gland, Switzerland: IUCN.

Ekins, P. (2003). Identifying critical natural capital: Conclusions about critical natural capital. Ecological Economics 44(2-3): 277-292.

Eggermont, H., Balian, E., Manuel, J., Azevedo, N., Beumer, V., Brodin, T., Claudet, J., Fady, B., Grube, M., Keune, H., Lamarque, P., Reuter, K., Smith, M., van Ham, C., Weisser, W.W. and Le Roux, X. (2015). Nature-based Solutions: New Influence for Environmental Management and Research in Europe. GAIA 24(4): 243-248.

Emerton, L. and Bos, E. (2004). Value. Counting Ecosystems as an Economic Part of Water Infrastructure., Gland, Switzerland and Cambridge, UK.

Ericksen, P.J., Ingram, J.S.I. and Liverman, D.M. (2009). Food security and global environmental change: emerging challenges. Environmental Science Policy 12(4): 373377.

European Commission and Directorate-General for Research and Innovation (2015). Towards an EU Research and Innovation policy agenda for Nature-Based Solutions \& ReNaturing Cities. Brussels, Belgium: European Commission. doi: 10.2777/765301

European Commission (2013). Green Infrastructure (GI) - Enhancing Europe's Natural Capital. Communication from the Commission to the European Parliament, the Council, the European Economic and Social Committee and the Committee of the Regions., Brussels, Belgium.

European Environment Agency (2011). Green Infrastructure and territorial cohesion. The concept of green infrastructure and its integration into policies using monitoring systems, Luxembourg: publication office of the European Union.

FAO, IFAD and WFP (2015). The State of Food Insecurity in the World 2015. Meeting the 2015 international hunger targets: taking stock of uneven progress. Rome: Food and Agriculture Organization.

Fisher, R., Maginnis, S., Jackson, W., Barrow ., Jeanrenaud, S., Ingles, A., Friend, R., Mehrotra, R., Farvar, T., Laurie, M., and Oviedo, G. (2008). Linking Conservation and Poverty Reduction: Landscapes, People and Power, Gland, Switzerland: International Union for the Conservation of Nature.

Girot, P., Ehrhart, C. and Oglethorpe, J. (2011). Integrating Community and EcosystemBased Approaches in Climate Change Adaptation. Ecosystem \& Livelihoods Adaptation Networks. 
GIZ. Blue Solutions: global knowledge exchange and capacity development for marine and coastal biodiversity [online factsheet], (2015). www.bluesolutions.info/links-resources/

Gosselin, F. (2008). Redefining ecological engineering to promote its integration with sustainable development and tighten its links with the whole of ecology. Ecological Engineering 32(3): 199-205.

Gregory, A.J., Atkins, J.P., Burdon, D. and Elliott, M. (2013). A problem structuring method for ecosystem-based management: The DPSIR modelling process. European Journal of Operational Research 227(3): 558-569.

Hanjra, M.A. and Qureshi, M.E. (2010). Global water crisis and future food security in an era of climate change. Food Policy 35(5): 365-377.

Hansen, L.J., Biringer, J.L. and Hoffman, J.R. (2003). Buying Time: A User's Manual for Building Resilience and Resistance to Climate Change in Natural Systems., Washington, DC: WWF-US.

Harker, D., Evans, S., Evans, M. and Harker, K. (1993). Landscape Restoration Handbook. Bocan Raton, USA: Lewis Publishers.

Hartig, T., Mitchell, R., de Vries, S, and Frumkin, H. (2014). Nature and Health. Annual Review of Public Health 35: 207-28.

Higgs, E.S. (1997). What is Good Ecological Restoration? Conservation Biology 11(2): 338348.

Hobbs, R.J and Norton, D.A. (1996). Towards a Conceptual Framework for Restoration Ecology. Restoration Ecology 4: 93-110.

Hobbs, R.J., Hallett, L.M., Ehrlich, P. and Mooney, H.A. (2011). Intervention Ecology: Applying Ecological Science in the Twenty-first Century. BioScience 61(6):442-450.

Hook, W.H. (2000). U.S. participation in international decade for natural disaster reduction. Natural Hazards Review 1: 2-9.

IPCC (2014). Climate Change 2014: Synthesis Report. Contribution of Working Groups I, II and III to the Fifth Assessment Report of the Intergovernmental Panel on Climate Change [Core Writing Team, R.K. Pachauri and L.A. Meyer (eds.)]. Geneva, Switzerland: IPCC.

IUCN. Panorama [webpage], (2016). www.iucn.org/theme/protected-areas/our-work/planetinspiring-protected-area-solutions/panorama

IUCN (2013a). Food security policies : making the ecosystem connections, Gland, Switzerland.

IUCN (2013b). The IUCN Programme 2013-2016, Gland, Switzerland: International Union for the Conservation of Nature.

IUCN (2011). Investing in Ecosystems as Water Infrastructure, Water Economics Briefing note, Gland, Switzerland.

IUCN (2009). Position paper for UNFCCC COP15, Copenhagen. Gland, Switzerland: IUCN.

Jones, H.P., Hole, D.G. and Zavaleta, E.S. (2012). Harnessing nature to help people adapt to climate change. Nature Climate Change 2(7): 504-509. 
Kabisch, N., Bonn, A., Korn, H. and Stadler, J. (eds.) (Forthcoming) Nature-based Solutions to Climate Change in Urban Areas and their Rural Surroundings - Linkages between Science, Policy, and Practice. Springer Publishing.

Kabisch, N., Frantzeskaki, N., Pauleit, S., Naumann, S., Davis, M., Artmann, M., Haase, D., Knapp, S., Korn, H., Stadler, K., Zaunberger, K. and Bonn, A. (2016). Nature-based solutions to climate change mitigation and adaptation in urban areas: perspectives on indicators, knowledge gaps, barriers, and opportunities for action. Ecology and Society 21(2):39.

Keniger, L., Gaston, K.J., Irvine, K.N. and Fuller, R.A. (2013). What are the Benefits of Interacting with Nature? International Journal of Environmental Research and Public Health 10(3): 913-935.

Klimmek, H. \& van Ham, C., Innovative partnerships for implementing nature-based solutions in urban areas. In Springer, ed. Nature-based Solutions to Climate Change in Urban Areas and their Rural Surroundings - Linkages between Science, Policy, and Practice. In press

Krchnak, K., Smith, M. and Deutz, A. (2011). Putting Nature in the Nexus: Investing in Natural Infrastructure to Advance Water-Energy Food Security. In The Water, Energy and Food Security Nexus - Solutions for the Green Economy Background Papers for the Stakeholder Engagement Process. Bonn, Germany: IUCN and The Nature Conservancy.

Kreimer, A. and Arnold, M. (2000). World Bank's role in reducing impacts of disasters. Natural Hazards Review 1: 37-42.

Kumar, C., Saint-Laurent, C., Begeladze, S. and Calmon, M. (eds.) (2015). Enhancing food security through forest landscape restoration: Lessons from Burkina Faso, Brazil, Guatemala, Viet Nam, Ghana, Ethiopia and Philippines, Gland, Switzerland: International Union for the Conservation of Nature.

Laestadius, L., Buckingham, K., Maginnis, S. and Saint-Laurent, C, (2015). Before Bonn and beyond: the history and future of forest landscape restoration. Unasylva 245(66): 11-17.

Lavorel, S., Colloff, M.J., Mclntyre, S., Doherty, M.D., Murphy, H.T., Metcalfe, D.J., Dunlop, M., Williams, R.J., Wise, R.M. and Williams, K. (2015). Ecological mechanisms underpinning climate adaptation services. Global Change Biology 21(1): 12-31.

Leach, M., Scoones, I. and Stirling, A. (2010). Dynamic sustainabilities: technology, environment, social justice, London, UK: Earthscan.

Leopold, A. (2013). Aldo Leopold: a Sand County almanac and other writings on ecology and conservation. Based on A Sand County almanac, first published 1949. New York: Literary Classics of the United States.

Leslie, H.M. and McLeod, K.L. (2007). Confronting the challenges of implementing marine ecosystembased management. Frontiers in Ecology and the Environment 5(10): 540-548.

Liu, J. et al., 2015. Systems integration for global sustainability. Science, 347.

Locatelli, B., Evans, V., Wardell, A., Andrade, A. and Vignola, R. (2011). Forests and climate change in latin America: Linking adaptation and mitigation. Forests 2: 431-450.

Loughlin, M (2002). On the buzzword approach to policy formation. Journal of Evaluation in Clinical Practice 8(2): 229-242. 
Lü Y, Fu B, Feng X, Zeng Y, Liu Y, Chang R, Sun G and Wu B (2012) A Policy-Driven Large Scale Ecological Restoration: Quantifying Ecosystem Services Changes in the Loess Plateau of China. [online journal] PLoS ONE 7(2): e31782. doi:10.1371/journal.pone.0031782

Maas, J., Verheij, R.A., de Vries, S., Spreeuwenberg, P., Schellevis. F.G. and Groenewegen, P.P. (2009). Morbidity is related to a green living environment. Journal of Epidemiology \& Community Health 63(12): 967-973.

Mace, G.M. (2014). Whose conservation? Science 345(6204): 1558-1560.

MacKinnon, K., Dudley, N. and Sandwith, T. (2011). Natural solutions: protected areas helping people to cope with climate change. Oryx 45(4): 461-462.

MacKinnon, K. and Hickey, V. (2009). Nature-based solutions to climate change. Oryx 43(1): 13-16.

Macleod, A., Jones, D.G., Anderson, H.M. and Mumford, R.A. (2016). Plant health and food security, linking science, economics, policy and industry. Food Security 8(1): 17-25.

Maes, J. and Jacobs, S. (2015). Nature-Based Solutions for Europe's Sustainable Development. Conservation Letters [online journal]

Maginnis, S., Laestadius, L., Verdone, M., DeWitt, S., Saint-Laurent, C., Rietbergen-McCracken, J. and Shaw, D.M.P.(2014). Assessing forest landscape restoration opportunities at the national level: A guide to the Restoration Opportunities Assessment Methodology (ROAM), Gland, Switzerland: International Union for the Conservation of Nature.

McGinnis, M.D. and Ostrom, E. (2014). Social-ecological system framework: Initial changes and continuing challenges. Ecology and Society 19(2): 30.

Maltby, E. (2000). Ecosystem Approach: from principle to practice. Paper presented at Ecosystem Service and Sustainable Watershed Management in North China International Conference, Beijing, P.R. China, August 23 - 25, 2000.

Mansourian, S. and Vallauri, D. (2014). Restoring forest landscapes: Important lessons learnt. Environmental Management 53: 241-251.

Mansourian, S., Vallauri, D. and Dudley, N. (eds.) (in cooperation with WWF International) (2005). Forest Restoration in Landscapes: Beyond Planting Trees, Springer, New York.

Matthews, R. B. and van Noordwijk, M. (2014). From euphoria to reality on efforts to reduce emissions from deforestation and forest degradation (REDD+). Mitigation and Adaptation Strategies for Global Change, 19(6): 615-620.

McGinnis, M.D. and Ostrom, E. (2014). Social-ecological system framework: Initial changes and continuing challenges. Ecology and Society 19(2): 30.

Millennium Ecosystem Assessment (2005). Ecosystems and Human Well-being: Synthesis. Island Press, Washington, DC.

Mitsch, W.J. (2012). What is ecological engineering? Ecological Engineering, 45(October): 5-12.

Mitsch, W.J. and Jørgensen, S.E. (2004). Ecological Engineering and Ecosystem Restoration, John Wiley \& Sons.

Mittermeier, R A., Totten, M., Pennypacker, L.L., Boltz, F., Mittermeier, C.G., Midgley, G., Rodriguez, C.M., Prickett, G., Gascon, C., Seligmann, P.A. and Langrand, O. (2008). Climate for Life, Washington DC: Conservation International. 
Mohamed-Katerere, J. and Smith, M. (2013). the Role of Ecosystems in Resilient Food Systems. Unasylva 64: 14-22.

Mohamed-Katerere, J. \& Smith, M., 2013. the Role of Ecosystems in Resilient Food Systems. Unasylva, 64, pp.14-22.

Mueller, L and Bresch, D. (2014). Economics of climate adaptation in Barbados - facts for decision making. In R. Murti and C. Buyck (eds.) Safe Havens: Protected Areas for Disaster Risk Reduction and Climate Change Adaptation. Gland, Switzerland: IUCN.

Murti, R. and Buyck, C. (2014). Safe Havens, Gland: International Union for the Conservation of Nature.

Naeem, S., Ingram, J.C., Varga, A., Agardy, T., Barten, P., Bennett, G., Bloomgarden, E., Bremer, L.L., Burkill, P., Cattau, M., Ching, C., Colby, M., Cook, D.C., Costanza, R., De Clerck, F., Freund, C., Gartner, T., Goldman-Benner, R., Gunderson, J., Jarrett, D., Kinzig, A.P., Kiss, A., Koontz, A., Kumar, P., Lasky, J.R., Masozera, M., Meyers, D., Milano, F., Naughton-Treves, L., Nichols, E., Olander, L., Olmsted, P., Perge, E., Perrings, C., Polasky, S., Potent, J., Prager, C., Quétier, R., Redford, K., Saterson, K., Thoumi, G., Vargas, M.T., Vickerman, S., Weisser, W., Wilkie, D, and S. Wunder(2015). Get the science right when paying for nature's services. Science 347(6227): 1206-1207.

New Climate Economy 2014 Report. Better Growth Better Climate [online report] (2014) http://www.newclimateeconomy.report/2014/

Opperman, J.J., Galloway, G.E., Fargione, J., Mount, J.F., Richter, B.D. and Secchi, S. (2009). Sustainable Floodplains Through Large-Scale Reconnection to Rivers. Science 326(5959): 1487-1488.

Ozment, S., DiFrancesco, K. and Gartner, T. (2015). The role of natural infrastructure in the water, energy and food nexus. Nexus Dialogue Synthesis Papers. Gland, Switzerland: IUCN.

Palmer, M.A., Filoso, S. and Fanelli, R.M., (2014). From ecosystems to ecosystem services: Stream restoration as ecological engineering. Ecological Engineering 65: 62-70.

Parmesan, C. and Yohe, G. (2003). A globally coherent fingerprint of climate change impacts across natural systems. Nature 421(6918): 37-42.

Pendleton, L., Donato, D.C., Murray, B.C., Crooks, S., Jenkins, W.A., Sifleet, S., Craft, C., Fourqurean, J.W., Kauffman, J.B., Marbà, N., Megonigal, P., Pidgeon, E., Herr, D., Gordon, D. and Baldera, A. (2012) Estimating Global "Blue Carbon" Emissions from Conversion and Degradation of Vegetated Coastal Ecosystems. [online journal] PLoS ONE 7(9): e43542.

Potschin, M., Kretsch, C., Haines-Young, R., Furman, E. Berry, P. Baró, F. (2015). Nature-based solutions. In: M. Potschin and K. Jax (eds.) OpenNESS Ecosystem Service Reference Book. OpenNESS Synthesis Paper No. 18. Available at: http://www.openness-project.eu/sites/ default/files/SP_Nature-based-solutions.pdf [Accessed 9 August, 2016].

Renaud, F. and Murti, R. (2013). Ecosystems and disaster risk reduction in the context of the Great East Japan Earthquake and Tsunami - a scoping study. UNU-EHS Publication Series No. 10.

Renaud, F., Sudmeier-Rieux, K. \& Estrella, M. eds., 2013. The Role of Ecosystems in Disaster Risk Reduction. Tokyo, Japan: United Nations University Press. 
Rizvi, A.R. (2014). Nature Based Solutions for Human Resilience Nature Based Solutions for Human Resilience: a mapping analysis of IUCN's Ecosystem Based Adaptation Projects. Gland, Switzerland: IUCN.

Rizvi, A.R., Baig, S. and Verdone, M. (2014). Ecosystem Based Adaptation. Knowledge Gaps in Making an Economic Case for Investing in Nature Based Solutions for Climate Change. Gland, Switzerland: IUCN.

Rockström, J. Steffen, W., Noone, K., Persson, A., Chapin, F.S. III., Lambin, E., Lenton, T.M., Scheffer, M., Folke, C., Schellnhuber, H., Nykvist, B., De Wit, C.A., Hughes, T., van der Leeuw, S., Rodhe, H., Sorlin, S., Snyder, P.K., Costanza, R., Svedin, U., Falkenmark, M., Karlberg, L., Corell, R.W., Fabry, V.J., Hansen, J., Walker, B., Liverman, D., Richardson, K., Crutzen, P., and Foley, J. (2009). Planetary Boundaries : Exploring the Safe Operating Space for Humanity. Ecology and Society 14(2):32

Rockström, J. \& Sukhdev, P., 2016. How food connects all the SDGs. Stockhold Resilience Centre. Available at: http://www.stockholmresilience.org/research/research-news/201606-14-how-food-connects-all-the-sdgs.html [Accessed July 6, 2016].

Root, T.L., Price, J.T., Hall, K.R., Schneider, S.H., Rosenzweig, C. and Pounds, J.A. (2003). Fingerprints of global warming on wild animals and plants. Nature 421(57-60).

Roy, D., Barr, J. and Venema, H. (2011). Ecosystem Approaches in Integrated Water Resources Management (IWRM): a review of transboundary river basins, Geneva: United Nations Environment Programme and the International Institute for Sustainable Development.

Russi, D., ten Brink, P., Farmer, A., Badura, T., Coates, D., Förster, R.K. and Nick, D. (2013). The Economics of Ecosystems and Biodiversity for Water and Wetlands. IEEP, London and Brussels; Ramsar Secretariat, Gland.

Samson, F.B. and Knopf, F.L. (1996). Prairie Conservation: Preserving North America's Most Endangered Ecosystem, Washington DC: Island Press.

Schulze, P. (1996). Engineering Within Ecological Constraints. National Academy of Engineering, Washington, DC.

Shepherd, G., 2004. The Ecosystem Approach: five steps to implementation, Gland, Switzerland and Cambridge, UK.: International Union for Conservation of Nature.

Slocombe, D.S. (1998). Lessons from experience with ecosystem-based management. Landscape and Urban Planning 40: 31-39.

Smith, M. (2013). Water for Nature, Nature for Water. The Post 2015 Water Thematic Consultation - Water Resources Management Stream Framing Paper. Gland, Switzerland: IUCN.

Smith, M. and Cartin, M. (2011). Water Vision to Action: Catalysing Change through the IUCN Water and Nature Initiative, Gland, Switzerland: IUCN.

Smith, R.D. and Maltby, E. (2003). Using the Ecosystem Approach to implement the convention on biological diversity: key issues and case studies, Gland, Switzerland and Cambridge, UK: IUCN.

Society for Ecological Restoration (2004). Ecological Restoration Primer [online document] www.ser.org/resources/resources-detail-view/ser-international-primer-on-ecologicalrestoration. 
Stanturf, J.A., Palik, B.J. and Dumroese, R.K. (2014). Contemporary forest restoration: A review emphasizing function. Forest Ecology and Management 331: 292-323.

Staudinger, M.D., Grimm, M.B., Staudt, A., Carter, S.L., Stuart, F.S., Kareiva, P., Ruckelshaus, M. and Stein, B.A. (2012). Impacts of Climate Change on Biodiversity, Ecosystems, and Ecosystem Services: Technical Input to the 2013 National Climate Assessment. Cooperative Report to the 2013 National Climate Assessment.

Stolton, S. and Dudley, N. (2009). Vital Sites: The contribution of protected areas to human health, Gland, Switzerland: WWF International.

Suding, K.N. (2011). Toward an Era of Restoration in Ecology: Successes, Failures, and Opportunities Ahead. Annual Review of Ecology, Evolution, and Systematics 42: 465487.

Sudmeier-Rieux, K., Ash, N. and Murti, R. (2011). Environmental Guidance Note for Disaster Risk Reduction, Revised Edition. Gland, Switzerland: IUCN.

Teal, J.M. and Weinstein, M.P. (2002). Ecological engineering, design, and construction considerations for marsh restorations in Delaware Bay, USA. Ecological Engineering 8(5): 607-618.

Temmerman, S., Meire, P., Bouma, T.J., Herman, P.M.J., Ysebaert, T. and de Vriend, H.J. (2013). Ecosystem-based coastal defence in the face of global change. Nature, 504: 79-83.

Thompson Coon, J., Boddy, K., Stein, K., Whear, R., Barton,. J, Depledge,. MH.(2011). Does Participating in Physical Activity in Outdoor Natural Environments Have a Greater Effect on Physical and Mental Wellbeing than Physical Activity Indoors? A Systematic Review. Environmental Science \& Technology 45(5): 1761-1772.

TNC (The Nature Conservancy) Sustainable Cities: nature-based solutions in urban design, [online resources] (n.d.). www.natureworkseverywhere.org/resources/sustainable-cities/

Tzoulas, K., Korpela, K., Venn, S., Yli-Pelkonen, V., Kazmierczak, A., Niemela, J. and James, P. (2007). Promoting ecosystem and human health in urban areas using Green Infrastructure: A literature review. Landscape and Urban Planning 81(3): 167-178.

UICN France (2015). Des solutions fondées sur la nature pour lutter contre les changements climatiques. Paris France: Comité francais de I'UICN.

UNEP (2014). Green Infrastructure Guide for water management: Ecosystem-based management approaches for water-related infrastructure projects. UNEP, UNEP-DHI, IUCN and TNC.

UNFCCC (2008). Report of the Conference of the Parties on its thirteenth session, held in Bali from 3 to 15 December 2007: Addendum Part Two: Action taken by the Conference of the Parties at its thirteenth session.

UNISDR, 2007. List of terminologies. Available at: http://www.unisdr.org/we/inform/ terminology\#letter-d.

Uy, N. and Shaw, R. (eds.) (2012). Ecosystem-Based Adaptation. Community, Environment and Disaster Risk Management, Volume 12. Emerald Group Publishing.

Uzzi, B., Mukherjee, S., Stringer, M. and Jones, B. (2013). Atypical combinations and scientific impact. Science, 342(October): 468-72. 
Verdone, M. (2015). A Cost-Benefit Framework for Analyzing Forest Landscape Restoration Decisions. Gland, Switzerland: IUCN.

De Vries, S., Verheij, R.A., Groenewegen, P.P., Spreeuwenberg, P. (2003). Natural environments - healthy environments? An exploratory analysis of the relationship between greenspace and health. Environment and Planning A, 35(10): 1717-1731.

Warber,S., Irvine,K., Devine-Wright,P. and Gaston,K. (2013). Modelling well-being and the relationship between individuals and their environments. In: Coles, R., Millman, Z. (eds.), Landscape, Well-Being and Environment. Routledge, Abingdon, pp.20-37.

Waylen, K.A., Blackstock, K.L. \& Holstead, K.L. (2015). How does legacy create sticking points for environmental management? Insights from challenges to implementation of the ecosystem approach. Ecology and Society 20(2): 21.

Weigel, L. and Metz, D. (2015). How to communicate successfully regarding Nature-Based Solutions : key lessons from research with American voters and elites, Washington, DC: The Nature Conservancy.

Woodhouse, E., Homewood, K.M., Beauchamp, E., Clements , T., McCabe, .T., Wilkie, D. and Milner-Gulland, E.J. (2015). Guiding principles for evaluating the impacts of conservation interventions on human well-being. Philosophical Transactions of the Royal Society B: Biological Sciences, 370(1681): 20150103.

World Bank (2008). Biodiversity, Climate Change and Adaptation: Nature-Based Solutions from the World Bank Portfolio. Washington, DC.

Wu, J., 2013. Landscape sustainability science: Ecosystem services and human well-being in changing landscapes. Landscape Ecology, 28, pp.999-1023. 


\section{Annex 1: NbS approaches: definitions and related terminologies}

\section{arme \\ Ecological restoration}

The process of assisting the recovery of an ecosystem that has been degraded, damaged or destroyed (Society for Ecological Restoration, 2004).

The attempt to repair or otherwise enhance the structure and function of an ecosystem that has been impacted by disturbance or environmental change (Suding, 2011).

\section{Related terminologies Objectives}

Functional restoration, habitat restoration, intervention ecology, mitigation, reclamation, reconstruction, recovery, reforestation, rehabilitation, structural restoration, revegetation.
Repair or enhance the structure and function of an ecosystem that has been impacted by disturbance or environmental change (Suding, 2011). Ecological restoration projects have different objectives, such as providing habitat for rare species; providing a diverse gene pool for selected species; provide specified natural goods and services for social benefit (Society for Ecological Restoration, 2004).

\section{Ecological engineering}

\section{Management of systems of human and} environmental self-design or light management that joins human design and environmental self-design, so that they are mutually symbiotic (Odum, 1996).

The design of sustainable ecosystems that integrate human society with its natural environment for the benefit of both (Mitsch, 2012).
Nature-based engineering, ecosystem engineering species, ecological engineering, genetic engineering, biological monitoring, bio-chemical engineering, nature engineering, ecotechnology

\section{Forest landscape restoration}

A planned process that aims to regain ecological integrity and enhance human well-being in deforested or degraded landscapes (Mansourian et al., 2005).

Forest landscape restoration is the long-term process of regaining ecological functionality and enhancing human well-being across deforested or degraded forest landscapes (Maginnis et al., 2014).
Forest rehabilitation, forest restoration.
Restore substantially disturbed ecosystems by human activities (e.g. environmental pollution); Develop new sustainable ecosystems that have both human and ecological values (Mitsch, 2012). 


\section{Natural and Green infrastructure}

$\mathrm{NI}$ is defined as a "strategically planned and managed network of natural lands, such as forests and wetlands, working landscapes, and other open spaces that conserves or enhances ecosystem values and functions and provides associated benefits to human populations" (Benedict \& McMahon, 2006).

Gl comprises of all natural, semi-natural and artificial networks of multifunctional ecological systems within, around and between urban areas, at all spatial scales. The green infrastructure concept emphasises on the quality as well as quantity of urban and periurban green spaces, their multifunctional role, and the importance of interconnections between habitats (Tzoulas et al., 2007).

An interconnected network of green space that conserves natural ecosystem values and functions and provides associated benefits to human populations (Benedict and McMahon, 2002).

GI is a strategically planned network of natural and semi-natural areas with other environmental features designed and managed to deliver a wide range of ecosystem services. It incorporates green spaces (or blue if aquatic ecosystems are concerned) and other physical features in terrestrial (including coastal) and marine areas. On land, $\mathrm{Gl}$ is present in rural and urban settings (European Commission, 2013).
Ecological infrastructure, blue infrastructure.
Promote ecosystem health and resilience, contribute to biodiversity conservation and enhance ecosystem services (Naumann et al., 2011).

\section{Ecosystem-based management}

Integrated, science-based approach to the management of natural resources that aims to sustain the health, resilience and diversity of ecosystems while allowing for sustainable use by humans of the goods and services they provide (Kappel et al., 2006; Garcia et al., 2003).
Ecosystem-based approach to land management, ecosystem management, ecosystembased fisheries management, marine ecosystem-based management, ecosystembased approach to (marine and coastal) management.
Maintain an ecosystem in a healthy, productive and resilient condition so that it can provide the services humans want and need (Leslie \& McLeod, 2007).

\section{Ecosystem-based adaptation}

The use of biodiversity and ecosystem services as part of an overall adaptation strategy to help people to adapt to the adverse effects of climate change (CBD, 2009).
Ecosystem-based approach to adaptation, community-based adaptation.
Help vulnerable communities adapt to climate change through good ecosystem management practices (Munang et al., 2013). 


\begin{tabular}{|c|c|c|}
\hline Definitions & Related terminologies & Objectives \\
\hline \multicolumn{3}{|l|}{ Ecosystem-based mitigation } \\
\hline $\begin{array}{l}\text { Enhance the benefits for, and avoid negative impacts } \\
\text { on biodiversity from reducing emissions, taking into } \\
\text { account the need to ensure the full and effective } \\
\text { participation of indigenous and local communities } \\
\text { in relevant policy-making and implementation } \\
\text { processes, where appropriate. Enhance the } \\
\text { conservation, sustainable use and restoration of } \\
\text { marine and coastal habitats that are vulnerable to } \\
\text { the effects of climate change or which contribute to } \\
\text { climate-change mitigation (CBD, 2010). }\end{array}$ & $\begin{array}{l}\text { Ecosystem-based } \\
\text { approach to mitigation }\end{array}$ & $\begin{array}{l}\text { Enhance carbon sequestration and } \\
\text { maintain existing carbon stocks, } \\
\text { through the use of ecosystems. }\end{array}$ \\
\hline
\end{tabular}

\section{Ecosystem-based disaster risk reduction}

The sustainable management, conservation and restoration of ecosystems to provide services that reduce disaster risk by mitigating hazards and by increasing livelihood resilience (Pedrr 2010).
Natural infrastructure for risk management, Natural infrastructure for risk reduction, Nature based solutions for DRR, Ecosystems for resilience, Ecosystem-based disaster risk reduction and climate change adaptation, nature based disaster risk reduction, no-regret disaster risk reduction.
Proactive risk reduction management strategies supplying multiple benefits in absence/ presence of disaster.

\section{Climate adaptation services}

Benefits to people from increased social ability to respond to change, provided by the capacity of ecosystems to moderate and adapt to climate change and variability (Lavorel et al., 2015).
Adaptation services, climate change adaptation services.
Complements the ES approach and helps people develop choices for adaptation to climate change (Lavorel et al., 2015).

\section{Annex 1 References}

Benedict, M.A. and McMahon, E.T. (2006). Green Infrastructure: linking landscapes and communities. Washington DC: Island Press.

Benedict, M.A. and McMahon, E. (2002). Green Infrastructure: Smart Conservation for the 21st Century. Sprawl Watch Clearinghouse Monograph Series. Washington DC: Sprawlwatch Clearinghouse.

CBD (Convention on Biological Diversity) (2009). Connecting Biodiversity and Climate Change Mitigation and Adaptation. Report of the 2nd Ad Hoc Technical Expert Group (AHTEG) on Biodiversity and Climate Change. Technical Series No. 41, Montreal, Canada.

CBD (Convention on Biological Diversity) (2010). X/33 Biodiversity and climate change, Decision Adopted by the Conference of the Parties to the Convention on Biological Diversity at its Tenth Meeting; UNEP/CBD/COP/DEC/x/33; 29 October 2010, Nagoya, Japan.

European Commission (2013). Green Infrastructure (GI) - Enhancing Europe's Natural Capital. Communication from the Commission to the European Parliament, the Council, the European Economic and Social Committee and the Committee of the Regions., Brussels, Belgium. 
Garcia, S.M., Zerbi, A., Aliaume, C., Do Chi, T. and Lasserre, G. (2003). The Ecosystem Approach to Fisheries: Issues, Terminology, Principles, Institutional Foundations, Implementation and Outlook. FAO Fisheries Technical Paper. No. 443, Rome, Italy: Food and Agriculture Organization.

Kappel, C., Martone, R.G. \& Duffy, J.E., 2006. Ecosystem-based management. Encyclopedia of Earth, pp.1-4. http://www.eoearth.org/view/article/152249.

Lavorel, S., Colloff, M.J., McIntyre, S., Doherty, M.D., Murphy, H.T., Metcalfe, D.J., Dunlop, M., Williams, R.J., Wise, R.M. and Williams, K. (2015). Ecological mechanisms underpinning climate adaptation services. Global Change Biology 21(1): 12-31.

Leslie, H.M. and McLeod, K.L. (2007). Confronting the challenges of implementing marine ecosystembased management. Frontiers in Ecology and the Environment 5(10): 540-548.

Maginnis, S., Laestadius, L., Verdone, M., DeWitt, S., Saint-Laurent, C., Rietbergen-McCracken, J. and Shaw, D.M.P.(2014). Assessing forest landscape restoration opportunities at the national level: A guide to the Restoration Opportunities Assessment Methodology (ROAM), Gland, Switzerland: International Union for the Conservation of Nature.

Mansourian, S., Vallauri, D. and Dudley, N. (eds.) (in cooperation with WWF International) (2005). Forest Restoration in Landscapes: Beyond Planting Trees, Springer, New York.

Mitsch, W.J. (2012). What is ecological engineering? Ecological Engineering, 45(October): 5-12.

Munang, R. et al., 2013. The role of ecosystem services in climate change adaptation and disaster risk reduction. Current Opinion in Environmental Sustainability, 5(1), pp.47-52.

Naumann, S., McKenna, D. \& Kaphengst, T. (2011). Design, implementation and cost elements of Green Infrastructure projects, Brussels. http://ec.europa.eu/environment/enveco/biodiversity/ pdf/GI_DICE_FinalReport.pdf.

Odum H. (1996). Scales of ecological engineering. Ecological Engineering 6: 7-19.

Pedrr (2010). Demonstrating the Role of Ecosystems-based Management for Disaster Risk Reduction. Partnership for Environment and Disaster Risk Reduction.

Society for Ecological Restoration (2004). Ecological Restoration Primer [online document] www.ser. org/resources/resources-detail-view/ser-international-primer-on-ecological-restoration.

Suding, K.N. (2011). Toward an Era of Restoration in Ecology: Successes, Failures, and Opportunities Ahead. Annual Review of Ecology, Evolution, and Systematics 42: 465-487.

Tzoulas, K., Korpela, K., Venn, S., Yli-Pelkonen, V., Kazmierczak, A., Niemela, J. and James, P. (2007). Promoting ecosystem and human health in urban areas using Green Infrastructure: A literature review. Landscape and Urban Planning 81(3): 167-178. 


\section{Annex 2: Linkages and relationships between NbS approaches}

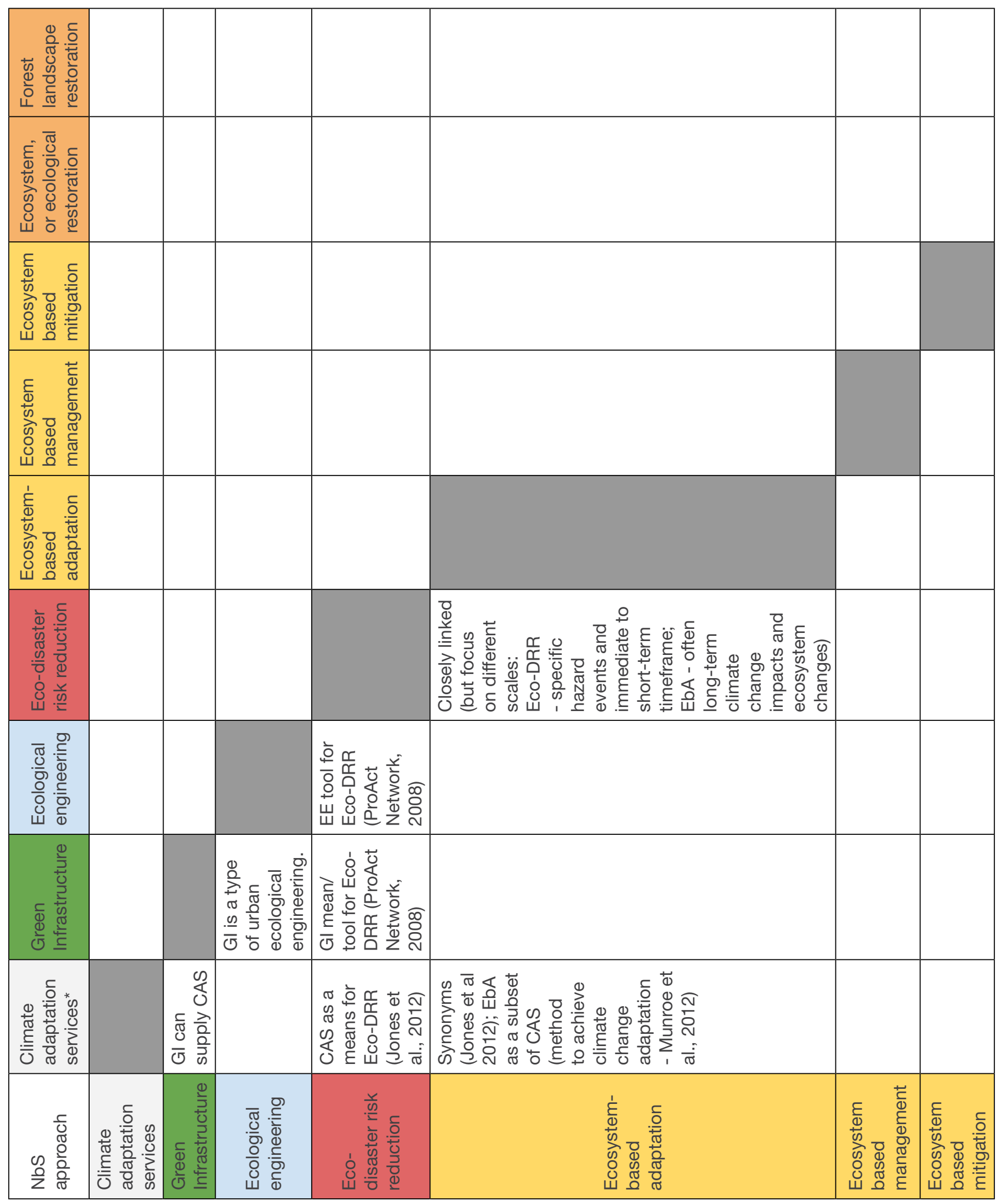




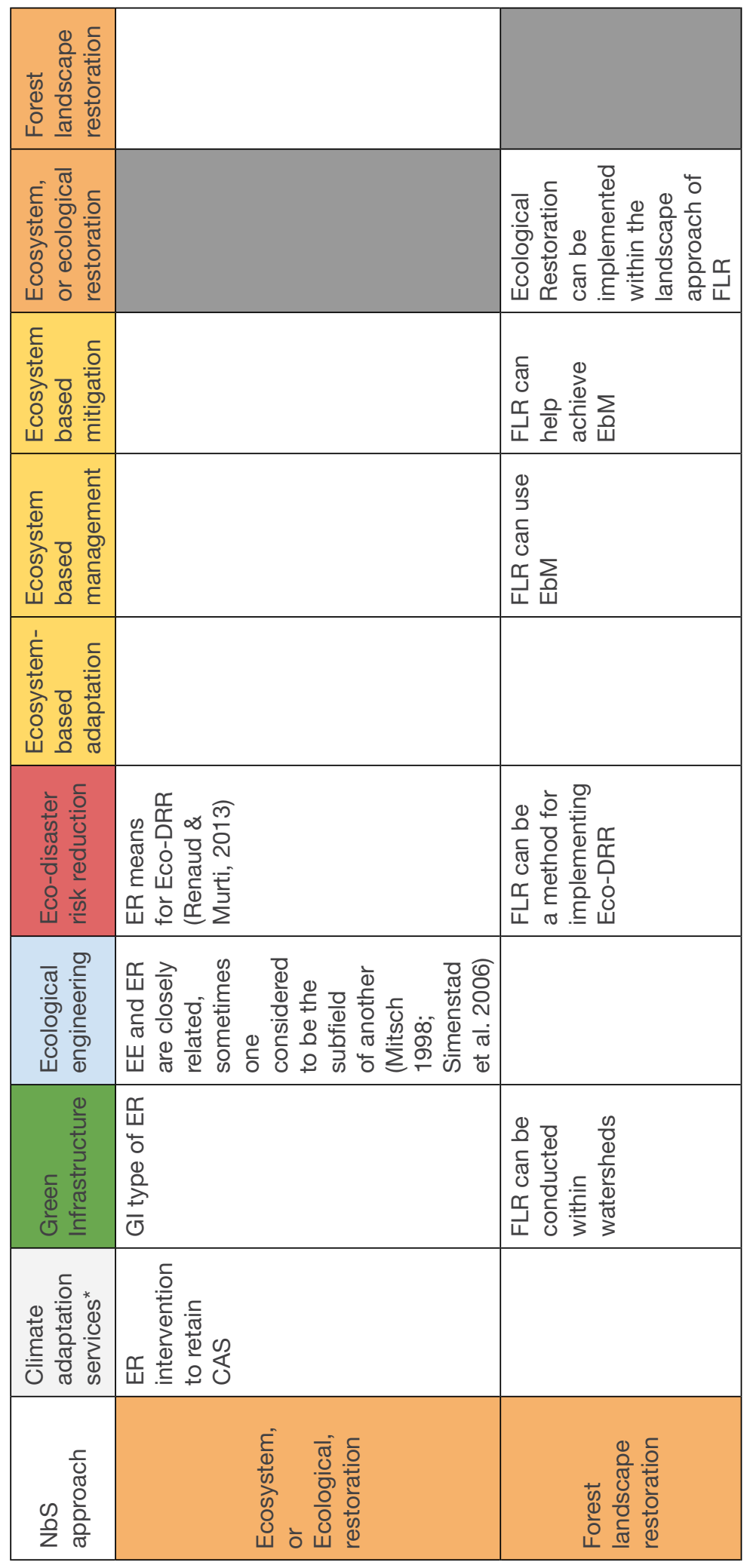




\section{Annex 2 References}

Jones, H.P., Hole, D.G. and Zavaleta, E.S. (2012). Harnessing nature to help people adapt to climate change. Nature Climate Change 2(7): 504-509.

Mitsch, W.J. (1998). Ecological engineering - the 7-year itch 1. Ecological Engineering, 10: 119-130.

Munroe, R., Doswald, N., Roe, D., Reid, H., Giuliani, A., Castelli, I., et al. (2011). Does EBA work? A review of the evidence on the effectiveness of ecosystem-based approaches to adaptation. BirdLife International, UNEP-WCMC, IIED and Cambridge University.

ProAct Network (2008). The role of environmental management and eco-engineering in disaster risk reduction and climate change adaptation, Tannay, Switzerland.

Renaud, F. and Murti, R. (2013). Ecosystems and disaster risk reduction in the context of the Great East Japan Earthquake and Tsunami - a scoping study. UNU-EHS Publication Series No. 10.

Simenstad, C., Reed, D. \& Ford, M. (2006). When is restoration not? Incorporating landscape-scale processes to restore self-sustaining ecosystems in coastal wetland restoration. Ecological Engineering, 26, pp.27-39. 



\section{IUCN}

INTERNATIONAL UNION FOR CONSERVATION OF NATURE

WORLD HEADQUARTERS

Rue Mauverney 28

1196 Gland, Switzerland

Tel: +41229990000

Fax: +41229990002

www.iucn.org

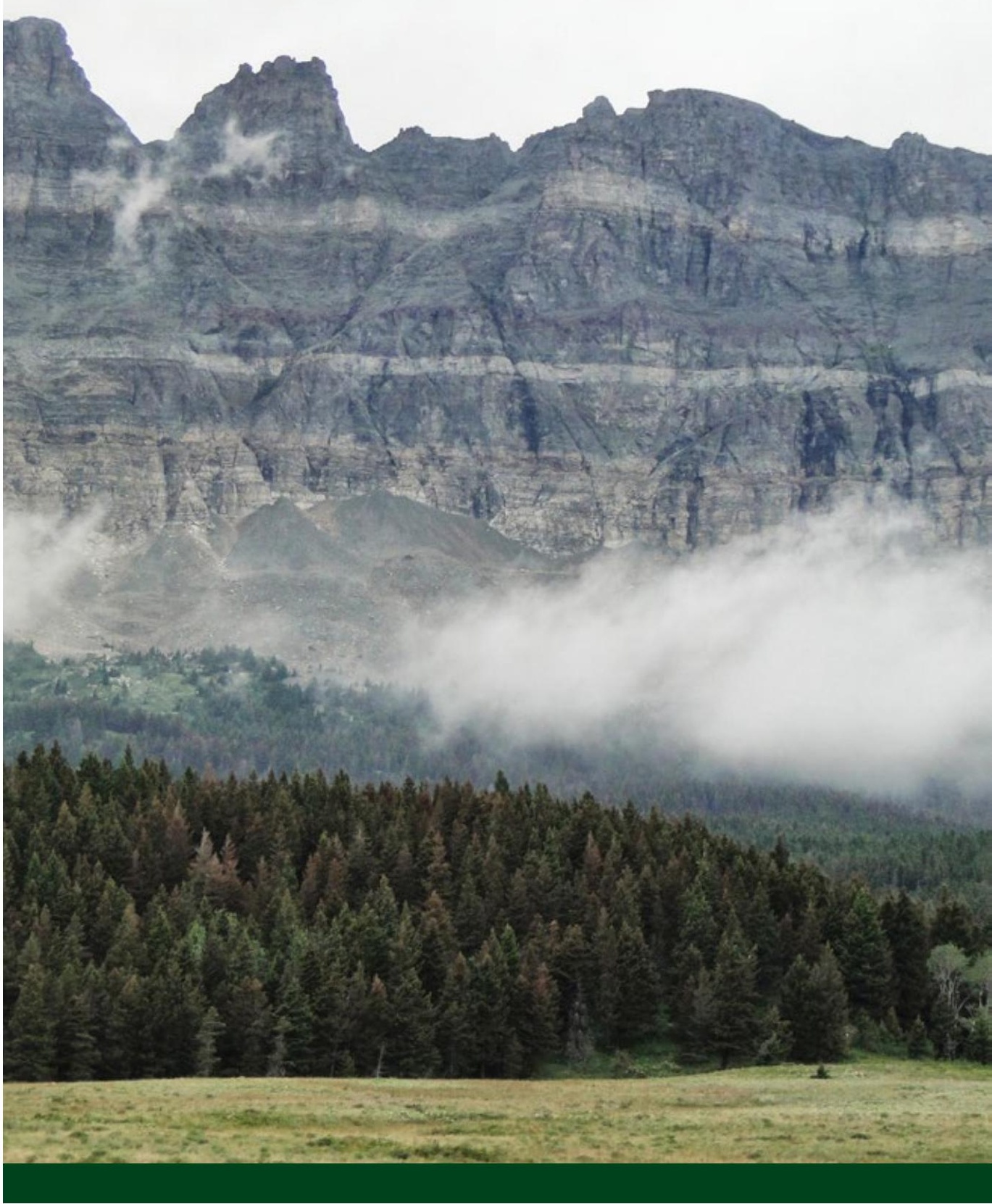

